\title{
The Processing and Potential Applications of Porous Silicon
}

\author{
Symyan Shieh \\ Ph.D. Thesis \\ Department of Materials Science and Mineral Engineering \\ University of California \\ and \\ Materials Science Division \\ Lawrence Berkeley Laboratory \\ University of California \\ Berkeley, CA 94720
}

July 1992

This work was supported by the Director, Office of Energy Research, Office of Basic Energy Sciences, Materials Sciences Division, of the U.S. Department of Energy under Contract No. DE-AC03-76SF00098. 
The Processing and Potential Applications of Porous Silicon

by

Sy-yuan Shieh

\begin{abstract}
The processing of porous silicon (PS) and its potential applications, especially in the integrated circuit industry, are studied. The stability of a cylindrical pore under the influence of surface energy is very important for the porous silicon processing. Once the zig-zag cylindrical pores of porous silicon or oxidized porous silicon (OPS) are unstable and breakup into rows of isolated spherical pores, the oxidation of PS and densification/nitridation of OPS become difficult. This is attributed to the difficulty of the transport of the reactant gas (oxygen and ammonia for the oxidation of PS and nitridation of OPs, respectively) or the trapped gas (for the densification of OPS). Therefore, a first order analysis of the stability of a cylindrical pore (or a cylinder) is considered first. The growth of small sinusoidal perturbations by viscous flow or by evaporation/condensation are examined. The principal results are the dependence of perturbation growth rate on perturbation wavelength. In the case of viscous flow, the result of the first order analysis is examined experimentally by heat treatment of artificial pores inside a glass wafer, which are created by employing the photolithography method and glass bonding method. Besides elongated straight pores, zig-zag artificial pores are also produced to examine whether the bending point is a preferential breakup point.

To mitigate the adverse effect of the breakup of pore, rapid thermal processing is recommended for PS processing. Rapid thermal oxidation (RTO) of porous silicon is
\end{abstract}


proposed as an alternative for the tedious two-step oxidation process, which oxidizes the porous silicon at a low temperature $\left(e . g ., 300^{\circ} \mathrm{C}\right)$ to stabilize the pore structure then at a high temperature $\left(>800^{\circ} \mathrm{C}\right.$ ) to fully oxidize the porous silicon. Transmission electron micruscopy (TEM), energy dispersive spectroscopy (EDS), and electron spectroscopy for chemical analysis (ESCA) are employed to ensure that the result of RTO is as good as that of the twu-siep oxidation. Also, rapid thermal nitridation (RTN) of oxidized porous silicon in ammonia is proposed to enhance the OPS resistance to the attack of a hycrofluoric acid (HF) solution. The etching rates in a buffered HF solution before and after RTN are weasured. TEM and ESCA are used to characterize the nitridized OPS.

The breakup of pores of OPS results in the trapped gas problem during the OPS densification. Helium, with high permeability in silica (the composition of OPS), can alleviate this problem. Also, the viscasity of silica is low when the water conteat of silica is high. So wet helium (helium bubbled through water) is proposed as the OPS densification ambient gas to shorten the densification time. TEM is employed to characterize the densification results of different ambient gases to examine the validity of this proposal.

Finally, the porous silicon is proposed to be an extrinsic gettering center in silicon wafers. The suppression of the formation of oxidation induced stacking faults is used to demonstrate the gettering abiliry. The possible mechanism is discussed. 
Table of Contents

List of Figures

Figure Captions vi

List of Tables $\quad x$

Acknowledgements

1. Introduction and Previous Investigations 1

2. The Stability of Cylindrical Pores Under the Influence of Surface Energy

$\begin{array}{ll}2.1 \text { Introduction } & 30\end{array}$

2.2 Theoretical consideration of stability 33

2.3 Experiments $\quad 47$

2.4 Results and discussions $\quad 51$

$\begin{array}{ll}2.5 \text { Summary } & 57\end{array}$

3. Oxidation of Porous Silicon

3.1. Introduction $\quad 62$

3.2 Rapid thermal ox idation of porous silicon 64

3.3 Experiments and results 65

3.4 Discussion $\quad 72$

$\begin{array}{ll}3.5 \text { Summary } & 75\end{array}$ 
4. Densification and Nitridation of Oxidized Porous Silicon

4.1 Introduction

4.2 Densification of oxidized porous silicon

4.3 Experiments: densification of oxidized porous sili ion

4.4 Results and discussion: densification of oxidized porous silicon 88

4.5 Nitridation of oxidized porous silicon

4.6 Experiments: nitridation of oxidized porous silicon

4.7 Results and discussion: nitridation of oxidized porous silicon

4.8 Summary

5. Suppression of Oxidation-Induced Stacking Faults by Using Porous Silicon as a Gettering Center in Silicon Wafers

5.1 Introduction

5.2 Experimental Procedures

5.3 Results and discussion

5.4 Summary

6. Summary 
List of Figures

page

Figure 1.1

XBB 9242357

3

Figure 1.2

8

Figure 1.3

Figure 1.4

13

Figure 1.5

14

Figure 1.6

15

Figure 1.7

17

Figure 1.8

17

Figure 1.9

18

Figure 1.10

18

Figure 1.11

\begin{tabular}{l}
$\times B B \quad 9242358$ \\
\hline
\end{tabular}

22

Figure 2.1

32

Figure 2.2

34

Figure 2.3

39

Figure 2.4

49

Figure 2.5

50

Figure 2.6

XBB 9242359-60

52

Figure 2.7

XBB $9242361-62$

54

Figure 2.8

XBB 9242363

56

Figure 2.9

XBB 9242364

58

Figure 3.1

66 


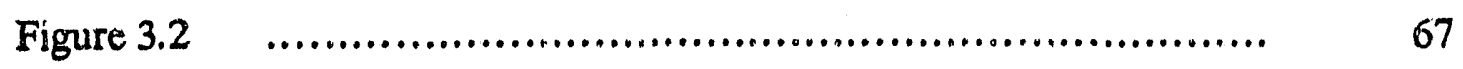

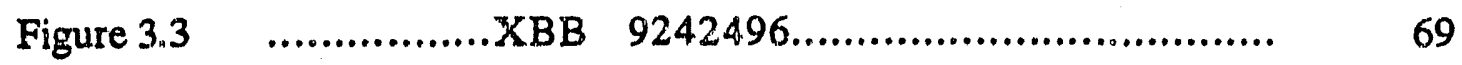

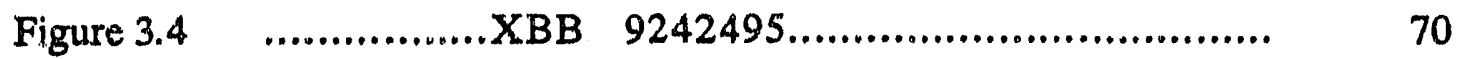

Figure $3.5 \quad$...................................................... 71

Figure $3.6 \quad$....................................................... 71

Figure $3.7 \quad$......................................................... 73

Figure $3.8 \quad$......................................................... 74

Figure $4.1 \quad$........................................................ 82

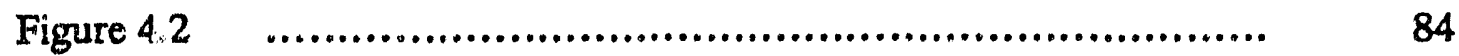

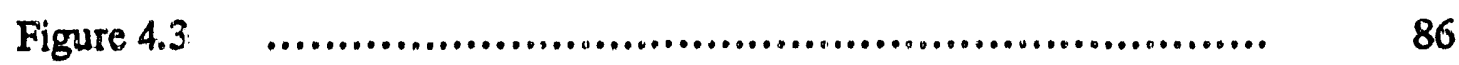

Figure $4.4 \quad \ldots \ldots \ldots \ldots \ldots . . . . \times B B \quad 9242493-94 \ldots \ldots \ldots \ldots \ldots \ldots \ldots \ldots \ldots . \ldots \ldots$

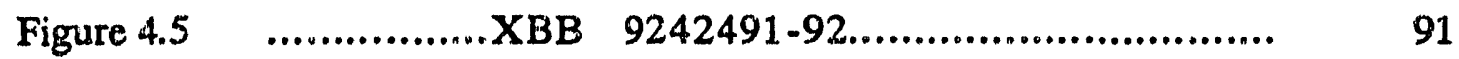

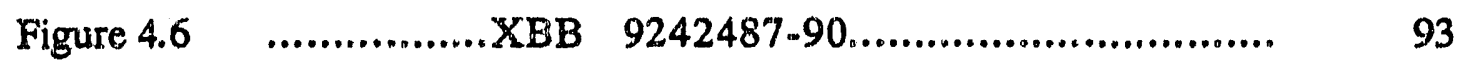

Figure $4.7 \quad$.......................................................... 101

Figure $4.8 \quad$...................................................... 102

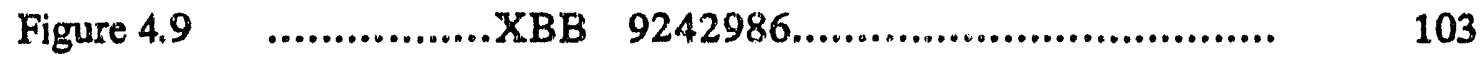

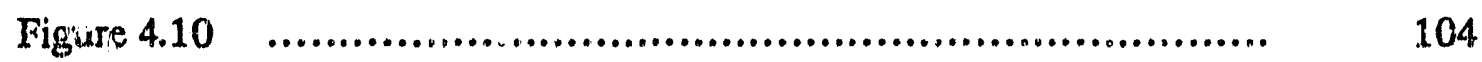

Figure $5.1 \quad$...................................................... 114

Figure $5.2 \quad$....................................................... 116

Figure $5.3 \quad$.............XBB $9242366-65 \ldots \ldots \ldots \ldots \ldots \ldots \ldots \ldots . \ldots \ldots \ldots$

Figure $5.4 \quad$...................................................... 119

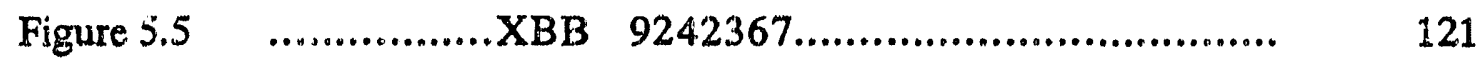

Figure $5.6 \quad$..................................................... 122

Figure $4.4 \quad$..............XBB $9242987 \ldots \ldots \ldots \ldots \ldots \ldots \ldots \ldots \ldots \ldots . . \ldots \ldots \ldots$

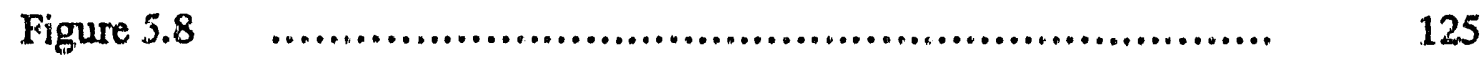

Figure $5.9 \quad$..................................................... 127 
Figure Captions

Figure 1.1 TEM bright field micrographs and electron diffraction patterns of PS formed from $0.02 \cdots 0.005 \mathrm{ohm}-\mathrm{cm},(100), \mathrm{p}-\mathrm{Si}$, anodization conditions: $50 \mathrm{~mA} / \mathrm{cm}^{2}$, 25 wt\% HF solution. (a) plane view and (b) cross section.

Figure 1.2 (a) A patterned substrate as used in Luryi's theory and (b) a real PS substrate. 46

Figure 1.3 Dialectically isolated structures formed from PS. 68

Figure 1.4 Fabrication process of the injection type deep sidewall isolation scheme. ${ }^{34}$

Figure 1.5 Fabrication process of FIYOS scheme. 61

Figure 1.6 Fabrication process of SOPS scheme. ${ }^{41}$

Figure 1.7 Conceptual fabrication process of ZMR structure. ${ }^{71}$

Figure 1.8 Conceptual fabrication process of SIMOX structure. ${ }^{71}$

Figure 1.9 Conceptual fabrication process of WB structure. ${ }^{71}$

Figure 1.10 Schematic cross section of striated-mesa device. 78

Figure 1.11 TEM bright field micrographs and electron diffraction patterns of OPS formed from 0.02-0.065 ohm-cm, (100), p-Si, anodization conditions: 50 $\mathrm{mA} / \mathrm{cm}^{2}, 25 \mathrm{wt} \%$ HF solution; oxidation conditions: $300^{\circ} \mathrm{C}$ dry oxygen one hour, then $800^{\circ} \mathrm{C}$ wet oxygen one hour. (a) plane view and (b) cross section.

Figure 2.1 Detailed fabrication process of silicon wafer bonding SOI scheme. 
Figure 2.2 Cylindrical coordinates used in the instability study.

Figure 2.3 The rate of growth of the perturbation vs. wavelength.

Figure 2.4 Fabrication process of the artificial pore.

Figure 2.5 Mask pattern used to generate artificial pore.

Figure 2.6 Optical microscope pictures (a) plane view of the as-etched pore shows the undercut effect and the cross section diagram gives the equivalent radius 4 $\mu \mathrm{m}$ and (b) the as-formed pores.

Figure 2.7 Optical microscope pictures of artificial pores after beat treatment.

Figure 2.8 Optical microscope pictures of artificial pores after heat treatment;

b: breakup at the bending point; n: no breakup at the bending point.

Figure 2.9 Optical microscope pictures of artificial pores after heat treatment show the end effecr

Figure 3.1 (a) RTO oxide thickness vs. oxidation time at different temperatures ${ }^{17}$ and (b) oxide thickness vs. oxidation time at $900^{\circ} \mathrm{C}$ for RTO (curve A) and CFP (curve B). ${ }^{24}$

Figure 3.2 Electrolytic cell used for PS formation. (Reprinted from Anderson 46 1991)

Figure 3.3 TEM bright field micrographs and electron diffraction patterns of PS formed from p-Si, (a) before RTO and (b) after RTO.

Figure 3.4 TEM bright field micrographs and electron diffraction patterns of PS formed from $\mathrm{p}^{++}-\mathrm{Si}$, (a) before RTO and (b) after RTO.

Figure 3.5 EDS spectrum for RTOPS.

Figure 3.6 EDS spectrum for COPS. 
Figure 3.7 ESCA spectrum for RTOPS.

Figure 3.8 ESCA spectrum for COPS.

Figure 4.1 Geometrical model used in the derivation of Scherer's model. ${ }^{19}$

Figure 4.2 Silica viscosity vs. temperature for different (a) $\mathrm{OH}$ contents and (b) fictive temperatures.

Figure 4.3 Diffusivity vs. temperature for different gases in silica.

Figure 4.4 TEM bright field, plane view micrographs for OPS (a) as-formed, (b) after $1100^{\circ} \mathrm{C} 1 \mathrm{hr}$ densification in dry $\mathrm{He}$, (c) after $1100^{\circ} \mathrm{C} 1 \mathrm{br}$ densification in dry $\mathrm{Ar}$, and (d) after $1100^{\circ} \mathrm{C} 1 \mathrm{hr}$ densification in vacuum.

Figure 4.5 TEM bright field, plane view micrographs for OPS afte: $1 \mathrm{hr}$ densification at $1090^{\circ} \mathrm{C}$ (a) in dry $\mathrm{Ar},(\mathrm{b})$ in dry $\mathrm{O}_{2}$, and (c) in dry $\mathrm{N}_{2}$.

Figure 4.6 TEM bright field, plane view micrographs for OPS after densification at $1090^{\circ} \mathrm{C}$ (a-1) 5 mins wet $\mathrm{He}$, (a-2) 5 mins wet Ar, (b-1) 20 mins wet He, (b-2) 20 mins wet $\mathrm{Ar}$, (c-1) 40 mins wet He, (c-2) 40 mins wet $\mathrm{Ar}$, (d-1) 1 hr wet He, and (d-2) $1 \mathrm{hr}$ wet Ar.

Figure 4.7 Etching rates in a buffered HF solution of OPSs after different processes.

Figure 4.8 ESCA spectrum for nitridized OPS.

Figure 4.9 TEM bright field, plane view micrographs for nitridized OPS.

Figure 4.10 Fabrication process for microfilter.

Figure 5.1 Conceptual gettering process of segregation model.122

Figure 5.2 Experimental procedures of the suppression of OISF by using PS. 
Figure 5.3 SEM pictures (a) boundary between high and low OISF' region, (b) PS patch on the back side, and (c) no PS patch on the back side.

Figure 5.4 Experimental procedures to examine the PS/Si and OPS/Si interfaces.

Figure 5.5 SEM pictures (a) PS/Si interface and (b) OPS/Si interface.

Figure 5.6 Experimental procedures to examine the role of PS

Figure 5.7 Optical microscope picture of the boundary between the area of high defect density and low defect density.

Figure 5.8 Experimental procedures for DLTS study.

Figure 5.9 The DLTS measurements, (a) without PS gettering and (b) with PS gettering. 
List of Tables

page

Table $1.1 \quad$......................................................................... 7

Table $1.2 \quad$........................................................................ 10

Table $1.3 \quad$....................................................................... 19

Table $2.1 \quad$......................................................................... 44

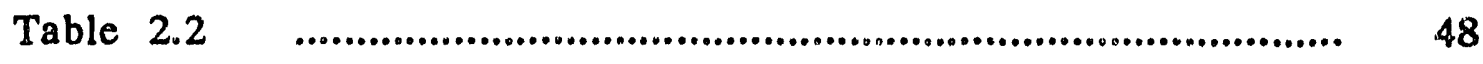


Acknowledgements

The author takes pleasure in acknowledging the support and encouragement of Professor James W. Evans who guided this research with active interest and patience. Appreciation is extended to Professor Romald Gronsky and Professor Nathan Cheung for their review of this manuscript.

The kind assistance provided by the staff of (1) the Materials Science Division of the Lawrence Berkeley Laboratory, (2) the Departinent of Materials Science and Mineral Engineering of the U.C. Brkeley, and (3) the U.C. Berkeley Microfabrication Laboratory is greatly appreciated. The author would also like to thank the entire Evans group for their helpful suggestions.

The author remains forever obligated to his parents, his wife Wen-shan, and his daughter Iris for their love, support, and endurance during his gradvate stady.

This work was supported by the Director, Office of Energy Research, Office of Brsic Energy Sciences, Materials Science Division of the U.S. Department of Energy under Contract No. DE-AC03-76SF00098. 
Chapter 1 Introduction and Previous Investigations

The goal of this research is to study the processing of porous silicon (PS) and its potential applications, especially in the integrated circuit (IC) industry. PS is formed by the anodic reaction of monocrystalline silicon in a hydrofluoric acid (HF) solution at a current deasity below a critical vaiue.1-12 The formation mechanism of PS is still not . very clear. It has been proposed $2,7,8,13$ that the inhomogeneous dissolution of the silicon, resulting from a divalent electrochemical reaction of silicon with HF, is responsible for the formation of PS:

$$
\begin{aligned}
& \mathrm{Si}+2 \mathrm{HF}+(2-\lambda) \mathrm{h}^{+} \rightarrow \mathrm{SiF}_{2}+2 \mathrm{H}^{+}+\lambda \mathrm{e}^{-} \\
& \mathrm{SiF}_{2}+4 \mathrm{HF} \rightarrow \mathrm{H}_{2} \mathrm{SiF}_{6}+\mathrm{H}_{2}
\end{aligned}
$$

here $\lambda<2$, and $\mathrm{h}^{+}$and $\mathrm{e}^{-}$are an electron hole and an electron, respectively. Mass spectroscopy studies 13,22 confirmed the evolution of $\mathrm{H}_{2}$ from the anode under the condition of porous silicon formation. When the current density exceeds a critical value, a tetravalent electrochemical reaction dominates the anodization process ${ }^{7}$, which removes the silicon homogeneously:

$$
\begin{aligned}
& \mathrm{S}:+4 \mathrm{HF}+(4-\lambda) \mathrm{h}^{+} \rightarrow \mathrm{SiF}_{4}+4 \mathrm{H}^{+}+\lambda \mathrm{E}^{-} \\
& \mathrm{SiF}_{4}+2 \mathrm{HF} \rightarrow \mathrm{H}_{2} \mathrm{SiF}_{6}
\end{aligned}
$$

here $\lambda<4$. Zhang ${ }^{2}$ proposed another set of tetravalent electrochemical reaction, which in rolved the formation of $\mathrm{SiO}_{2}$ : 


$$
\begin{aligned}
& \mathrm{Si}+4 \mathrm{OH}^{-}+\lambda \mathrm{h}^{+} \rightarrow \mathrm{Si}(\mathrm{OH})_{4}+(4-\lambda) \mathrm{e}^{-} \\
& \mathrm{Si}(\mathrm{OH})_{4} \rightarrow \mathrm{SiO}_{2}+\mathrm{H}_{2} \mathrm{O} \\
& \mathrm{SiO}_{2}+6 \mathrm{HF} \rightarrow \mathrm{H}_{2} \mathrm{SiF}_{6}+2 \mathrm{H}_{2} \mathrm{O}
\end{aligned}
$$

When the porous silicon film was formed, Unagami ${ }^{7}$ found that the net valency of the overall anode reaction varied from 2 to 2,8 , which was obtained by dividing the number of flowing elementary charges by the number of dissolved silicon atoms. This implies that the divalent (EQ. 1) and tetravalent (EQ. 2 or 3) reactions proceed simultaneously and compete with earh other during the silicon anodization process. The reaction rates of those tetravalent reactions increase with increasing current deasity ${ }^{2}$. When the current density exceeds a critical value, the tetravalent reactions dominate and the silicon is removed homogeneously, i.e., only an electropolishing effect occurs and no PS is formed. Generally, the critical current density depends on the Hr concentration and dopant type and consentration of the silicon wafer. Hill ${ }^{5}$ and Zhang ${ }^{14}$ proposed that pores initiated at surface defects, e.g., lattice strain, broken bonds, surface vacancies, and kinks. Once the pore initiates, experimental evidence $2,15,16$ shows that $[100]$ is the preferential direction for pore propagation and the silicon dissolution reaction only takes place at the tip of the pore. Therefore, the pore is a zig-zag elongated void and generally perpendicular to the surface. Figure 1.1 is a transmission electron microscope (TEM) image of PS used for the present study and shows a zig-zag elongated pore shape. There are four modiels proposed to explain why the silicon dissolution reaction only occurs at the tip of pore:

(1) Silicic acid passivation model": Silicic acid $\left(\mathrm{H}_{2} \mathrm{Si}_{2} \mathrm{O}_{5}\right)$, an HF insoluble product formed during silicon anodization, deposits on the pore wall to hinder further silicon dissolution, resulting in the silicon dissolution only at the tip of the pore. This model could not explain the effect of anodization conditions (current density, HF solution 


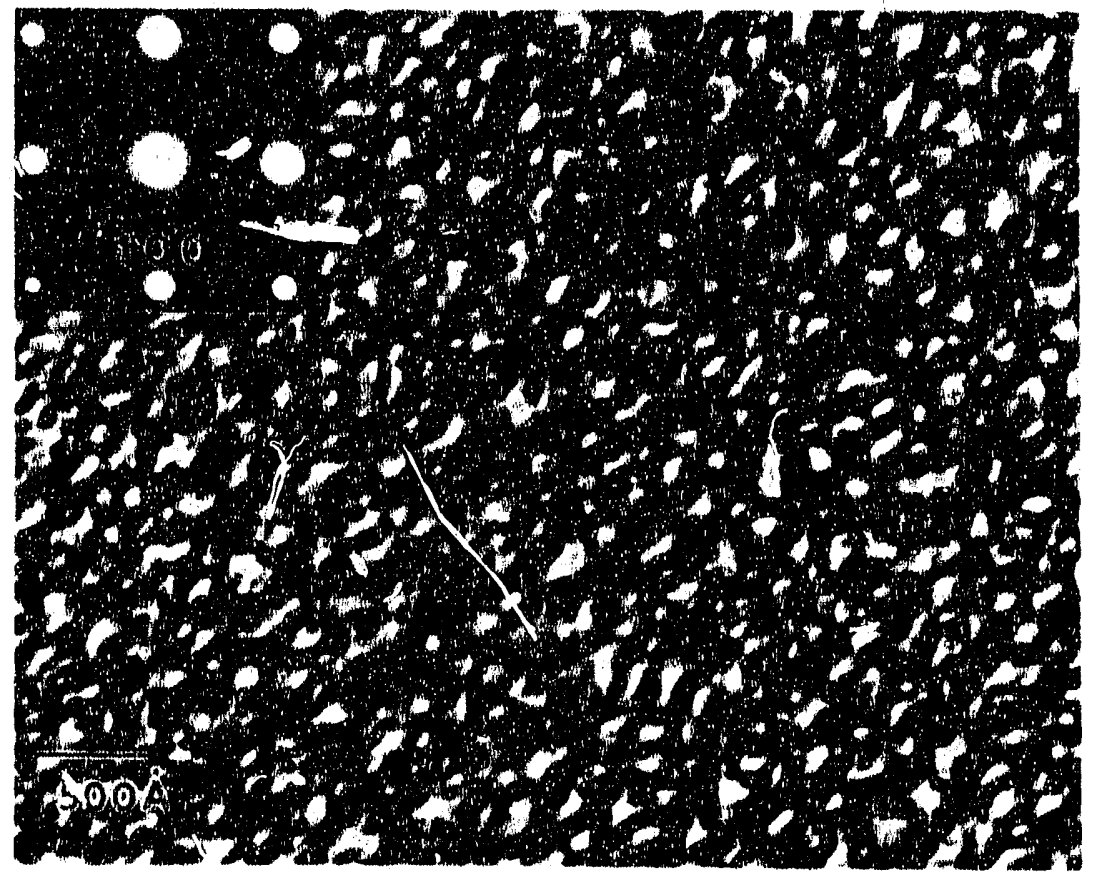

a

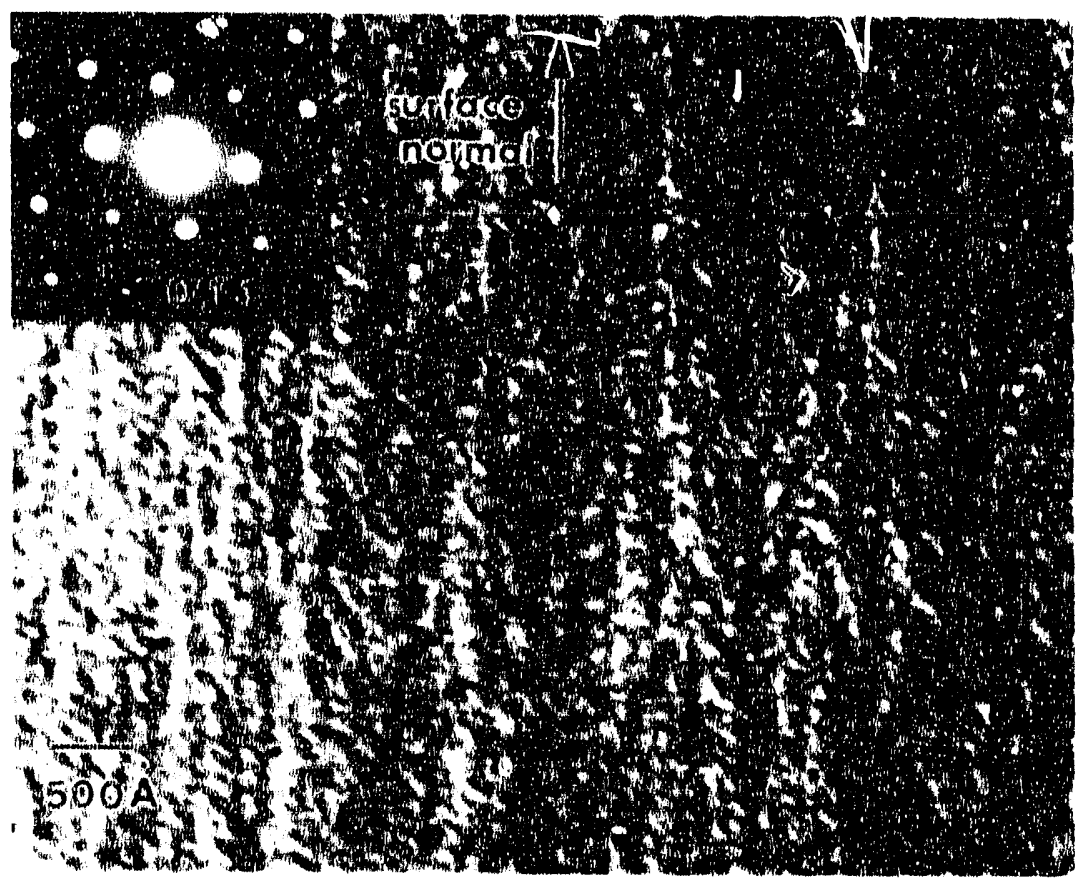

b

Fig. 1.1

XBB $\quad 924-2357$ 
concentration, and resistivity of silicon wafer) on the pore size and porosity. Also, why the silicic acid does not protect the tip area of pore is not answered.

(2) Carrier depletion model17: The Fermi level at the Si/electrolyte interface is pinned due to the large surface state density. Therefore, the silicon between two nearby pores is carrier-depleted totally or partially ${ }^{18}$ and has very high resistivity $\left(>10^{7} \mathrm{ohm}-\mathrm{cm}^{18}\right)$, which forces the anodic current to flow through the tip of pore only. The silicon dissolution reaction takes place where the anodic current flows, $i e$. , the tip of pore. Tenhunen ${ }^{19}$ exploited this model by using percolation theory to simulate the structural characteristics of PS and their dependence on the anodization conditions. The simulation result was consistent with the experimental observation. Generally, this model is the most plausible one so far.

(3) Reactant diffusion-limited model 20 : The pore formation is controlied by the diffusion of reactants from the bulk silicon to the silicon/electrolyte interface. The pore tip is close to the bulk silicon, therefore has the highest provability to get the reactants. This results in the silicon dissolution reaction preferentially occurring at the tip of the pore. To accommodate the electropolishing effect at a high current density, a sticking probability function of reactant was also introduced into this model. This model proposed that the pore structure depended on the diffusion length and sticking probability of the reactant. A two-dimension random walk computer program was developed to simulate the pore structure by adjusting these two parameters (diffusion length and sticking probability). Unfortunately, these two parameters used in the model do not have clear plysical meaning (e.g., what is the reactant ?) and cannot be obtained from anodization conditions. Therefore, it is impossible to predict the pore structure when the anodization conditions are given. 
(4) Electric field model 14 : Because of the difference in the radius of curvature, the electric field at the tip is much larger than that of the sidewall of pore. Then, the silicon dissolution reaction prefers to occur at the tip of the pore.

Several tools have been used to characterizi: porous silicon. Beckmann 21 found that the as-formed PS contained silicon hydrides by using Fourier fransform infrared spectroscopy (FIIR). Therefore, when the PS is heated above $250^{\circ} \mathrm{C}$, hydrogen gas is released. 22 Electron spectroscopy for chemical analysis (ESCA) 22,23 and Auger electron spectroscopy (AES) 22 measurements detected the existences of carbon, oxygen, fluorine and trace amount of nitrogen. Reflection high energy electron diffraction (RHEED) ${ }^{22}$, TEM 24 , and X-ray diffraction 16,25 results showed that the PS preserved the single crystal property of its parent silicon wafer. This is also confirmed from the electron diffraction patterns of Figure 1.1. Barla 25 and Bellet ${ }^{16}$ found that the lattice parameter of PS was larger than that of bulk silicon (0.0004 - 0.0046 angstroms larger, dependent upon the anodization conditions) by using a $x$-ray topographic technique.

Overall, porous silicon has the following usable properties:

(1) High oxidation rate: Porous silicon can be rapidly oxidized to form a thick insulating tilm because of its high specific surface area (up to $600 \mathrm{~m}^{2} / \mathrm{cm}^{3}$ ). $24,27-30$ It has also been claimed that the surface of PS is intrinsically more reactive than that of bulk silicon. 27 This can considerably mitigate the problem of countendiffusion of dopants during the high temperature oxidation step common in the IC processing.

(2) Formation selectivity: Since only p-type silicon (or a-type silicon with illumination) can be anodized, $1,15,17,27,31,33,34$ the porous silicon can be formed at a specific area of a device. This selectivity property can be rationalized by examining the silicon dissolution reactions (EQ. 1,2, and 3). Those electrochemical reactions need the presence of holes, which are majority carriers in p-type silicon. On the other hand, for n-type silicon, the 
holes are minority carriers and illumination with wavelength shorter than $1 \mu \mathrm{m}$ is needed to generate electron-hole pairs to supply the holes for the anodization reaction.

(3) Controllable pore structure: The anodization conditions can be adjusted so that the porosity is 0.56 so as to compensate for the volume increase on oxidation, thus allowing the mininum step formation and defect development during the oxidation step in the IC processing. The PS formation rate increases with increasing HF concentration ${ }^{2,9}$ and anodic current density $9{ }^{9} 35$ but decreases with increasing wafer resistivity. The porosity increases with increasing wafer resistivity 36,37 and anodic current density $36-38$ but decreases with increasing HF concentration.9,33,36-38 At very low anodic current densities, the porosity decreases with increasing anodic current density. 9 The pore size increases with increasing anodic current density 28,29 but decreases with increasing wafer resistivity ${ }^{37}$ and $H F$ concentration. 29,37 Table 1.1 summarizes the dependence of pore structure on the anodization conditions.

(4) Single crystalline: Porous silicon preserves the monocrystalline structure of its parent silicon, so it can perform as a suitable substrate for silicon epitaxial growth.39-41. Recently, Luryi ${ }^{42}$ predicted that a defect-free heterogeneous epi-layer (e.g. GaAs or Ge) could grow on the PS substrate. Because of the "patterned" surface of PS, the lattice mismatch strain could be released. But the experimental results (GaAs on $\mathrm{PS}^{43}, 44, \mathrm{CoSi}_{2}$ on $\mathrm{PS}^{45}$, and $\mathrm{Ge}_{x} \mathrm{Si}_{1-x}$ on $\mathrm{PS}^{46}$ ) did not show this strain relaxation effect. One explanation 46 is that the "pattern" of PS is not a "checkerboard" with continuous voids as Luryi thought but just the opposite, i.e., the void is not the continuous phase, as shown in Figure 1.2

(5) Visible luminescence: Porous silicon can photoluminesce in the visible region of the spectrum. ${ }^{47-58}$ This visible emission has been proposed 50 to be due to the quantum size effect, which arises from the confinement of free excitons to a volume smaller than is available in the bulk material. In PS case, when the thickness of the silicon pore vall is 


\begin{tabular}{|c|c|c|c|}
\hline & wafer resistivity & current density & [HF] \\
\hline etching rate & ) & ( & ( \\
\hline porosity & ( & ( & ) \\
\hline pore size & ) & ( & ) \\
\hline
\end{tabular}

Table 1.1 The characteristics of PS formation vs. anodization conditions.

$(:$ increase $):$ docrease 


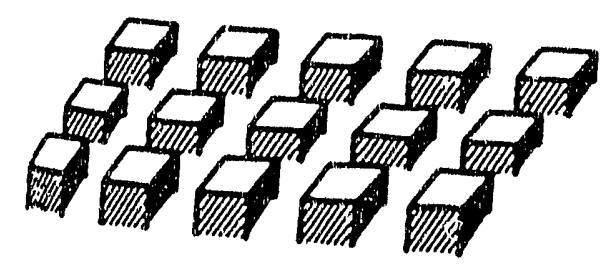

(a)

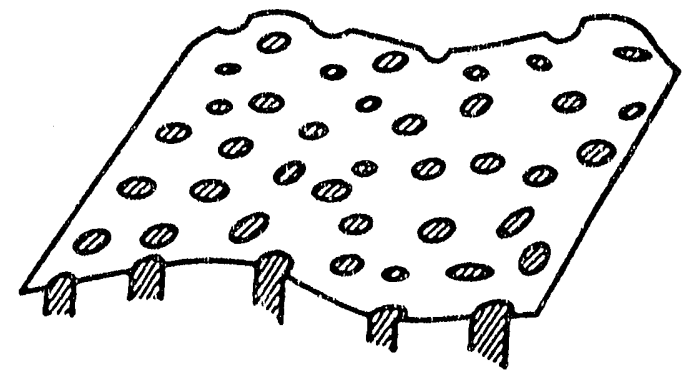

(b)

Figure 1.2 (a) A patterned substrate as used in Luryi's theory and (b) a real PS substrate. 46 
smaller than the free exciton's Bohr radius of bull. silicon (about 50 angstroms ${ }^{59}$ ), the band structure of PS is modified and a blue $\operatorname{shift}^{50}$ (e.g., band gap shifts from $1.1 \mathrm{eV}$ to 1.5 - $1.9 \mathrm{eV}^{48,51}$ ) occurs. Furthermore, the indirect band gap begins to resemble a direct band gap as the thickness of the silicon pore wall decreases.60 Although the quantum size effect seems to be plausible, there are new challenges, e.g., Heinrich 52 found the photoluminescence was from an amorphous area of PS by using TEM convergent beam diffraction technique. The light-emitting PS can be created directly by adjusting anodization conditions to get the pore wall thin enough to reach the quantum size effect region. 55 The PS without photoluminescence ability can become light-emitting by thinning the silicon pore wall through chemical etching 48 or oxidation followed by HF etching. 56

Based on above special properties, porous silicon has several potential applications: (1) Thick dielectric injulating material:

Porous silicon (after oxidation) has been proposed for dielectric isolation in the IC technology, 15,31,32,38,39,61,62 particularly in a silicon-on-insulator (SOI) structure $15,31,35,38,39,61,64-67$, because of its high oxidation rate, formation selectivity, controllable porosity, and monocrystalline properties. The published IC devices, based upon oxidized porous silicon (OPS) dielectric isolation, are summarized in Table 1.2. Generally, these device structures can be classified into three kinds of dielectric isolation schemes as shown in Figure 1.3.

(A) Lateral (deep sidewall) Isolation:

Porous silicon can be selectively formed by using an insulating mask which is impervious to a $\mathrm{HF}$ solution, such as $\mathrm{Si}_{3} \mathrm{~N}_{4}$, to block the anodic current flow. But due to the spreading of current beneath the insulating mask, the sidewalls are curved as shown in Figure 1.3. To form vertical sidewalls, Unagami ${ }^{34}$ proposed a better processing technology in which an n-type layer is anodized by the injection of holes from the heavily 


$\begin{array}{lll}\text { Author } & \text { Year } & \text { Comments } \\ \text { Imai84 } & 1981 & \text { 51-stage NMOS ring oscillator } \\ \text { Imai85 } & 1981 & 1.3 \mathrm{k} \text { gate CMOS logic array } \\ \text { Imai86 } & 1981 & 16 \mathrm{k} \text { CMOS static RAM } \\ \text { Mano }^{87} & 1982 & \text { CMOS NAND address decoder } \\ \text { Imai88 } & 1983 & \text { test MOSFET } \\ \text { Imai61 } & 1984 & 1.3 \mathrm{k} \text { CMOS gate array } \\ \text { Nesbit73 } & 1984 & \text { test NMOSFET } \\ \text { Anzai89 } & 1984 & 1 \mu \mathrm{m} \text { COMS 100-stage ring oscillator } \\ \text { Ehara90 } & 1985 & 64 \mathrm{k} \text { RAM }\end{array}$

Table 1.2 Published devices based on the OPS dielectric isolation 


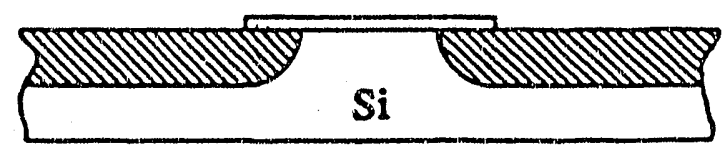

LATERAL ISOLATIOA

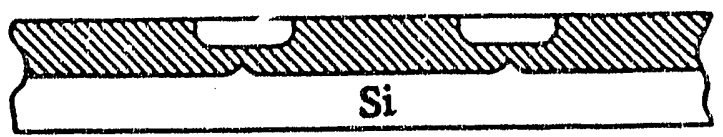

Full Isolation by Porous Oxidized Silicon

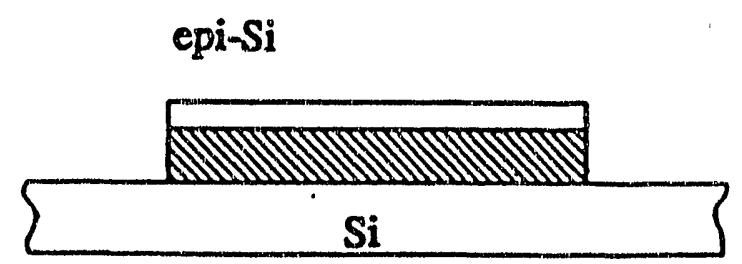

Silicon on Oxidized Porous Silicon (SOI)
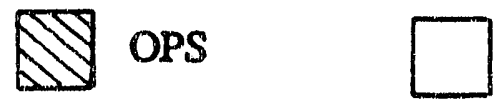

$\mathrm{Si}$

Figure 1.3 Dialectically isolated structures formed from PS.68 
doped p-type regions $\left(\mathrm{P}^{+}\right)$adjacent to $\mathrm{n}$-type layer as shown in Figure 1.4. The lateral isolation structure has been suggested for high-voltage bipolar application. 68

(B) Full Isolation by Porous Oxidized Silicon (FIPOS):

The processing steps of an FIPOS structure are shown in Figure 1.5:61

(a) p-type silicon - starting material.

(b) Donor doping to transform the device island area into n-type silicon.

(c) Selective anodization to convert the p-type region into PS.

(d) Oxidation.

Since the lateral PS size under the device island is smaller than the PS film depth, the maximum lateral dimension of device island is smaller than twice the PS film thickness. But this processing technology is able to provide very thick device island, which gives good quality high lifetime property. ${ }^{69}$ Therefore, FIPOS could be an excellent choice for dielectric isolation bipolar circuits. This processing technology can not be used for the fabrication of three-dimension circuits, ${ }^{69}$ because it is very difficult to put one transistor on the top of other in this isolation structure.

(C) Silicon on Oxidized Porous Silicon (SOPS):

The processing steps of SOPS structure are shown in Figure 1.6:41

(a) Formation of PS.

(b) Epi-silicon growth on the PS and mask formation.

(c) Etching of epi-silicon.

(d) Oxidation

The SOPS structure is a kind of SOI structure, which has the following advantages:70,71 (1) reducing parasitic capacitance, (2) avoidance of latch-up problems (a parasitic p-n-p-n transistor in a CMOS device), (3) simpler process, (4) radiation hardness, and (5) ease of design. The SOPS method is very suitable for large area devices requiring thicker silicon layers, such as high voltage circuits. 68 The lateral size 


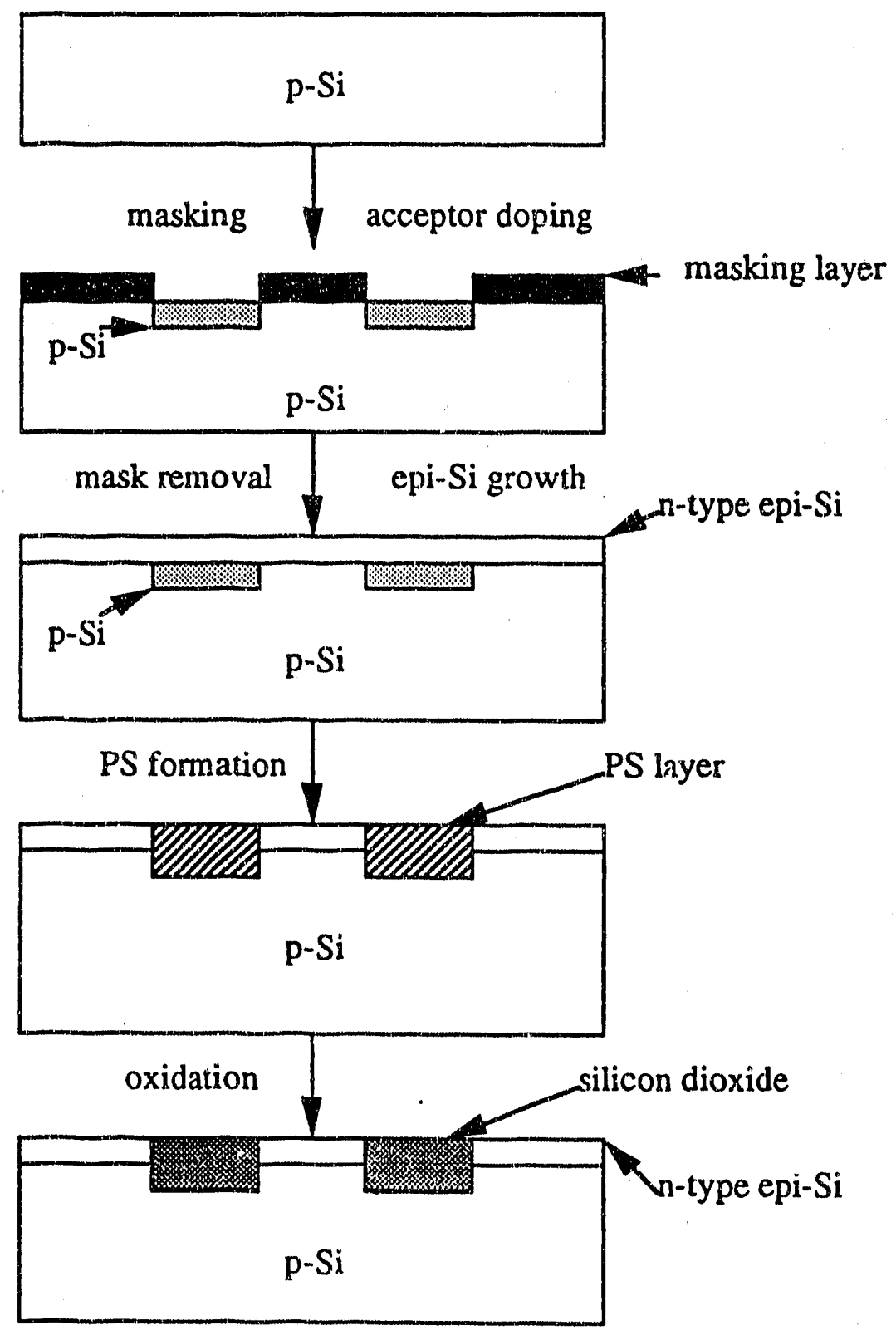

Figure 1.4 Fabrication process of the injection type deep sidewall isolation scheme. 34 


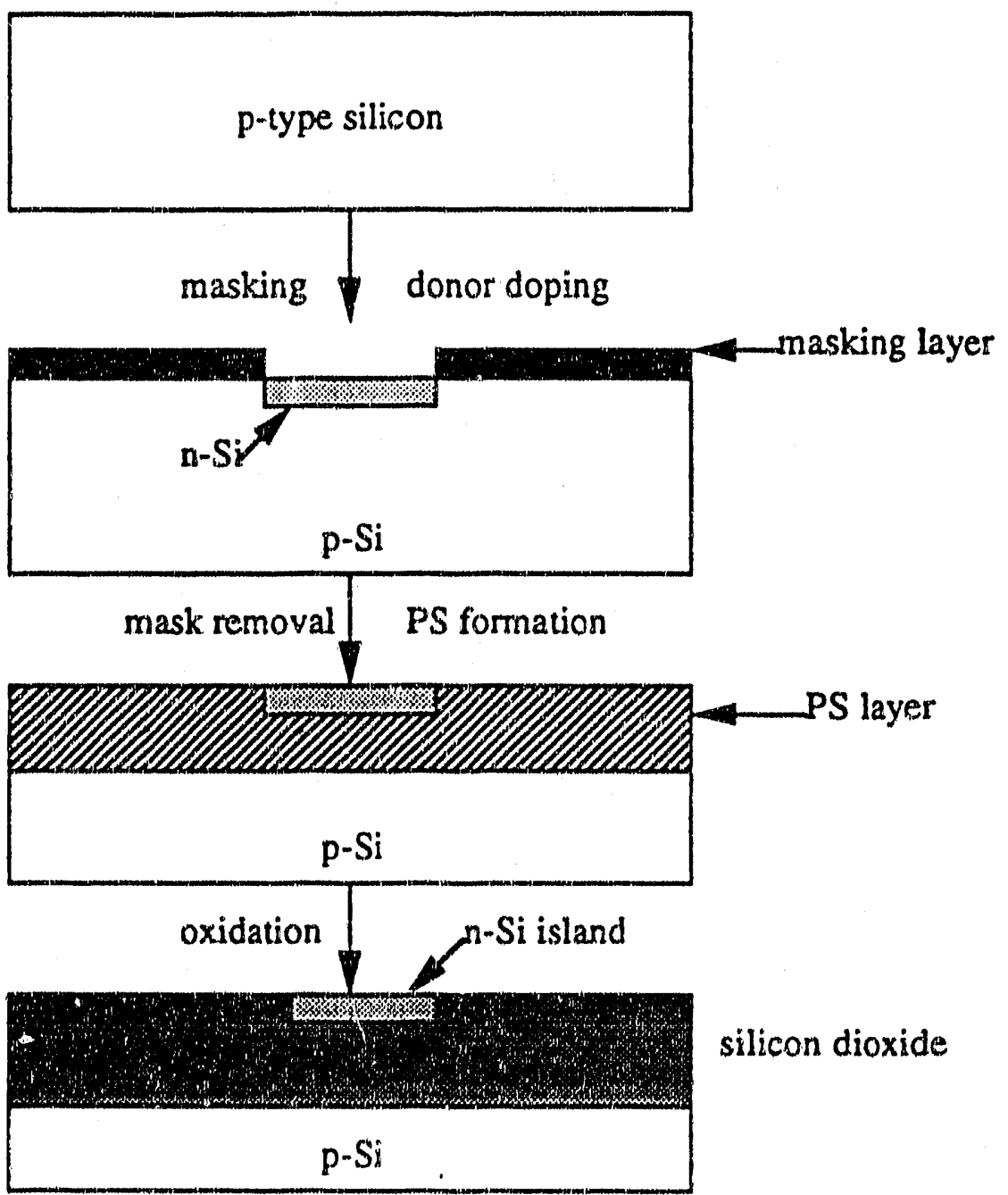

Figure 1.5 Fabrication process of FLPOS scheme61 
Formation of PS layer
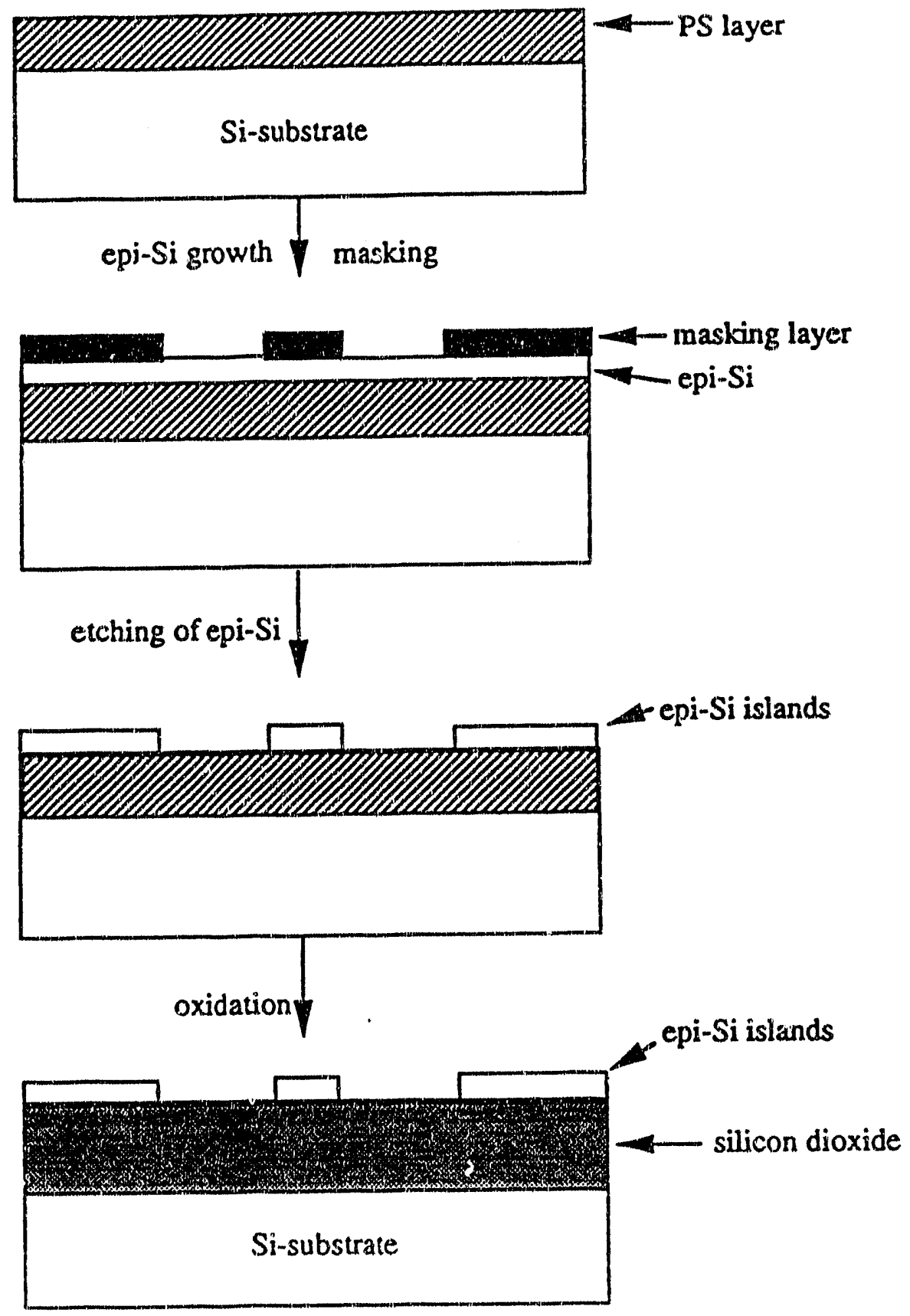

Figure 1.6 Fabrication process of SOPS scheme.41 
limitation in the SOPS structure is the extent to which the oxide can laterally penetrate beneath the epitaxial layer. Wafer warpage, which is introduced during the porous silicon formation 72 and oxidation ${ }^{73}$, is another problem for SOPS technology. Minimum demonstrated warpage during oxidation is of the order of $25 \mu \mathrm{m}$ in the frontside convex direction across a 4 -inch wafer 73 . Goodenough ${ }^{65}$ proposed that the warpage could be minimized when the oxidation was done in a high pressure environment, e.g., 10 atms oxygen.

Besides SOPS, there are three other popular SOI structure processing technologies: (A) Zone Melting Recrystallization (ZMR), (B) Separation by IMplantation of Oxygen (SMMOX) ${ }^{63}$, and (C) Wafer Bonding method (WB). ${ }^{74-76}$ Figure 1.7, 1.8, and 1.9 show the conceptual fabrication processes of ZMR, SIMOX, and WB, respectively. Generally, the main drawback of ZMR is its high defect density due to the sharp temperature gradient around the melt/solid interface ${ }^{63}$. The high throughput is its key advantage. ${ }^{69}$ In contrast to the ZMR structure, SIMOX structure has low defect density and warpage but low throughput and high cost due to the need for high dose (about $10^{18} \mathrm{~cm}^{-2}$ ) deep-oxygen implantation. The SOPS processing technology provides very high quality SOI structure, i.e. low defect density, with low cost. But an extra bigh temperature densification process is needed to ensure the quality of the insulator. 30,77 The WB processing technology also can create very high quality SOI structure with low cost, but the wafer flatness is a problem. Table 1.3 summarizes the advantages and disadvantages of different SOI processing technologies. 71

(2) Gettering center:

Porous silicon is proposed to be an extrinsic gettering center to enhance the performance of IC devices in the present research. Its high specific surface area and 


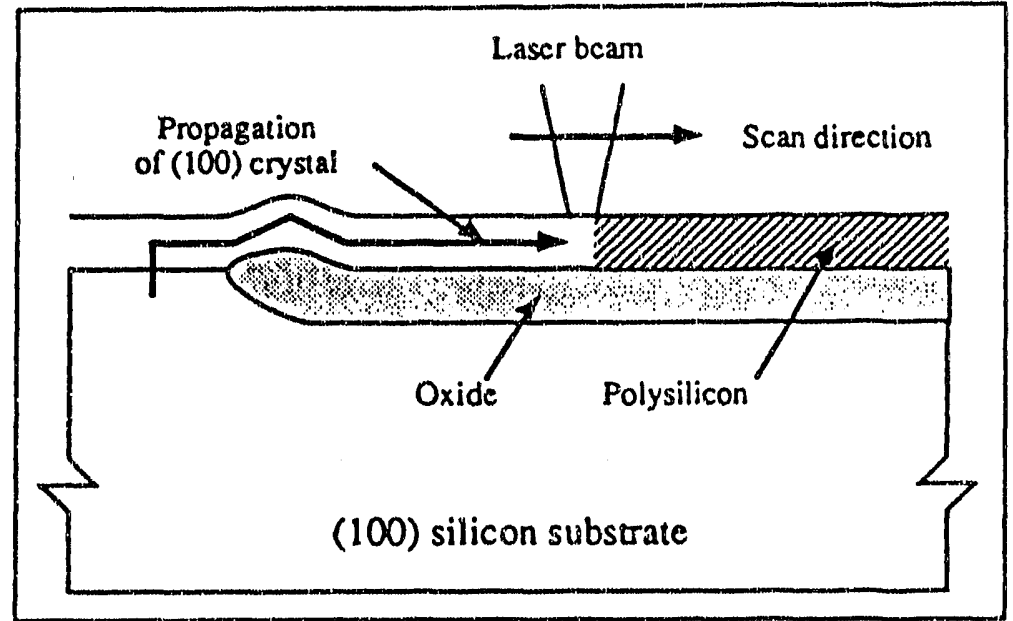

Figure 1.7 Conceptual fabrication process of ZMR structure.71

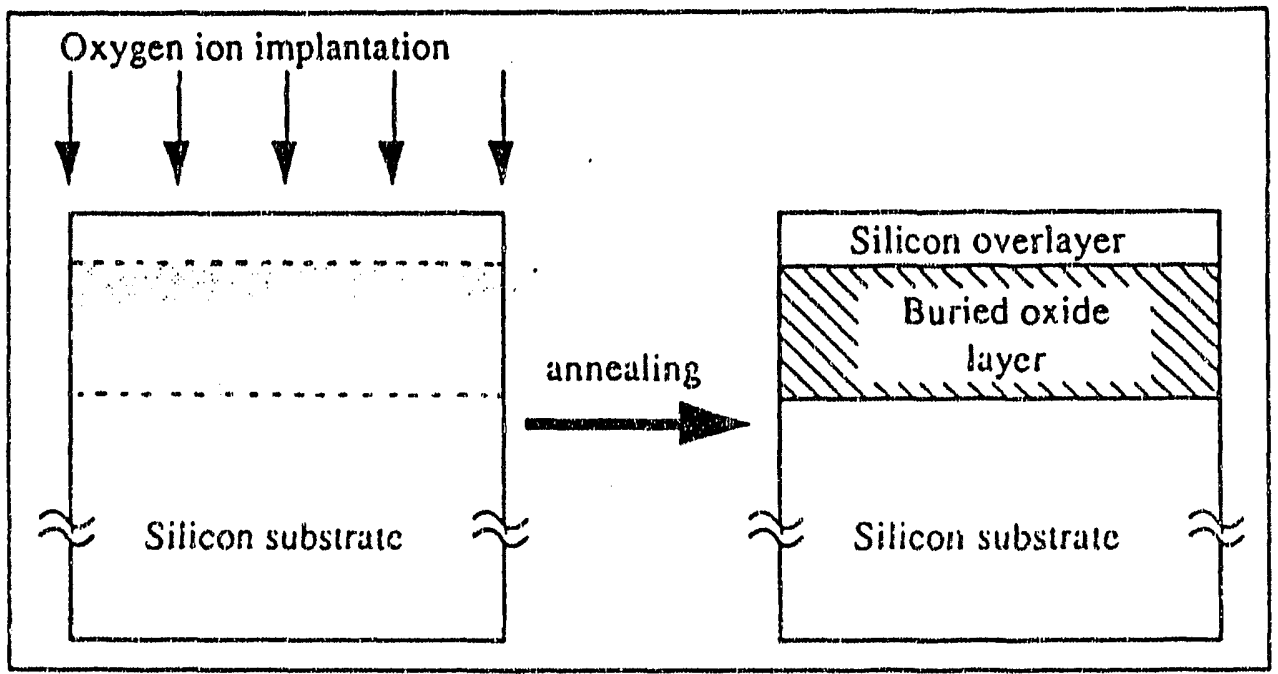

Figure 1.8 Conceptual fabrication process of SIMOX structure. ${ }^{71}$ 


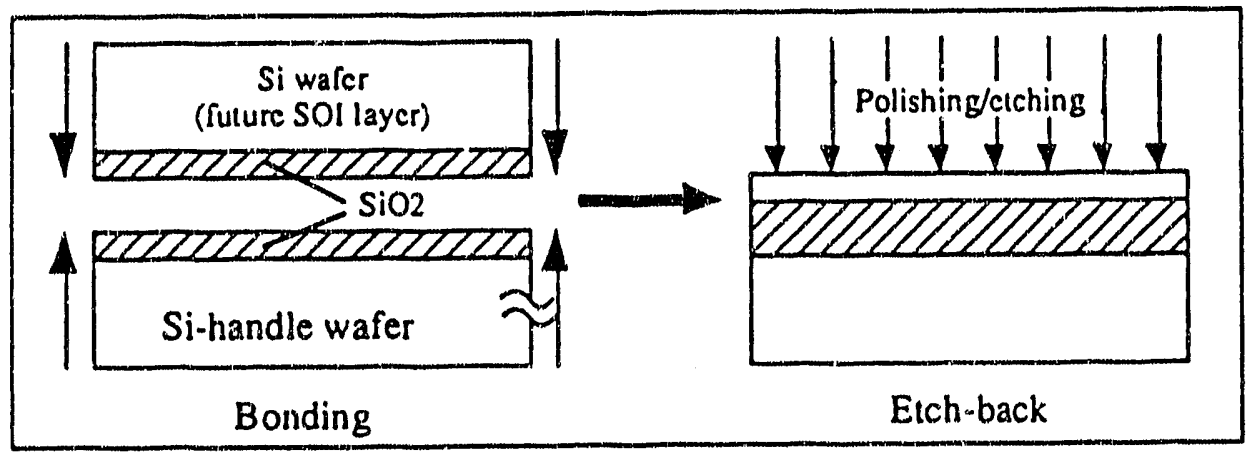

Figure 1.9 Conceptual fabrication process of WB structure. 71

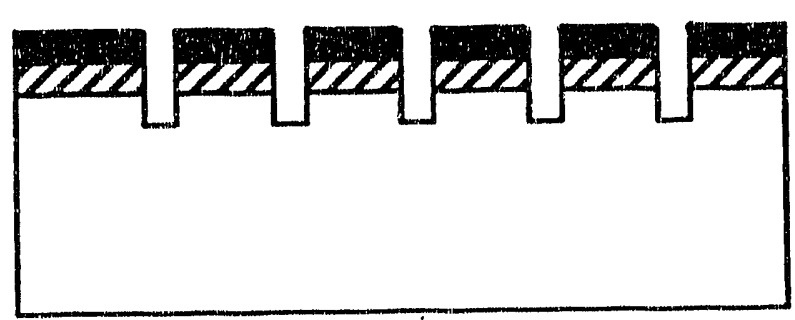

$\square$ silicon

87 porous silicon

aluminum

Figure 1.10 Schematic cross section of striated-mesa device. 78 


\begin{tabular}{|c|c|c|c|c|}
\hline Material & $\begin{array}{c}\text { Defect } \\
\text { densily }\end{array}$ & $\begin{array}{c}\text { Thin Si film } \\
\text { inickness conirol }\end{array}$ & $\begin{array}{c}\text { Minor. carrier } \\
\text { lifelime }\end{array}$ & $\begin{array}{c}\text { Channel } \\
\text { mobllity }\end{array}$ \\
\hline SPOS & $+t$ & + & $+t$ & + \\
\hline ZMR & + & - & + & + \\
\hline SMMOX & + & + & $0 /+$ & + \\
\hline Bonding & ++ & + & $+t$ & + \\
\hline
\end{tabular}

Comparison of some physical and clectrical properties of the different SOI matcrials. Bulk silicon propertics are indicaled as a scalc reference. $t+=$ very good, $t=$ good, $0=$ average, $=$ poor,.$-=v e r y$ poor. Mobility rigures do not include thin-film effects (cnhanced mobility).

\begin{tabular}{|c|c|c|c|c|c|}
\hline Materlal & Country & Purpose & $\begin{array}{c}\text { Commercially } \\
\text { avallable? }\end{array}$ & $\begin{array}{c}\text { Thin } \\
\text { rilms ? }\end{array}$ & Maturity \\
\hline SPOS & US, Eu & Rad & $N$ & $Y$ & + \\
\hline ZMR & US, Eu & Rad & $Y\left(u p 106^{\prime \prime}\right)$ & $N$ & + \\
\hline SMMOX & US, J, Eu & Rad, ULSI & $Y$ (up $\left.106^{\prime \prime}\right)$ & $Y$ & + \\
\hline Banding & US, J,Eu & Rad & $Y$ (up $\left.106^{\prime \prime}\right)$ & $N$ & 0 \\
\hline
\end{tabular}

Comparison of the different SOl materials. US=USA, J=Japan, Eu=Europe, Rad=rad-hard, circuits, $Y=y c s, N=$ no, $+=$ good, $0=$ average. "mpoor.

Table 1.3 The characteristics of different SOI processing technologies. ${ }^{71}$ 
larger lattice parameter (relative to the bulk silicon) are the possible reasons why PS can perform as a gettering center.

\section{(3) Integrated Vapor Sensors:}

Anderson 78 designed a striated-mesa aluminum/PS/Si device to measure the relative humidity (RH) as shown in Figure 1.10. The water vapor condenses in the pores and changes the dielectric constant of PS, which can be sensed by the capacitance measurement. Therefore, the RH is measured by using the aluminum/PS/Si device to do the capacitance measurement. A group from Sandia National Lab. ${ }^{79}$ suggested that OPS could be substituted for the PS in the vapor sensor device

\section{(4) Microfilter:}

The PS and OPS have been proposed to form microfilters, 80 because the pore size can be as low as several angstroms. Furthermore, the pore size and porosity is controllable by adjusting the anodization conditions. This microfilter can be used to do gas separation.

(5) Optoelectronic material:

The visible luminescence of PS opens the door for silicon in optoelectronic applications. The wavelength of the emitting light can be tuned by modifying the pore structure (e.g., the thickness of pore wall). But so far there is no optoelectronic device made by PS.

Because the main potential application of PS is still to produce a thick dielectric insulating film, bow to form a high quality insulator is one of the most important issues for PS processing. This involves the oxidation of PS to form OPS and the quality 
enhancement of the OPS. The open, elongated cylindrical pores of PS are unstable at elevated temperatures $81,82\left(>400^{\circ} \mathrm{C}\right)$, called heat treatment effect. The pores disintegrate into rows of isolated pores to hinder the supply of oxidant species and coarsen to reduce the specific surface area, resulting in difficult PS oxidation. The driving force for the heat treatment effect is to reduce the total surface energy by reducing the total surface area. $\mathrm{A}$ two-step oxidation process ${ }^{38,81}$ is often employed to solve this problem: oxidize PS at $300^{\circ} \mathrm{C}$ to form a thin layer of oxide on the pore wall to stabilize the pore structure, then go to high temperature oxidation $\left(e . g ., 900^{\circ} \mathrm{C}\right)$ to fully oxidize the PS. When the oxidation temperature is lower than $960^{\circ} \mathrm{C}$, the OPS is still porous as shown in Figure 1.11. And due to these residual micropores, the quality of the OPS is poor, e.g., the resistance to the attack of a buffered $\mathrm{HF}$ solution (a standard test for a dense thick $\mathrm{SiO}_{2}$ film) is much weaker than that of thermally grown silicon dioxide of bulk silicon.29,83 Therefore, a densification step at a higher temperature $\left(>960^{\circ} \mathrm{C}\right)$ is needed to start the viscous flow of silica, the composition of OPS, to remove those residual pores. ${ }^{30,77}$ The densification rate depends on the pore structure of OPS, which changes due to the heat treatment effect too (when the temperature $>960^{\circ} \mathrm{C}$ ). Therefore, the stability of cylindrical voids at an elevated temperature is very important for the oxidation of PS and densification of OPS. Chapter 2 focuses on the stability of cylinders and cylindrical voids, when the volume diffusion, surface diffusion, evaporation/condensation, and viscous flow are the mass transport mechanisms. The first three mechanism are important for crystalline materials (e.g., PS). On the other hand, the last two mechanism are possible operative mechanisms for amorphous materials (e.g., OPS). For the viscous flow case, the stability of a cylindrical pore is examined experimentally by heat treatment of artificial pores. Those artificial pores are cylindrical and formed inside glass wafers. Chapter 3 discusses the oxidation of PS. Rapid thermal oxidation process is proposed to replace the tedious two-step oxidation process. Chapter 4 studies the ambient gas effect on the 


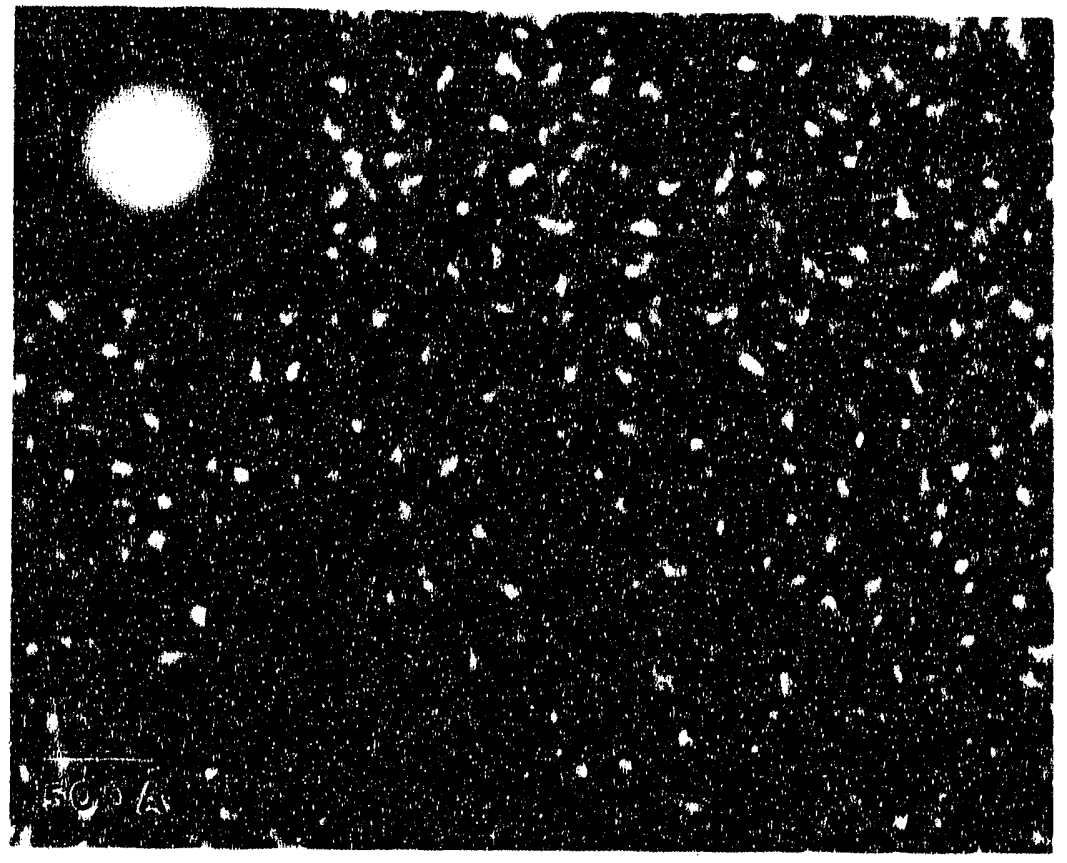

a

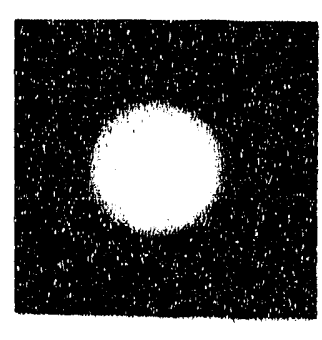

glue

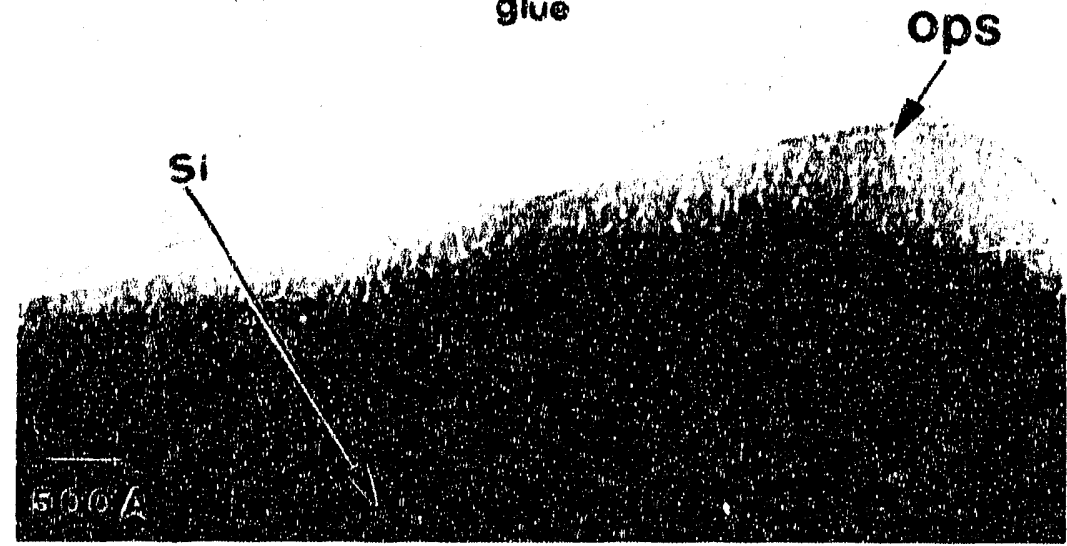

b

Fig. 1.11

XBB 924-2358 
densification rate of OPS and proposes a densification strategy to reduce the densification time. Also the feasibility of nitridizing OPS in ammonia gas to incorporate nitrogen to enhance the OPS's resistance to the HF attack is studied. Chapter 5 proposes to use PS as a gettering center to enhance the performance of devices. This is demonstrated by showing the concentration of the oxidation induced stack fault is reduced by applying a patch of PS on the back side of silicon wafer. Finally, a brief summary is given in Chapter 6. 
References

1. D. R. Turner, J. Electrochem. Soc., 105, 402 (1958).

2. X. G. Zhang, S. D. Collins, and R. L. Smith, J. Electrochem. Soc., 136, 1561 (1989).

3. M. J. J. Theunissen, J. Electrochem. Soc., 119, 351 (1972).

4. A. Uhlir, Bell System Tech. J., 333, March (1956).

5. M. J. Hill, J. Electrochem. Soc., 120, 142 (1973).

6. Y. Arita and Y. Sunohara, J. Electrochem. Soc., 124, 285 (1977).

7. T. Unagami, J. Electrochem. Soc., 127, 476 (1980).

8. V. Labunov, I. Baranov; and V. Bondarenko, Thin Solid Films , 64, 479 (1979).

9. H. Unno, K. Imai, and S. Muramoto, J. Electrochem. Soc., 134, 645 (1987).

10. F. Gaspard, A Bsiesy, M. Ligeon, F. Muller, and R. Herino, J. Electrochem. Soc., 136, 3043 (1989).

11. R. L. Smith, S. F. Chuang, and S. D. Collins, Sensors and Acttuators, A21-23, 825 (1990).

12. V. Lehmann and H. Foll, J. Electrochem. Soc. 137, 653 (1990).

13. R. Memming and G. Schwandt, Surf. Sci., 4, 109 (1966)

14. X. G. Zhang, J. Electrochem. Soc., 138, 3750 (1991).

15. J. D. Benjamin, J. M. Keen, A. G. Cullis, B. Innes, and N. G. Chew, Appl Phys. Lett., 49, 719 (1986).

16. D. Bellet, G. Dolino, and M. Ligeno, J. Appl. Phys., 71, 145 (1992).

17. M. I. J. Beale, N. G. Chew, M. J. Uren, A. G. Cullis, and J. D. Benjamin, Appl. Phys. Lett. , 46, 86 (1985).

18. R. C. Anderson, R.S. Muller, and C.W. Tobias, J. Electrochem. Soc. , 138, 3406 (1991).

19. H. A. Tenhunen, Ph.D. Thesis, Cornell University 1986. 
20. R. L. Smith, S.F. Chuang, and S. D. Collins, J. of Electronic Mater., 17, 533 (1988).

21. K. H. Beckman, Surf. Sci, , 3, 314 (1965).

22. R. W. Hardeman, M. I. J. Beale, D.B. Gassson, J. M. Keen, C. Pickering, and D. J. Robbins, Sur. Sci, 152, 1051 (1985).

23. L. G. Earwaker, J.P.G. Farr, I. Alexander, and I.M. Sturland, Nucl. Instr. and Meth, , 218, 481 (1983).

24. Y. Arita and Y. Sunohara, J. Electrochem. Soc. , 124, 285 (1977).

25. K. Barla, G. Bomchil, R: Herino, and J. C. Pfister, J. Crystal Growth , 68, 727 (1984).

26. C. Pickering, M.I.J. Beale, D.J. Robbins, P.J. Pearson, and R. Greef, J. Phys. C: Solid State Phys., 17, 6535 (1984).

27. T. Unagami, Jpn. J. Appl. Phys., 19, 231 (1980).

28. G. Bomchil, R. Herino, K. Barla, and J. C. Pfister, J. Electrochem. Soc., 130, 1611 (1983).

29. R. Herino, G. Bomchil, K. Barla, and C. Bertrand, J. Electrochem. Soc., 134, 1994 (1987).

30. K. Barla, J. J. Yon, R. Herino, and G. Bomchil, Insulating Films on Semiconductors (edited by J. J. Simonne, p53, Elsevier Sci. Pub. 1986).

31. Y. Watanabe, Y. Arita, T. Yokoyama, and Y. Igarashi, J. Electrochem. Soc., 122, 1351 (1975).

32. S. S. Tsao, D. R. Myers, T. R. Guilinger, and M. J. Kelly, J. Appl. Phys., 62 , $4182(1987)$.

33. R. P. Holmstrom and J. Y. Chi, Appl. Phys. Lett. , 42, 386 (1983).

34. T. Unagami and K. Kato, Japan J. Appl. Phys. , 16, 1635 (1977).

35. H. Takai and T. Itoh, J. Appl. Phys., 60, 222 (1986). 
36. M. I. J. Beale, J. D. Benjamin, M. J. Uren, N. G. Chew, and A. G. Cullis, J. Crystal Growth 73, 622 (1985).

37. M. I. J. Beale, N. G. Chew, M. J. Uren, A. G. Cullis, and J. D. Benjamin, Appl. Phys. Lett., 46, 86 (1986).

38. T. L. Lin and K. L. Wang, Appl. Phys. Lett. , 49, 1104 (1986).

39. H. Baumgart, R. C. Frye, F. Phillipp, and H. J. Leamy, Mat. Res. Soc. Symp. Proc. , 33, 63 (1984).

40. T. L. Lin, S. S. Chen, Y. C. Kao, K. L. Wang, and S. Iyer, Appl. Phys. Lett. , 48, 1973 (1986).

41. H. Takai and T. Itoh, J. Electro. Mater. , 12, 973 (1983).

42. S. Luryi and E. Suhir, Appl. Phys. Lett, , 49, 140 (1986).

43. T. L. Lin, L. Sadwick, K. L. Wang, S. S. Rhee, Y. C. Kao, R. Hull, C. W. Nieh, D. N. Jamieson, J. K. Liu, and M. A. Nicolet, Mat. Res. Symp. Proc., 91, 113 (1987).

44. K. Maehashi, M. Sato, S. Hasegawa, H. Nakashima, T. Ito, and A. Hiraki, Jpn. J. Appl. Phys., 30, L683 (1991).

45.Y. C. Kao, D. Jamieson, G. Bai, C. W. Nieh, T. L. Lin, B. J. Wu, H. Y. Chen, and K. L. Wang, Mat. Res. Symp. Proc., 91, 473 (1987).

46. Y. H. Xie and J. C. Bean, J. Appl. Phys., 67, 792 (1990).

47. H. Takagi, H. Ogawa, A. Ishizaki, and T. Nakagiri, Appl. Phy. Letto, 56, 2379 (1990).

48. L. T. Canham, Appl. Phy. Lett., 57, 1046 (1990).

49. Y. Maeda, N. Tsukamoto, and Y. Yazawa, Appl. Phy。 Lett., 59, 3168 (1991).

50. V. Lehmann and U. Gosele, Appl. Phy. Lett., 58, 856 (1991).

51. L. T. Canham, M. R. Houlton, W. Y. Leong, C. Pickering, and J. M. Keen, J. Appl. Phys., 70, 422 (1991). 
52. J. L. Heinrich, C. L. Curtis, G. M. Credo, K. L. Kavanagh, and J. Sailor, Science, 255, 66 (1992).

53. R. P. Vasquez, R. W. Fathauer, T. George, and A. Ksendzov, Appl. Phy. Lett., 60,1004 (1992).

54. R. W. Fathauer, T. George, A. Ksendzov, and R. P. Vasquez, Appl. Phy. Lett., 60, 995 (1992).

55. V. V. Doan and M. J. Sailor, Appl. Phy. Lett., 60, 619 (1992).

56. S. Shih, C. Tsai, K. H. Lin, K. H. Jung, J. C. Campbell, and D. L. Kwong, Appl. Phy. Lett., 60, 633 (1992).

57. M. A. Tischler, R. T. Collins, J. H. Stathis, and J. C. Tsang, Appl. Phy. Lett., 60, 639 (1992).

58. R. Tsu, H. Shen, and M. Dutta, Appl. Phy. Lett., 60, 112 (1992).

59. J. P. Wolfe, Phys. Today, March 46 (1982).

60. R. Rossetti, R. Hull, J. M. Gibson, and L. E. Brus, J. Chem. Phys., 83, 1406 (1985).

61. K. Imai and H. Unno, IEEE Trans. Electron Devices ,ED-31, 297 (1984).

62. T. C. Teng, J. Electrochem. Soc. , 126, 870 (1979).

63. D. Bensahel, Heterostructures on Silicon , 289, (1989).

64. S. Konaka, M. Tabe, and T. Sakai, Appl. Phys. Lett., 41, 86 (1982).

65. F. Goodenough, Electronic Design, 94, Nov. 29, 1984.

66. L. A. Nesbit, IEDM, 800 (1984).

67. Electronic Engineering, p31, May 1987.

68. R. C. Frye, Mat. Res. Symp. Proc. , 33, 53 (1984).

69. L. Jastrzebski, J. of Cryst. Growth , 70, 253 (1984).

70. D. Bensahel, in Heterostructures on silicom, Y. I. Nissim and E. Rusencher, Eds., Kluwer Academic Publisher, Boston 1989, p289. 
71. J.P. Colinge, Silicon-on-Insulator Technology: Materials to VLSI, Klumer Academ. Publishers, Boston 1991.

72. K. Barla, G. Bomchil, R. Herino, and J. C. Pfister, J. Crystal Growth , 68, 721 (1984).

73. L A Nesbit, IEDM Digest Techn Papers, 800 (1984).

74. R. Stengl, T. Tan, and U. Gosele, Jph. J. Appl. Phys., 28, 1735 (1989).

75. W. P. Maszara, G. Goetz, A. Caviglia, and J. B. McKitterick, J. Appl. Phys., 64, 4943 (1988).

76. M. "sashi, A. Nakano, S. Shoji, and H. Hebiguchi, Sensors and Actuators, A21. 23, 931 (1990)

77. N. Cheung, EECS243 classnote, UC Berkeley, 1991 Spring.

78. R. C. Anderson, R.S. Muller, and C.W. Tobias, Sensors and Actuators, A-23, 835 (1990).

79. M. J. Kelly, T.R. Guilinger, D.W. Peterson, M.R. Tuck, and J.N. Sweet, J. of Metals, 43-6, 4 (1991).

80. D. L. Parker, K R. Hall, and J. C. Holste, US Patent 4801380.

81. R. Herino, A Perio, K. Barla, and G. Bomchil, Materials Lett. , 2, 519 (1984).

82. T. Unagami and M. Seki, J. Electrochem. Soc. , 125, 1339 (1978).

83. J. J. Yon, K. Barla, R. Herino, and G. Bonchil, J. Appl. Phys., 62, 1042 (1987).

84. K. Imai, H. Unno, and S. Muramato, Digest of Tech. Papers 1981 Symp. on VLSI Tech. p76.

85. K. Imai and S. Nakajiwah, IEDM Digest Techn Papers, 376 (1981).

86. K Imai Solid State Electronics , 24, 159 (1981).

87. T. Nano, T. Baba, H. Sawada, and K. Imai,Digest of Tech. Papers 1982 Symp. on VISI Teck., p12.

88. K. Imai, H. Unno, and H. Takaoka, J. Crystal Growth, 63, 547 (1983). 
89. K. Anzai, F. Otoi, M. Ohnishi, and H. Kitabayashi, IEDM Digest Techn Papers, 796 (1984).

90. K. Ehara, H. Unno, and S. Muramoto, Electrochem. Soc. Meeting Extended Abstracts, 85-2, 457 (1985). 
Chapter 2 The Stability of Cylindrical Pores Under The Influence of Surface Energy

\subsection{Introduction}

It is well known that a cylindrical void (or cylinder) with nonzero surface energy may be unstable with respect to the disintegration of cylindrical void (or cylinder) into a number of isolated spherical voids (or spheres).1-7 Four possible mass transport mechanisms are involved in the disintegration process. They are volume diffusion, surface diffusion, evaporation-condensation, and viscous flow. For crystalline materials, the first three mechanisms are possible operative ones; the last two mechanisms are important for amorphous materials. Nichols and Mullins ${ }^{6}$ have examined the breakup of cylinders and cylindrical voids when the transport mechanism is surface diffusion or volume diffusion. For viscous flow as the transport mechanism, Lord Rayleigh ${ }^{7}$ treated the disintegration of cylinders, but there has been no corresponding treatment of cylindrical voids. In the case of evaporation-condensation as the transport mechanism, the instability of neither cylinders nor cylindrical voids appears in the literature. It is the purpose of this chapter to rectify these omissions. One application of this instability study is to the processing of porous silicon (PS), which contains long, nearly cylindrical pores, as shown in Figures 1.1 and 1.11, with an aspect ratio in excess of 1000:18:

(1) During oxidation of PS, when the pores break up into rows of isolated pores and are no longer open to the oxidant atmosphere, it is hard to fully oxidize PS. So keeping the pore shape stable (e.g., open to the atmosphere) is very important for the PS oxidation process.

(2) During densification of oxidized porous silicon (OPS), residual pores in the OPS are to be eliminated by densifying at an elevated temperatures where viscous flow is the mass transport mechanism. The shape and size of the pores, which change drastically tbrough 
the disintegration process, play an inportant role on the densification rate. Also, the ambient gas trapped inside those isolated pores has the chance to reduce the densification rate (perhaps to zero), which is discussed in detail in chapter 4.

For the viscous flow case, the instability of a cylindrical pore was also examined experimentally by heat treatment of artificial pores. The artificial pores were cylindrical and formed inside glass wafers ${ }^{9}$ by using a standard photolithography method in the integrated circuit (IC) industry and a glass bonding method. The glass bonding method is a modified silicon wafer bonding process, ${ }^{10-13}$ which welds silicon wafers together without applying adhesives. The silicon wafer bonding process has been extensively studied recently to create a silicon-on insulator (SOI) structure. 11 The silicon wafer bonding process consists of bonding and etch-back steps as shown in Figure 2.1. Two flat silicon wafers are cxidized to form a layer of silica $\left(e_{.} g_{\circ}, 1 \mu \mathrm{m}\right)$ and then placed together to form bonding. The bond type and strength depend on the annealing temperature 10,13:

(1) room temperature: the bonding forces are caused by the attraction of silanol groups ( $\cong \mathrm{Si}-\mathrm{OH})$ present at the bonding interface.

(2) $200-300^{\circ} \mathrm{C}$ : the bonding forces are increased by the formation of Si-O-Si bonds at the interface through the following reaction:

$$
\mathrm{Si}-\mathrm{OH}+\mathrm{HO}-\mathrm{Si} \rightarrow \mathrm{Si}-\mathrm{O}-\mathrm{Si}+\mathrm{H}_{2} \mathrm{O} \text {. }
$$

(3) $1100^{\circ} \mathrm{C}$ and above: the viscous flow of the silica completes the bonding of the wafers. The last annealing temperature can be lower if an uniaxial stress is applied perpendicularly to the wafers, ie., a kind of hot pressing processing ir the ceramic industry. 14 The top wafer is to be thinned down to a few micrometers or less by mechanical grinding or chemical etching to form a SOI structure. 


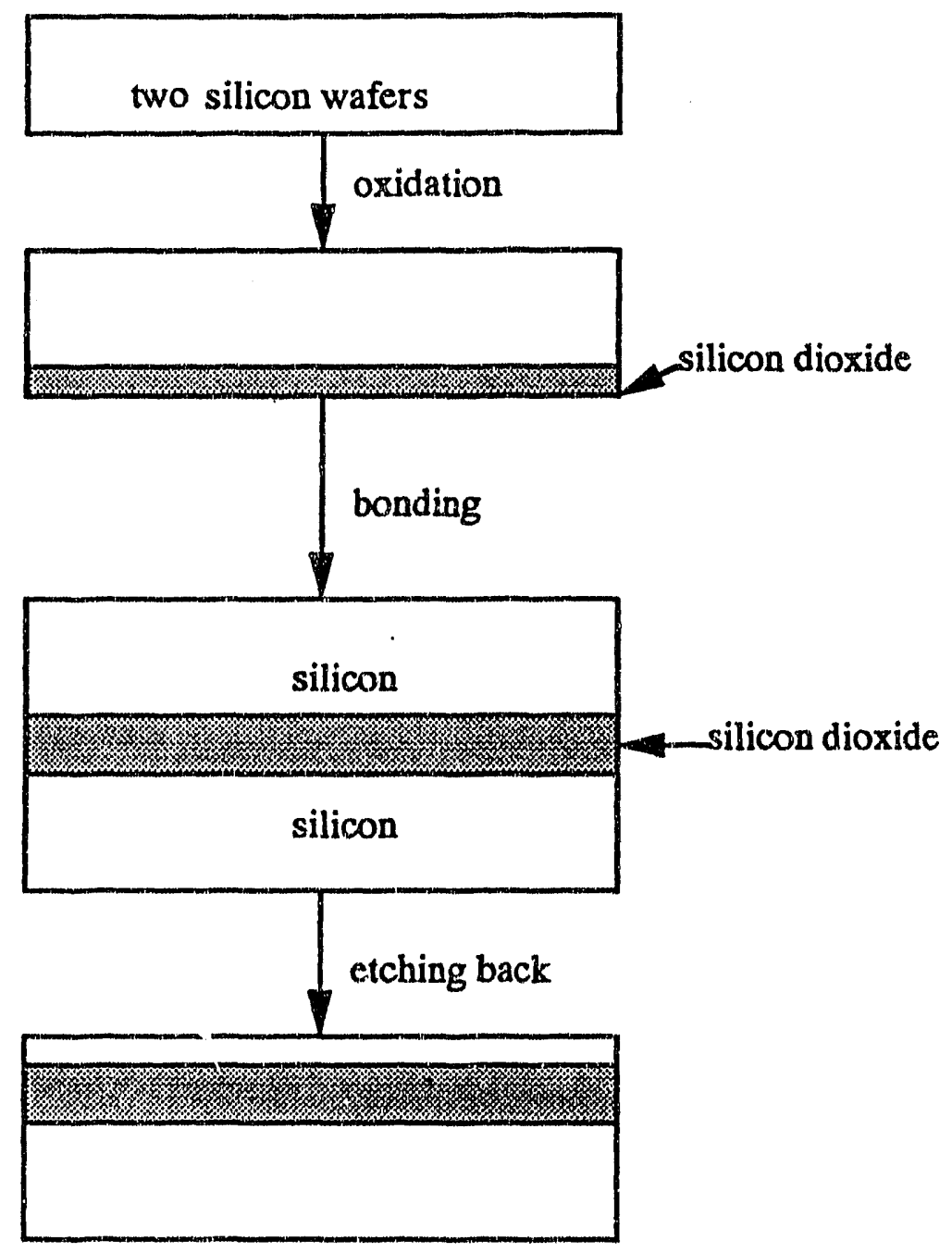

Figure 2.1 Detailed fabrication process of silicon wafer bonding SOI scheme 
The glass bonding method used in the present study only employs the bonding step of the silicon wafer bonding process with lower annealing temperature $\left(e . g ., 650^{\circ} \mathrm{C}\right)$. The detailed process is described in the experiment section.

The stability of those artificial cylindrical pores at an elevated temperature is observed and compared with the theoretical prediction.

\section{Theoretical Consideration of Stability 15}

The derivations consider a cylinder or a cylindrical pore of radius $r_{0}$ as shown in Figure 2.2, subjected to a sinusoidal perturbation of infinitesimal amplitude $\delta$ and wavelength $\lambda$. The rate of change of $\delta$ is determined as a function of $\lambda$. When the rate of change of $\delta$ is positive, i.e., the perturbation grows, the cylinder or the cylindrical pore is unstable and tends to break up into row of spheres or isolated spherical pores.

\subsubsection{Viscous Flow Case}

I. Cylindrical void

The following assumptions are made:

(1) quasi-steady state;

(2) gravitational effects may be neglected;

(3) the Reynolds number $(\operatorname{Re}=\rho \mathrm{pl} u / \mu$, here $\rho, l, u$, and $\mu$ are density, characteristic length, velocity, and viscosity, respectively) of the flow is sufficiently low that the inertial terms in the Navier-Stokes 16 equations may be neglected;

(4) physical properties are constant.

The Navier-Stokes equations then become

$$
\mu\left[\frac{\partial}{\partial r}\left(\frac{1}{r} \frac{\partial}{\partial r}(r u)\right)+\frac{\partial^{2} u}{\partial z^{2}}\right]=\frac{\partial p}{\partial r}
$$



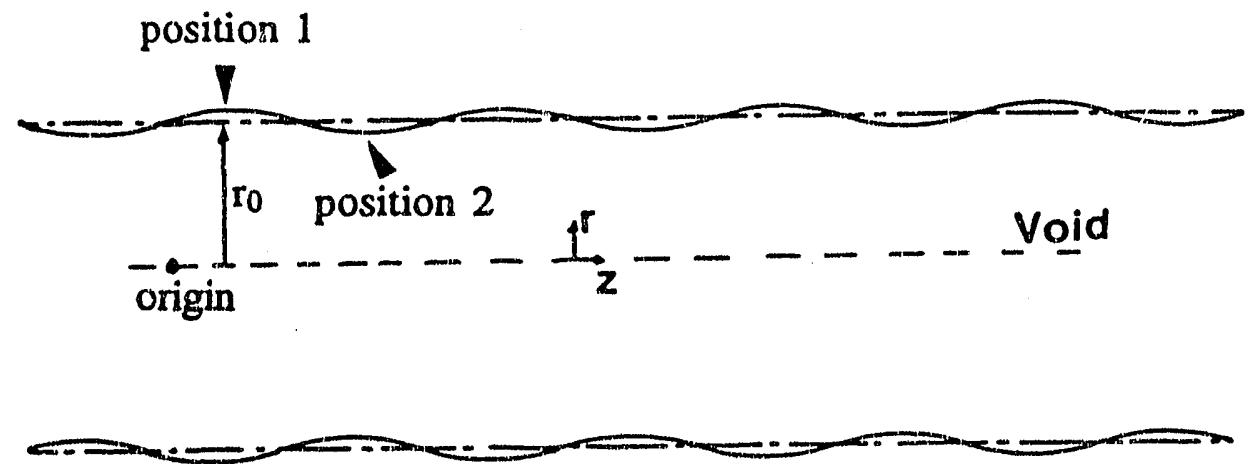

An Infinitesimal Sinusoidal and Longitudinal Perturbation:

$$
\text { ro }+\delta \sin (2 \pi z / \lambda)
$$

Figure 2.2 Cylindrical coordinates used in the instability study. 


$$
\mu\left[\frac{1}{r} \frac{\partial}{\partial r}\left(\frac{\partial w}{\partial r}\right)+\frac{\partial^{2} w}{\partial z^{2}}\right]=\frac{\partial p}{\partial z}
$$

where $\mathrm{p}$ is the pressure, $\mathrm{u}$ and $\mathrm{w}$ the velocities in the radial ( $\mathrm{r}$ ) and axial ( $\mathrm{z}$ ) directions, respectively.

The continuity equation becomes

$$
\frac{1 \partial}{r \partial r}(r u)+\frac{\partial w}{\partial z}=0
$$

Equations (1)-(3) lead to the usual result for creeping flow

$$
\nabla^{2} p=\frac{1}{r} \partial r\left(\frac{\partial p}{\partial r}\right)+\frac{\partial^{2} p}{\partial z^{2}}=0
$$

The equation of the perturbed surface is

$$
\mathrm{R}=\mathrm{r}_{0}+\delta \sin (\omega \mathrm{z})
$$

where $\omega=2 \pi / \lambda$

$$
\begin{aligned}
& \text { The curvature } K \text { is }-\left[\mathrm{R}^{-1}-\left(\frac{\partial^{2} \mathrm{R}}{\partial \mathrm{z}^{2}}\right)\right] \text { which, for small } \delta \text { yields } \\
& K=-\left(\mathrm{r}_{0}^{-1}+\left(\omega^{2}-r_{0}^{2}\right) \delta \sin (\omega z)\right)
\end{aligned}
$$

Taking the pressure within the void as a datum, that just beneath the surface is given by the Gibbs-Thompson equation 17 and fluid mechanics 18

$$
-\gamma K=-\mathrm{p}+\left.2 \mu \frac{\partial \mathrm{u}}{\partial \mathrm{r}}\right|_{r=\mathrm{R} \sim \mathrm{r}_{0}}
$$




$$
\mathrm{p}=-\frac{\gamma}{\mathrm{r}_{0}}-\gamma \delta\left(\omega^{2}-\mathrm{r}_{0}^{2}\right) \sin (\omega z)+\left.2 \mu \frac{\partial \mathrm{u}}{\partial \mathrm{r}}\right|_{\mathrm{r}=\mathrm{R} \operatorname{ar} \mathrm{r}}
$$

for $r=R=r_{0}$

where $\gamma$ is the specific surface energy.

From equations (1), (2), and (7),

$$
\begin{aligned}
& u=f(r) \sin (\omega z) \\
& w=g(r) \cos (\omega z) \\
& p=-\frac{\gamma}{r_{0}}-\sin \omega z\left[\gamma \delta\left(\omega^{2}-\frac{1}{r_{0}^{2}}\right)-\left.2 \mu \frac{\partial f(r)}{\partial r}\right|_{r=r_{0}}\right]
\end{aligned}
$$

for $r=R \sim r_{0}$

With this as a boundary condition, along with the requirement that the pressure be finite for any $r$ and $z$, the solution to (4) is obtained as

$$
\mathrm{p}=-\frac{\gamma}{\mathrm{r}_{0}}-\sin \omega_{2}\left[\gamma \delta\left(\omega^{2}-\frac{1}{\mathrm{r}_{0}^{2}}\right)-\left.2 \mu \frac{\partial f(\mathrm{r})}{\partial \mathrm{r}}\right|_{\mathrm{r}=\mathrm{r}_{0}}\right] \frac{\mathrm{K}_{0}(\omega \mathrm{r})}{\mathrm{K}_{0}\left(\omega \mathrm{r}_{0}\right)}
$$

where $\mathrm{K}_{0}$ is the modified Bessel function of the second kind, of order 0 .

The solutions to (1) and (2), with the right hand sides obtained from (8) and a requirement that the velocities be finite for any $r$ and $z$, are

$\mathrm{u}=\mathrm{C}(\mathrm{r}) \sin (\omega \mathrm{z}) \mathbb{K}_{1}(\omega \mathrm{r}), \quad \mathrm{w}=\mathrm{D}(\mathrm{r}) \cos (\omega \mathrm{z}) \mathrm{K}_{0}(\omega \mathrm{r})$

where $\mathrm{K}_{1}$ is the modified Bessel function of the second kind, of order 1 and,

$$
C(r)=-\frac{A_{r} K_{0}(\omega r)}{2 \omega K_{1}(\omega r)}+C_{2}
$$




$$
D(r)=\frac{A r K_{1}(\omega r)}{2 \omega K_{0}(\omega r)}+D_{2}
$$

and

$$
A=\frac{1}{\mu}\left[\delta \gamma\left(\omega^{2}-r_{0}^{-2}\right)-\left.2 \mu \frac{\partial f(r)}{\partial r}\right|_{r=r_{0}}\right] \frac{\omega}{K_{0}\left(\omega r_{0}\right)}
$$

with $C_{2}$ and $D_{2}$ constants obtainable from (3) and the boundary condition that the tangential stress vanish at the surface, i.e.,

$$
\frac{\partial u}{\partial z}+\frac{\partial w}{\partial r}=0
$$

the results are

$$
\begin{aligned}
& C_{2}=-\frac{A}{2 \omega^{2}}+\frac{A r_{0} K_{0}\left(\omega r_{0}\right)}{2 \omega K_{1}\left(\omega r_{0}\right)} \\
& \begin{aligned}
D_{2} & =-\frac{A}{2 \omega^{2}}-\frac{A r_{0} K_{0}\left(\omega r_{0}\right)}{2 \omega K_{1}\left(\omega r_{0}\right)} \\
f(r) & =C(r) K_{1}(\omega r) \\
& \left.=-\frac{A r}{2 \omega} K_{d} d \omega r\right)+C_{2} K_{1}(\omega r)
\end{aligned} \\
& \left.\frac{\partial f(r)}{\partial r}\right|_{r=r_{0}}=A\left[\frac{r_{0} K_{1}\left(\omega r_{0}\right)}{2}-\frac{r_{0} K_{0}^{2}\left(\omega r_{0}\right)}{2 K_{1}\left(\omega r_{0}\right)}+\frac{K_{1}\left(\omega r_{0}\right)}{2 \omega^{2} r_{0}}-\frac{K_{0}\left(\omega r_{0}\right)}{2 \omega}\right] \\
& (9)+(10) \rightarrow \\
& A=\delta \gamma\left(\omega^{2}-r_{0}^{2}\right) \frac{1}{\mu} \frac{1}{r_{0} K_{1}\left(\omega r_{0}\right)-r_{0} K_{2}^{2}\left(\omega r_{0}\right) / K_{1}\left(\omega r_{0}\right)+K_{1}\left(\omega r_{0}\right) /\left(\omega T_{0}^{2}\right)}
\end{aligned}
$$


The normalized growth rate of the perturbation is

$$
\begin{aligned}
\frac{1 \mathrm{~d} \delta}{\delta \mathrm{dt}}= & \frac{\mathrm{u}(\mathrm{R}, \mathrm{z})}{\delta \sin (\omega \mathrm{z})} \sim \frac{\mathrm{u}\left(\mathrm{r}_{0}, \mathrm{z}\right)}{\delta \sin (\omega \mathrm{z})} \\
& =\frac{\gamma}{\mu} \frac{\left(1-\omega^{2} \mathrm{~T}_{0}^{2}\right)}{2 \omega^{2} \mathrm{~T}_{0}^{2}} \frac{1}{\mathrm{r}_{0}} \frac{1}{1-\left[\mathrm{K}_{d}\left(\omega \mathrm{r}_{0}\right) / \mathrm{K}_{1}\left(\omega \mathrm{r}_{0}\right)\right]^{2}+1\left(\omega^{2} \mathrm{~T}_{0}^{2}\right)}
\end{aligned}
$$

Because for the modified Bessel functions, $\mathrm{K}_{1}>\mathrm{K}_{0}$, Equation (11) reveals that small perturbations must grow for $\omega<1 / r_{0}$ (i.e., for $\lambda>2 \pi r_{0}=\lambda_{c}$ ). The rate of growth of the perturbation increases monotonically with wavelengths shown in Figure 2.3. This is in contrast to the behavior for disintegration by surface or volume diffusion, in which cases Nichols and Mullins 6 showed that growth rate maxima occurred at wavelength $\left(\lambda_{m}\right)$ of $8.89 \mathrm{r}_{0}$ and $12.96 \mathrm{r} 0$, respectively.

II. Cylinder

Equations (1)-(4) are valid for this case. Boundary conditions at the free surface are akin to those used above (with an obvious sign change in (6)). The other necessary boundary conditions are obtained at the axis of symmetry by setting gradients of pressure and velocities equal to zero there.

The solutions are

$$
\begin{aligned}
& \mathrm{p}=\frac{\gamma}{\mathrm{r}_{0}}+\sin (\omega z)\left[\gamma \delta\left(\omega^{2}-\mathrm{r}_{0}^{2}\right)+\left.2 \mu \frac{\partial\left[\mathrm{E}(\mathrm{r}) \mathrm{I}_{1}(\omega \mathrm{r})\right]}{\partial \mathrm{r}}\right|_{r=\mathrm{r}_{0}} \frac{\mathrm{I}_{0}(\omega \mathrm{r})}{\mathrm{I}_{0}\left(\omega \mathrm{r}_{0}\right)}\right. \\
& \mathrm{u}=\mathrm{E}(\mathrm{r}) \sin (\omega \mathrm{z}) \mathrm{I}_{1}(\omega \mathrm{r}) \quad \mathrm{w}=\mathrm{F}(\mathrm{r}) \cos (\omega \mathrm{z}) \mathrm{I}_{0}(\omega \mathrm{r})
\end{aligned}
$$

with

$$
\begin{aligned}
& E(r)=\frac{\operatorname{ArI}_{0}(\omega r)}{2 \omega I_{1}(\omega r)}-\frac{A}{2 \omega^{2}}-\frac{A_{0} I_{0}\left(\omega r_{0}\right)}{2 \omega I_{1}\left(\omega r_{0}\right)} \\
& F(r)=\frac{A_{r I}(\omega r)}{2 \omega I_{0}(\omega r)}-\frac{A}{2 \omega^{2}}-\frac{A_{0} I_{0}\left(\omega r_{0}\right)}{2 \omega I_{1}\left(\omega r_{0}\right)}
\end{aligned}
$$



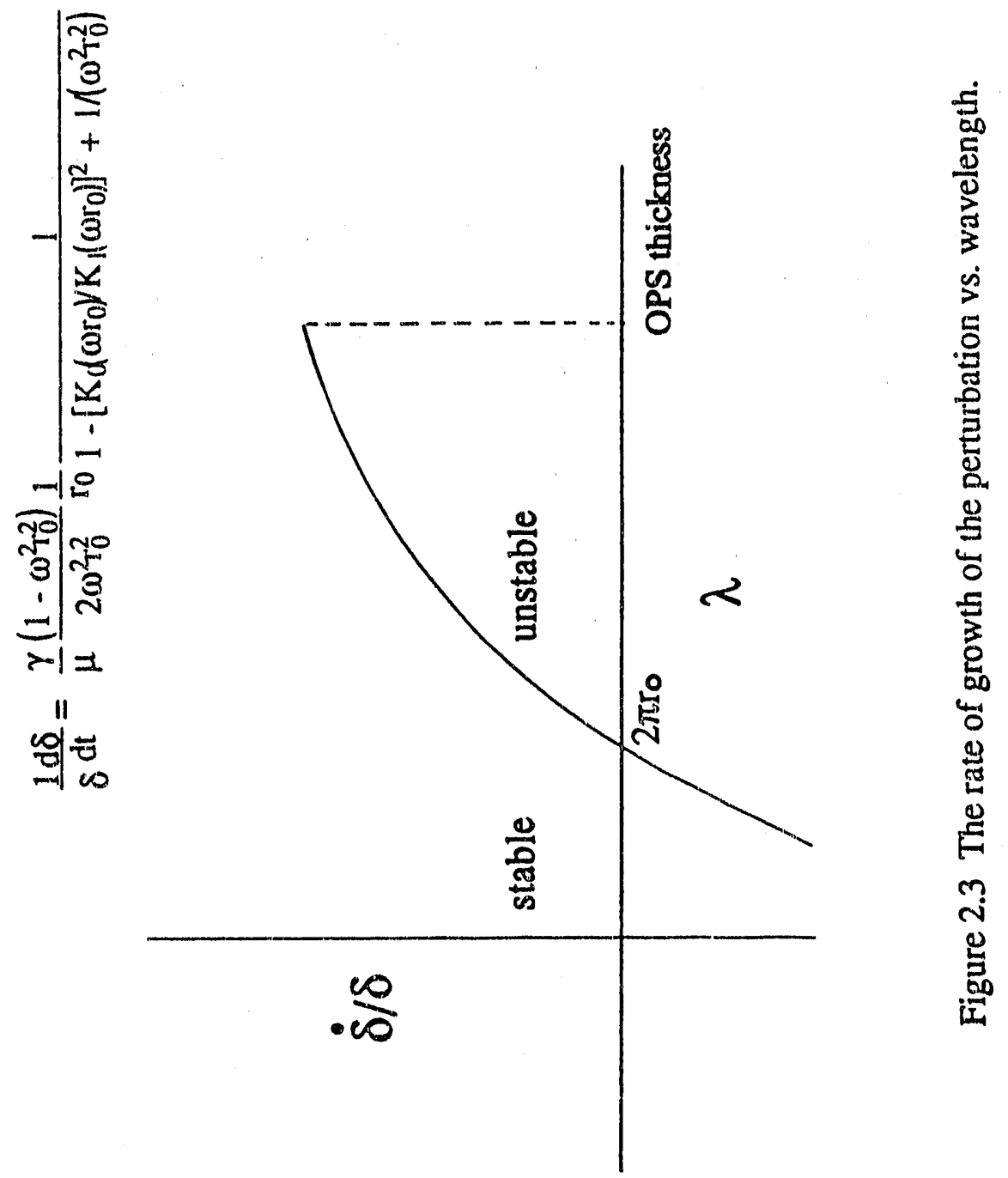
and

$$
A=\delta y\left(\omega^{2}-r_{0}^{2}\right) \frac{1}{\mu} \frac{1}{r_{0} I_{1}\left(\omega r_{0}\right)-r_{0} I^{2}\left(\omega r_{0}\right) / I_{1}\left(\omega r_{0}\right)+I_{1}\left(\omega r_{0}\right) /\left(\omega^{2} r_{0}\right)}
$$

where $I_{0}$ and $I_{1}$ are the modified Bessel function of the first kind, of order 0 and 1 , respectively.

The perturbation growth rate is

$$
-\frac{\gamma}{\mu} \frac{\left(1-\omega^{2} \mathrm{r}_{0 j}^{\prime}\right.}{2 \omega^{2} \mathrm{r}_{0}^{2}} \frac{1}{\mathrm{r}_{0}} \frac{1}{1-\left[\mathrm{I}_{0}\left(\omega \mathrm{r}_{0}\right) / I_{1}\left(\omega \mathrm{r}_{0}\right)\right]^{2}+1\left(\omega^{2} \mathrm{I}_{0}^{2}\right)}
$$

The modified Bessel functions are again positive, leading to positive growth rates for $\lambda$ $>2 \pi r_{0}$. The growth rate increases beyond this point to a maximum at infinity. This result agrees with the classical result of Rayleigh?, although the derivation presented here differs somewhat from Rayleigh's.

\subsubsection{Evaporation/Condensation Case}

Two extremes are considered here: rate limitation by diffusion in the gas phase (assumed Fickian here) and rate limitation by sublimation at the solid gas interface.

A. Rate limited by gas phase diffusion

The quasi-steady state vapor concentration of the diffusing species in a closed system is described by

$$
\frac{1}{r} \frac{\partial}{\partial r}\left(r \frac{\partial C}{\partial r}\right)+\frac{\partial^{2} C}{\partial z^{2}}=0
$$


This equation is applied to the two geometries as follows:

\section{Cylindrical Void}

The vapor concentration at the surface is given by the Gibbs-Thompson equation:

$$
\begin{aligned}
& C-C_{0}=\left(\frac{C_{0} \Omega \gamma}{k T}\right) K \\
& =-\frac{C_{0} \gamma \Omega}{k T}\left(r_{0}^{-1}+\left(\omega^{2}-r_{0}^{2}\right) \delta \sin (\omega z)\right) \quad \text { at } r=r_{0}
\end{aligned}
$$

where $C_{0}$ is the equilibrium vapor concentration above the flat surface, $\Omega$ the atomic/molecular volume, $\mathbf{k}$ is the Planck's constant, and $\mathrm{T}$ is the absolute temperature.

Applying a second boundary of zero concentration gradient at the axis of symmetry, the solution to (13) is obtained,

$$
\mathrm{C}=\mathrm{C}_{0}-\frac{\Omega \gamma}{\mathrm{kT}}\left[\mathrm{r}_{0}^{-1}+\left(\omega^{2}-\mathrm{r}_{0}^{2}\right) \delta \sin (\omega \mathrm{z}) \frac{\mathrm{I}_{0}(\omega \mathrm{r})}{\mathrm{I}_{0}\left(\omega \mathrm{r}_{0}\right)}\right] \mathrm{C}_{0}
$$

The rate of change of the radius at the soid-vapor interface is given by the product of $\Omega$ and the flux:

$$
\frac{\partial R}{\partial t}=-\Omega J(\text { at } r=R \approx r d)=D_{g} \Omega\left(\frac{\partial C}{\partial r}\right) \text { at } r=r_{C}
$$

(5) and (16) lead to

$$
\frac{1}{\delta} \frac{\partial \delta}{\partial \mathrm{t}}=\frac{1}{\delta} \frac{1}{\sin (\omega \mathrm{z})} \frac{\partial \mathrm{R}}{\partial \mathrm{t}}
$$


Equations (15), (16), and (17) lead to

$$
\frac{1 d \delta}{\delta d t}=-\frac{C_{0} D_{g} \gamma \Omega^{2}}{k T}-\left(\omega^{2}-r_{0}^{2}\right) \omega \frac{I_{1}\left(\omega r_{0}\right)}{I_{0}\left(\omega r_{0}\right)}
$$

where $D_{\mathfrak{g}}$ is the diffusivity in the gas. Again the perturbation growth rate is positive for $\lambda$ $>2 \pi \mathrm{r}_{0}$ but in this case a maximum growth rate sccurs at $\lambda=9.02 \mathrm{r}_{0}$ as can be seen by differentiating (18) with respect to wro and setting the result to zero.

\section{Cylinder}

The vapor concentration difference at the surface differs from that in (14) only in sign. The other boundary condition that is exploited is that the concentration remains finite at infinity. The solution of (1.3) then becomes

$$
C=C_{0}+\frac{\delta y}{k T}\left[r_{0}^{-1}+\left(\omega^{2}-r_{0}^{2}\right) \delta \sin (\omega z) \frac{K_{0}(\omega r)}{K_{0}\left(\omega r_{0}\right)}\right] C_{0}
$$

The rate of change of radius of the solid vapor interface is obtained as before, yielding

$$
\frac{1 d \delta}{\delta^{d t}}=-\frac{C_{0} D_{g} \gamma \Omega^{2}}{K T}\left(\omega^{2}-r_{0}^{2}\right) \omega \frac{K_{1}\left(\omega r_{0}\right)}{K_{d}\left(\omega r_{0}\right)}
$$

This growth rate is again positive for $\lambda>2 \pi \mathrm{r}_{0}$ and exhibits a maximum at $\lambda=1296 \mathrm{r}$.

B. Rate linited by the sublimation and condensation at the surface

From the Langmuir ${ }^{17}$ and Gibbs-Thomson equations the radius change can be described by 


$$
\frac{\partial R}{\partial t}=Q K
$$

where the curvature $K$ is taken positive for a concave surface (cylindrical void), negative for convex surface (cylinder), and

$$
Q=\frac{\alpha p_{0} \gamma \Omega^{2}}{\sqrt{2 \pi m(k T)^{3}}}
$$

with $p_{0}$ the equilibrium pressure over a flat surface, $\alpha$ the condensation coefficient, and $m$ the mass of the atom/molecule vaporized.

Substituting for the curvature from (6) yields

$$
\frac{1}{\delta} \frac{d \delta}{d t}=-\alpha\left(\omega^{2}-r_{0}^{2}\right)
$$

with an identical result obtained for the cylinder. The growth rate is seen to be positive for $\lambda>2 \pi r_{0}$ increasing monotonically with increasing wavelength.

\subsubsection{Discussions}

The significant results obtained above are summarized in Table 2.1, along with the results of Nichols and Mullins. 6 There is a common feature for all four transport mechanisms in both cylinder and cylindrical void cases: whenever the perturbation wavelength is larger than $2 \pi r 0$, disintegration occurs. This characteristic wavelength length ( $2 \pi r 0)$ can be obtained through a basic thermodynamic argurnent:

The disintegration occurs, when the transport of mass from position 1 to position 2 as shown in Figure 2.2, is thermodynamically favorable, ie., the change of chemical potential $\left(\mu_{2}-\psi_{1}=\Delta \mu_{1}\right)$ is negative. 


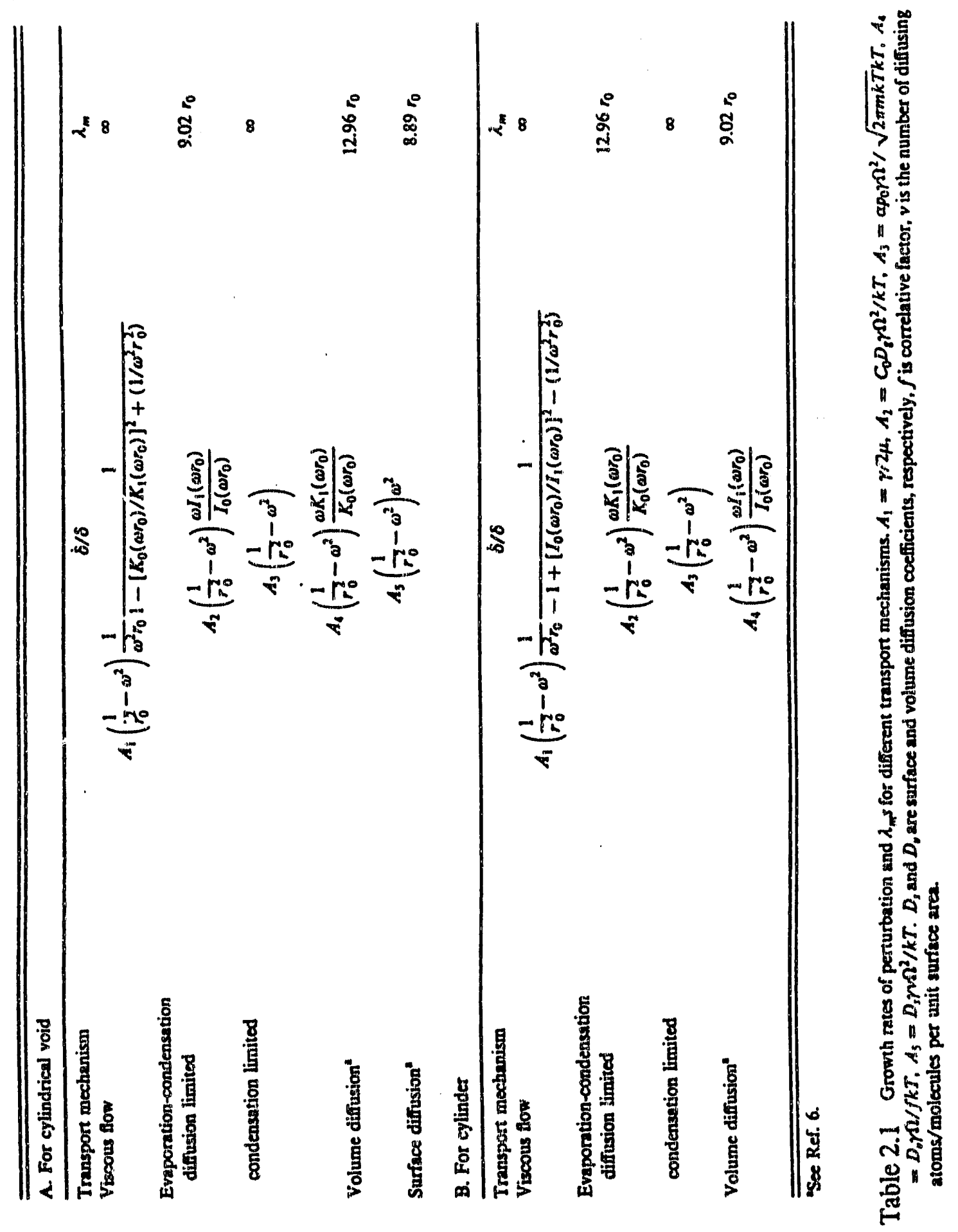




$$
\begin{aligned}
\Delta \mu & =\mu_{2}-\mu_{1}=\mu(z=3 \lambda / 4)-\mu(z=\lambda / 4) \\
& =\left(\mu_{0}+\gamma \Omega K(z=3 \lambda / 4)\right)-\left(\mu_{0}+\gamma \Omega K(z=\lambda / 4)\right)
\end{aligned}
$$

where $\Perp_{0}$ is the chemical potential of a flat surface. By using Eqs.(6), the above equation becomes

$$
\Delta \underline{\mu}=2 \delta \gamma \Omega\left[(2 \pi / \lambda)^{2}-\left(1 / \mathrm{r}_{0}\right)^{2}\right]
$$

Instability needs $\Delta \mu<0$, which gives $\lambda>2 \pi \mathrm{r}_{0}$.

The failure to appear, of a finite wavelength of maximum perturbation growth rate, in two viscous flow cases, can be rationalized as following argument. The viscous flow results were obtained from the creeping flow equations (Navier-Stokes equations with inertial terms neglected). The neglect of these terms is only valid for small Reynolds number. An appropriate choice of the characteristic length in forming the Reynolds number is the wavelength. The only other length scale available is the cylinder radius and that choice would imply that the character of flow is waveiength independent, an unlikely happening. Consequently the creeping flow approximation is isvalid at large wavelength and extrapolation of Eqs. (11) and (12) to infinite wavelength is unwarranted. This poses the question of the applicability of the results to the practical application mentioned in the Introduction. Here the largest possible wavelength is the OPS film thickness (of the order of micrometers). Employing representative numbers for the viscosity and for the velocity estimated from observed pore diameter and closing times yields a maximum Reynolds number of $2 \times 10^{-25}$. This value is much less than that of the requirement for $a$ creeping flow $(\operatorname{Re}<0.1)^{16}$. It is suggested that the results obtained here by the creeping approximation are valid for the densification of OPS case. The implication of this first order analysis is that a cylindrical pore disintegrating by viscous flow should yield spherical pores with large size compared to the initial pore radius because the longer the perturbation wavelength is the more unstable the cylindrical pore is. 
The monotonic increase of perturbation growth rate with wavelength in the evaporation-condensation case (when these two phenomena are rate controlling) is also artificial. While these phenomena (rather than diffusion in the vapor phase) can be rate controlling at short wavelength they cannot remain so as wavelength is increased. Eventually a wavelength must be reached where transport from a region of evaporation to a distant region of condensation starts to influence the perturbation growth rate.

The results of Nichols and Mullins for the cylindrical pore case are also very important for the processing of PS. The heat treatment effect of PS is the result of the instability of cylindrical pores. It causes the breakup of cylindrical pores into rows of isolated spherical pores. This kind of microstructure not only hinders oxidant species (oxygen or steam) from reaching the bottom of a PS layer but also has a thicker silicon wall to be oxidized. Therefore, the oxidation of PS is no longer a easy task. Since the PS is a crystalline material as shown in Figure 1.1, the surface diffusion, evaporation. condensation, and volume diffusion are the possible operative mass transport mechanisms for the disintegration process. A low-temperature $\left(300^{\circ} \mathrm{C}\right)$ dry oxidation process ${ }^{19}$ can stabilize the pore structure and avoid the heat treatment effect. Herino's explanation ${ }^{19}$ is that a thin layer of $\mathrm{SiO}_{2}$ is formed on the pore wall to hinder the surface diffusion, therefore, the pore structure is stabilized. A more comprehensive explanation is proposed here: Because the specific surface energy is decreased by the formation of a thin layer of oxide on the pore wall ( $\mathrm{Si}_{-} \mathrm{SiO}_{2}$ interface has less unsaturated bonds than the Si-atmosphere interface does), the driving force for the disintegration process is reduced. Also, the silicon surface diffusion coefficient along the $\mathrm{Si}-\mathrm{SiO}_{2}$ interface is expected to be smaller than that along the $\mathrm{Si}$-atmosphere interface. After thin oxide forming, any change of pore structure resulting from the surface diffusion or volume diffusion of silicon must be accompanied by the viscous flow of the thin layer of silicon oxide, which is very unlikely at a temperature lower than $960^{\circ} \mathrm{C}$. This is helpful to stabilize the pore structure 
too. The silicon evaporation-condensation mechanism does not exist any more since only oxide exposed to the atmosphere. Therefore, no matter what kind of transport mechanism is responsible for the heat treatment effect of PS, the formation of a thin layer of oxide on the pore wall can suppress this adverse effect.

\subsection{Experiments}

A photolithography method used in the IC industry and a glass bonding method were employed to produce artificial pores inside glass slides. Besides elongated cylindrical pore, artificial zig-zag pores were also formed to simulate the pore shape of a real OPS as shown in Figure 1.11. The glass slides used to form artificial pores are microscope glass slides, whose compasition and fhysical properties are listed in Table 2.2. Figure $\mathbf{2 . 4}$ shows the flow chart of the formation of artificial pores. The detail experimental procedures are:

(1) Cleaning step:

Ultrasonic cleaning in

$\mathrm{SC} 1$ solution $\left(\mathrm{H}_{2} \mathrm{O}: \mathrm{H}_{2} \mathrm{O}_{2}: \mathrm{NH}_{4} \mathrm{OH}=5: 1: 1\right), 10$ minutes;

Deionized (DI) water, 3 minutes;

$\mathrm{SC} 2$ solution $\left(\mathrm{H}_{2} \mathrm{O}: \mathrm{H}_{2} \mathrm{O}_{2}: \mathrm{HCl}=6: 1: 1\right), 10$ minutes;

DI water, 3 minutes.

(2) Photolithgraphy step:

Drying in air at $300^{\circ} \mathrm{C}, 1$ hour;

Exposure to the HMDS vapor 2 minutes;

Spin-on positive photoresist (PR) with $5000 \AA$ thickness;

Soft-bake in the air at $95^{\circ} \mathrm{C} 25$ minutes;

Exposure by using Canon $4 \mathrm{X}$ stepper with a mask shown in Figure 2.5;

Development in the PR developer 1.5 minutes; 
Table 2.2 Compositions of glass and its physical properties

component

$\mathrm{SiO}_{2}$

$\mathrm{Na}_{2} \mathrm{O}$

$\mathrm{CaO}$

$\mathrm{MgO}$

$\mathrm{Al}_{2} \mathrm{O}_{3}$

$\mathrm{K}_{2} \mathrm{O}$

$\mathrm{Fe}_{2} \mathrm{O}_{3}$

$\mathrm{TiO}_{2}$

$\mathrm{SO}_{3}$

$\mathrm{As}_{2} \mathrm{O}_{3}$ wt $\%$

72.1 density: $2.48 \mathrm{~g} / \mathrm{cm}^{3}$

14.15

6.4

4.1

1.1

1.25

0.02

0.02

0.42

0.13 softening point: $715^{\circ} \mathrm{C}$ annealing point: $533^{\circ} \mathrm{C}$ strain point: $492^{\circ} \mathrm{C}$ 


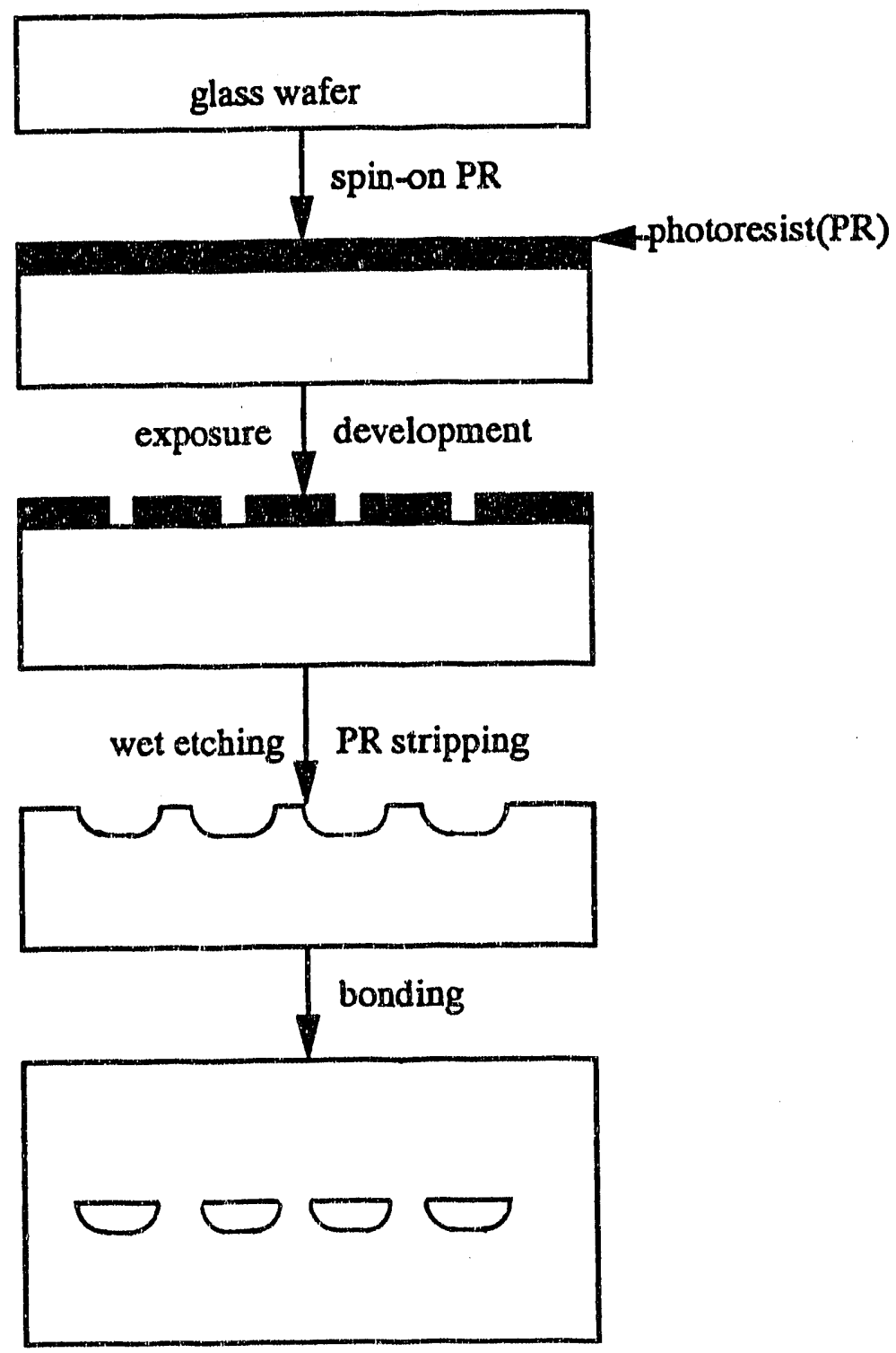

Figure 2.4 Fabrication process of the artificial pore. 

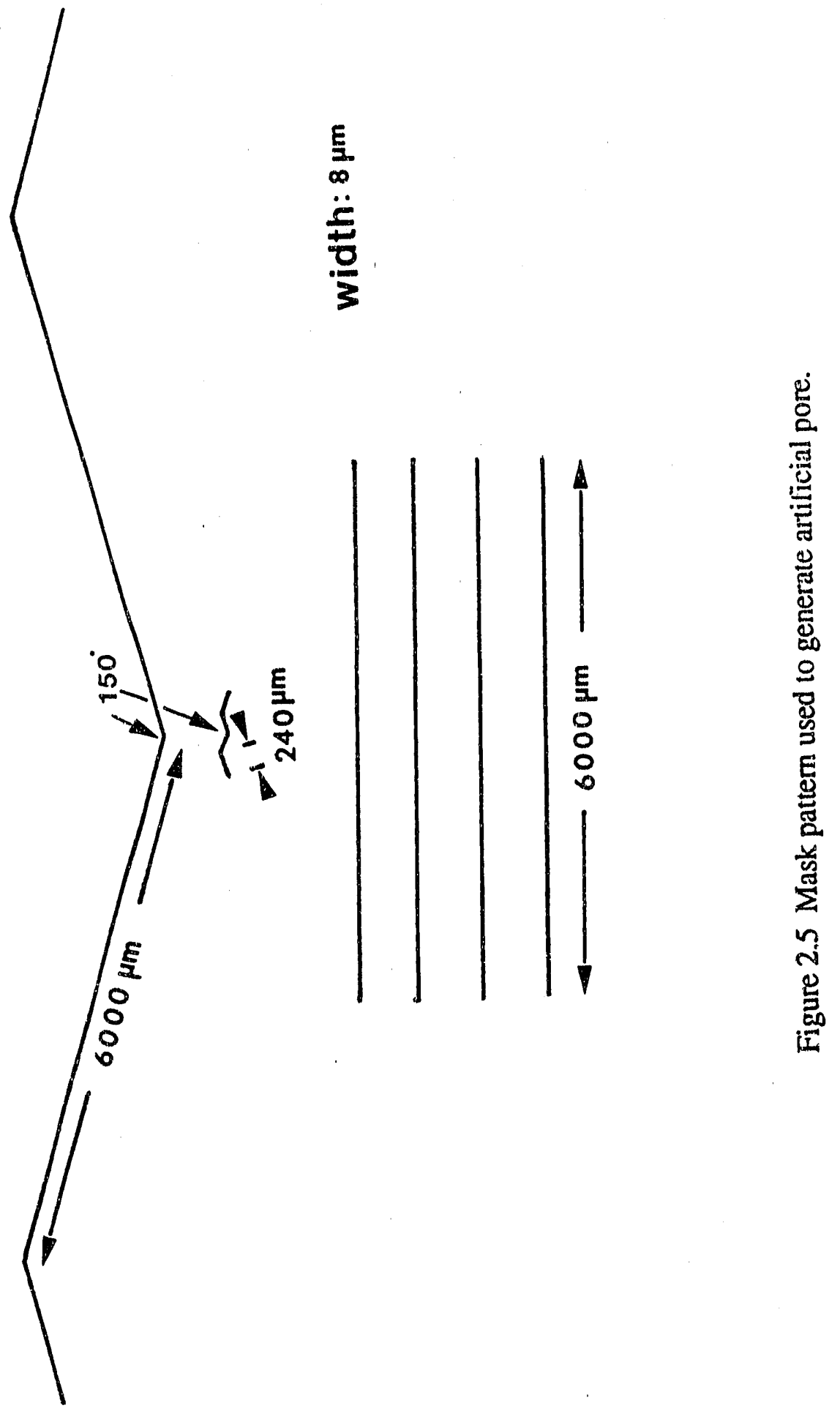
Hard-bake in the air at $120^{\circ} \mathrm{C}, 25$ minutes;

Etching in a 10:1 buffered hydrofluoric acid solution 4 minutes;

Stripping the residual PR in a PR stripper solution.

(3) Repeat the cleaning step

(4) Glass bonding step:

The etched glass slide and an unetched one are

Baked in the air at $275^{\circ} \mathrm{C}, 1.5$ hours;

bonded together in argon atmosphere at $650^{\circ} \mathrm{C}, 2$ hours.

(5) Characterization step:

An optical microscope is used to characterize the change of the pore shape during heat treatment (argon atmosphere, $650^{\circ} \mathrm{C}$ ).

\subsection{Results and Discussions}

Because the wet etching is isotropic, there is an undercut effect as shown in Figure 2.6(a). The equivalent radius ( $\mathrm{r}_{0}$ ) is about $4 \mu \mathrm{m}$. The as-formed pores (i.e., after bonding) are shown in Figure 2.6(b). There are two kinds of pores: straight and zig-zag (the angle is 150). Two kinds of zig-zag pores: one with long segments (1500 $\mu \mathrm{m}$ long) and the other one with short segments (60 $\mu \mathrm{m}$ long) as shown in Figure 2.6(b). As expected, the pores disintegrate during heat treatment. The observed phenomena are summarized:

(1) The pores disintegrated at a quite broad distribution of wavelengths $\left(7-70 \mathrm{r}_{0}\right)$ as shown in Figure 2.7. Roughly, most of the pores broke up at a wavelength $\left(\lambda_{m}\right)$ of about $10-15 \mathrm{r} 0$. This result is consistent with the Ackler 's result 20 , where $\lambda_{m}$ is about 13 ro.

(2) No preferential breakup occurred at the bending point as shown in Figure 2.8. Maybe it does when the angle is steeper. 

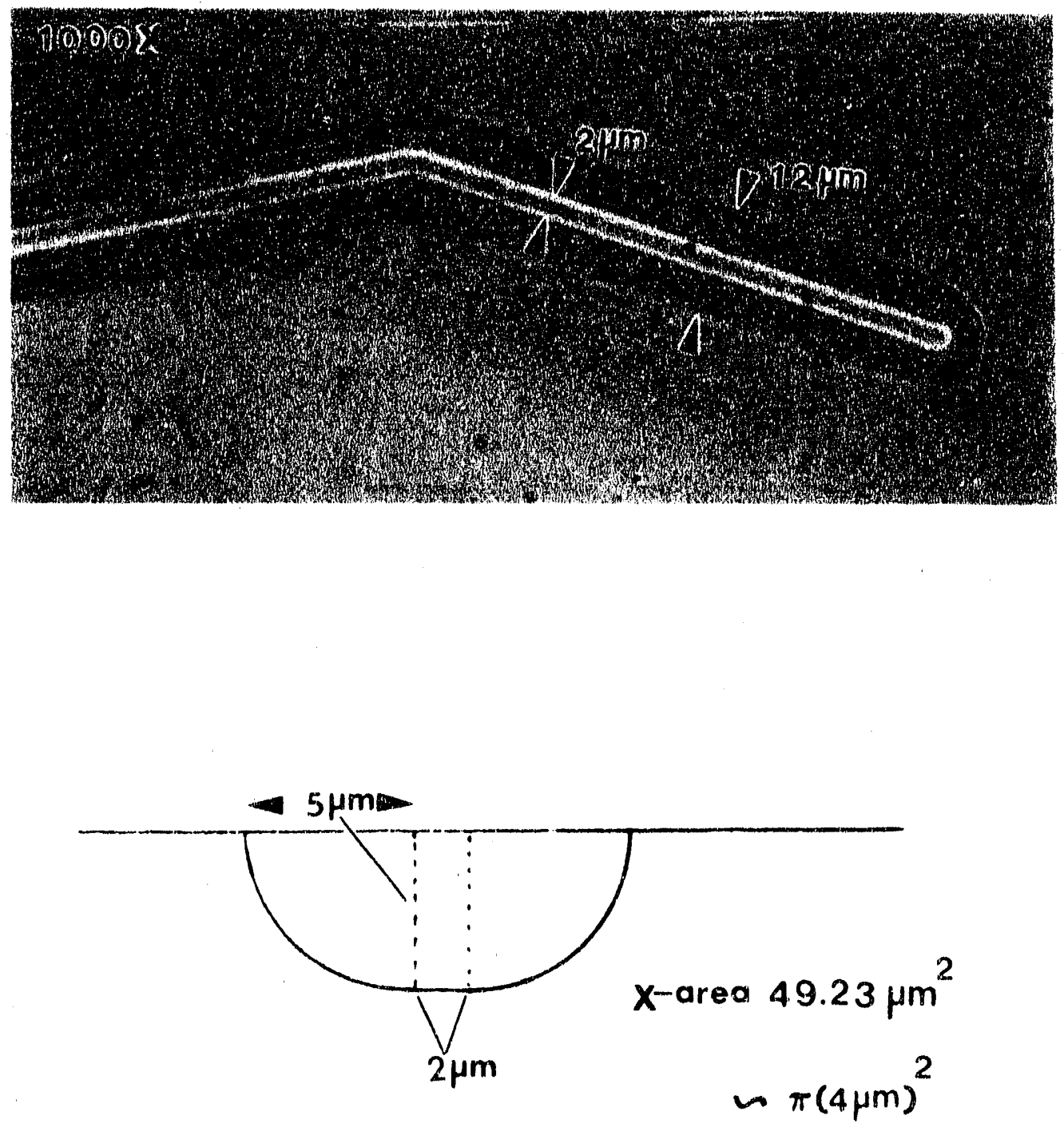

Fig. 2.6(a)

XBB $\quad 924 \cdots 2360$ 


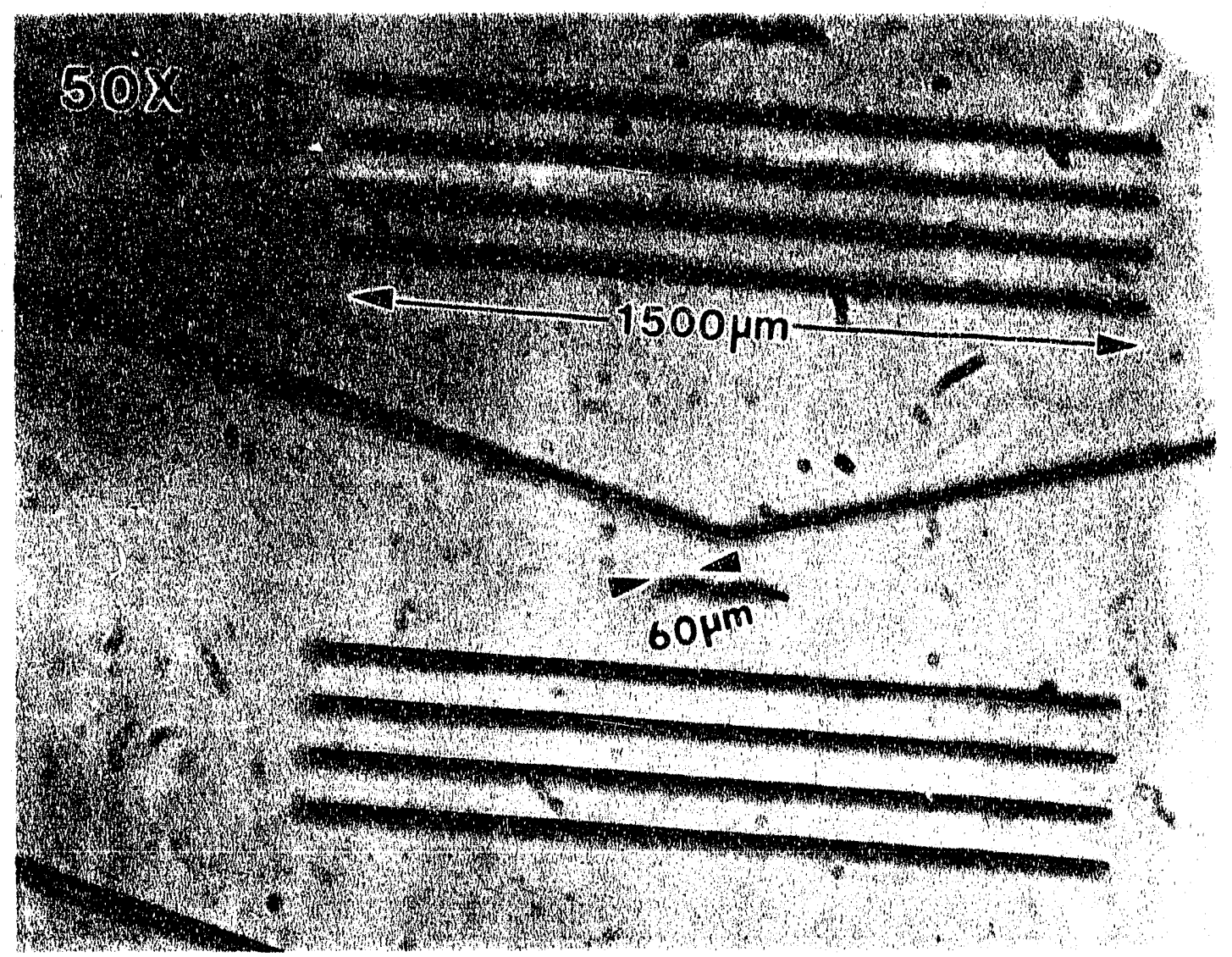

Fig. 2.6(b)

XBB 924-2359 

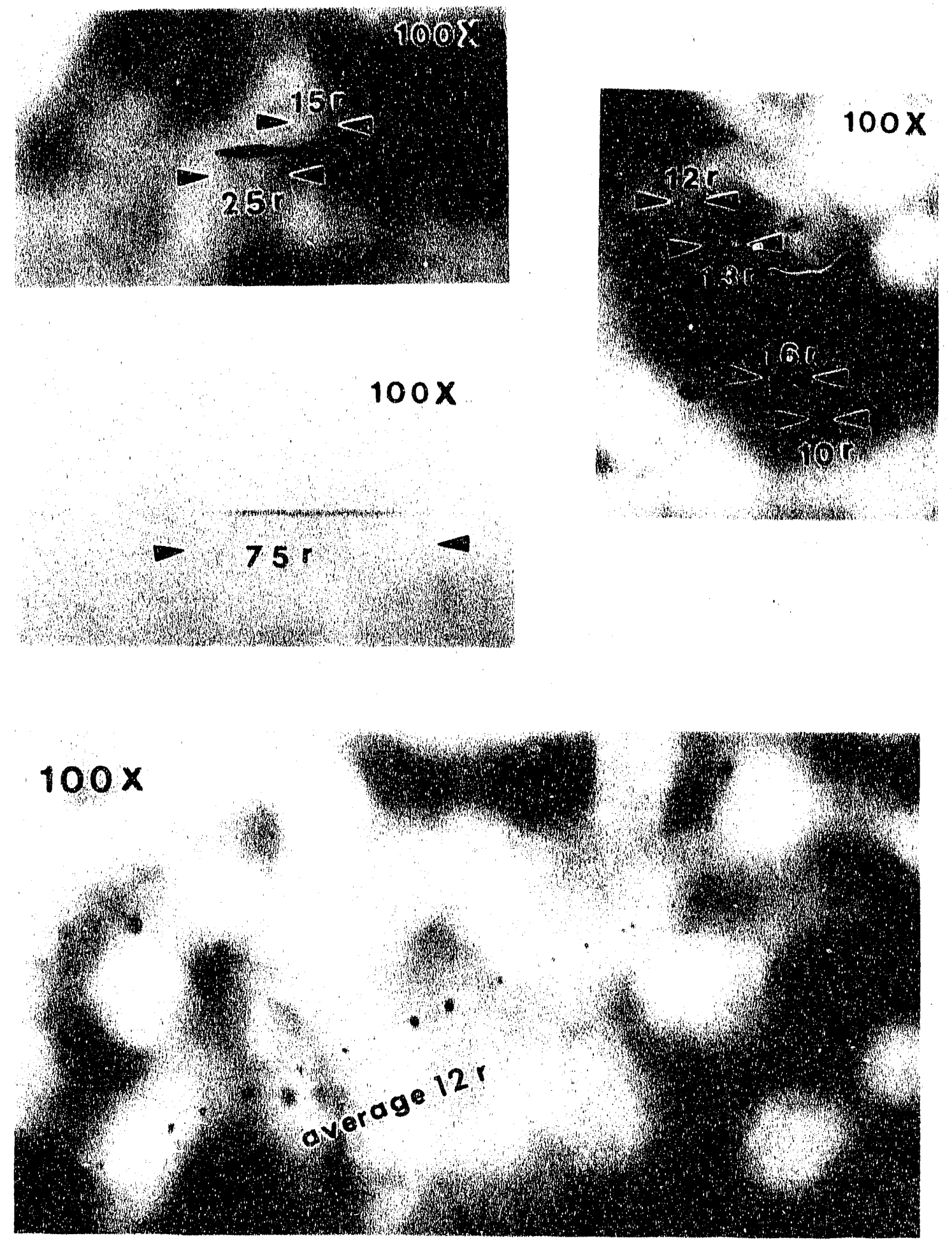

Fig. 2.7 

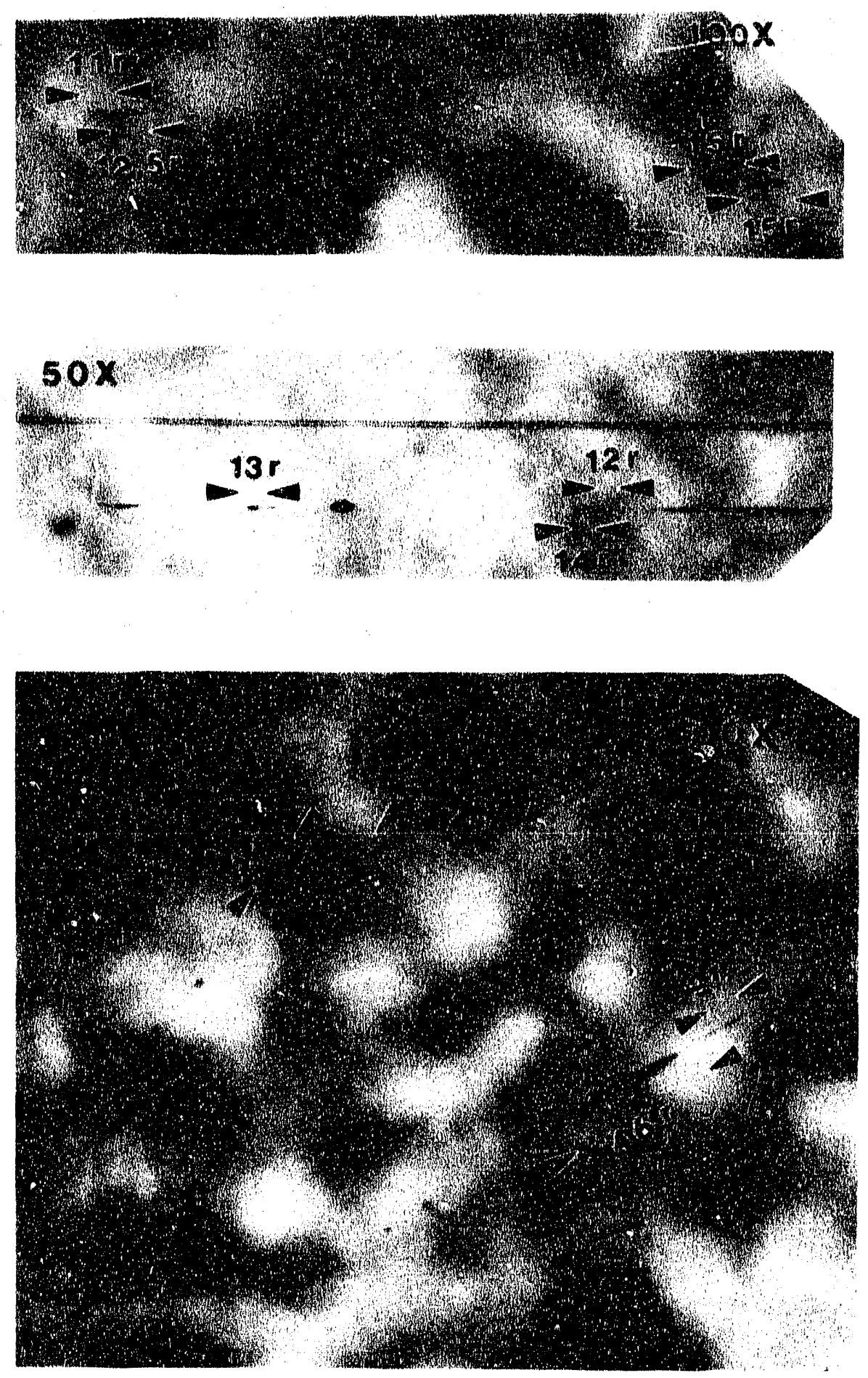

Fig. 2.7 cont. 

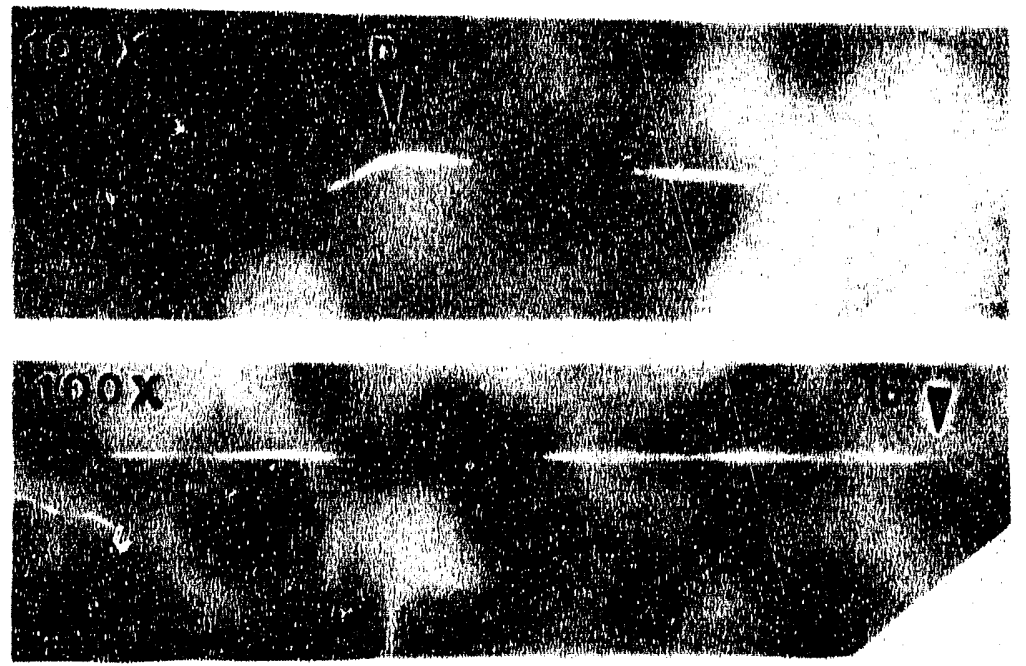

long segment
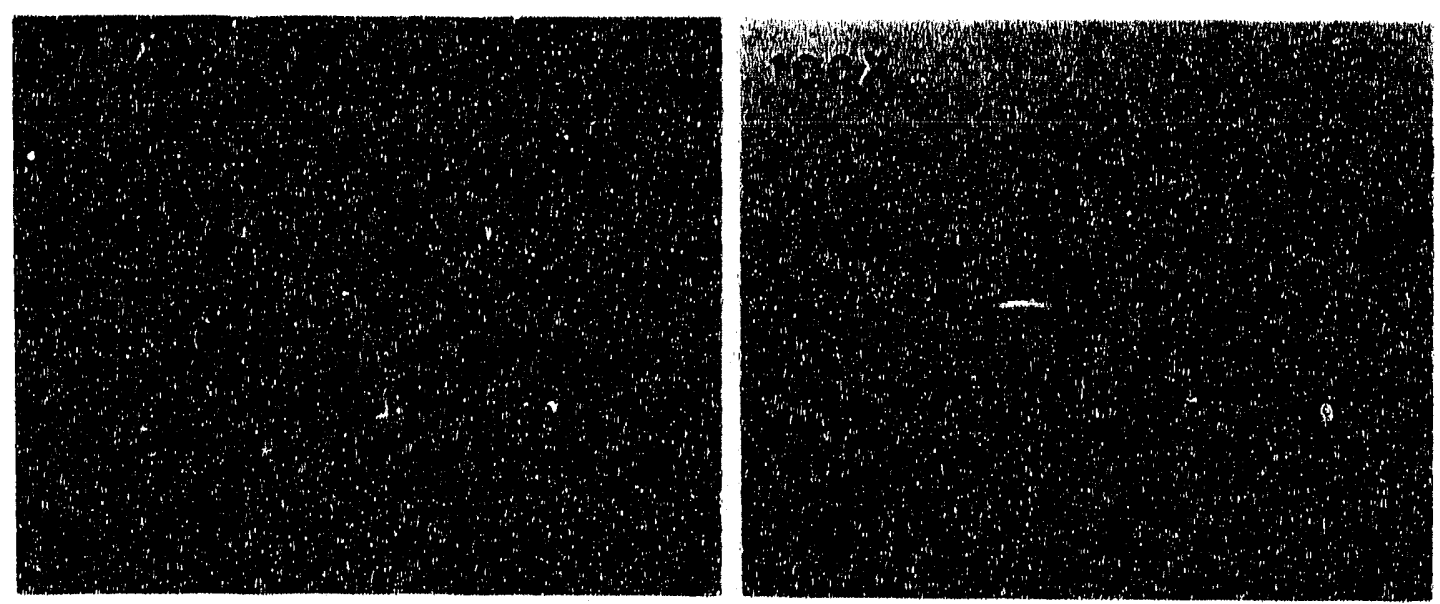

short segment

Fio. 2.8

XBB $924-2363$ 
(3) There was an ovulation phenomenon (pore enlargement and then breakup) at the tip of the cylindrical pore as shown in Figure 2.9. The breakup wavelengths for this ovulation were from 10ro to $25 \mathrm{r}_{0}$. This end effect has also been observed in the morphological change of a field-emitter cathode. ${ }^{2}$ And the breakup wavelength is $14.4 r_{0}$, when the surface diffusion is the operative transport mechanism. 3

The possible reasons why there appears a preferential breakup waveiength $\left(\lambda_{m}\right)$ are: the theoretical consideration is only a first order approximation, which assumes that the perturbations are infinitesimal. The large (compared to the radius) perturbations necessary for pore breakup may behave differently from small ones. Furthermore, the pores in the experimental investigation are not infinitely long and exhibit an end effect.

Because the zig-zag cylindrical pores do not have preference for breaking up at the bending point, the theoretical $\lambda_{\mathrm{m}}$ is infinite, and two adjacent pores have the chance to merge together after breakup to form a bigger pore, the pores of OPS after breakup are expected to be very large, compared ic "'e initial pore diameter.

\subsection{Summary}

The stability of cylindrical voids under the influence of surface energy is very important for the PS processing, e.g., oxidation of PS and densification of OPS. It is mainly attributed to the disintegration of cylindrical voids of PS and OPS, which drastically changes the pore structure of PS and OPS. For viscous flow and evaporation/condensation as the transport mechanisms for the disintegration processes, a first order analysis of the stability of cylindrical voids (and cylinders) is given. In the case of viscous flow, the longer the perturbation wavelength is, the more unstable the cylindrical void is. The implication of this result is that a cylindrical pore disintegrating by viscous flow should yield spherical pores with very large size compared to the initial pore radius. This theoretical predication has been examined experimentally by beat 

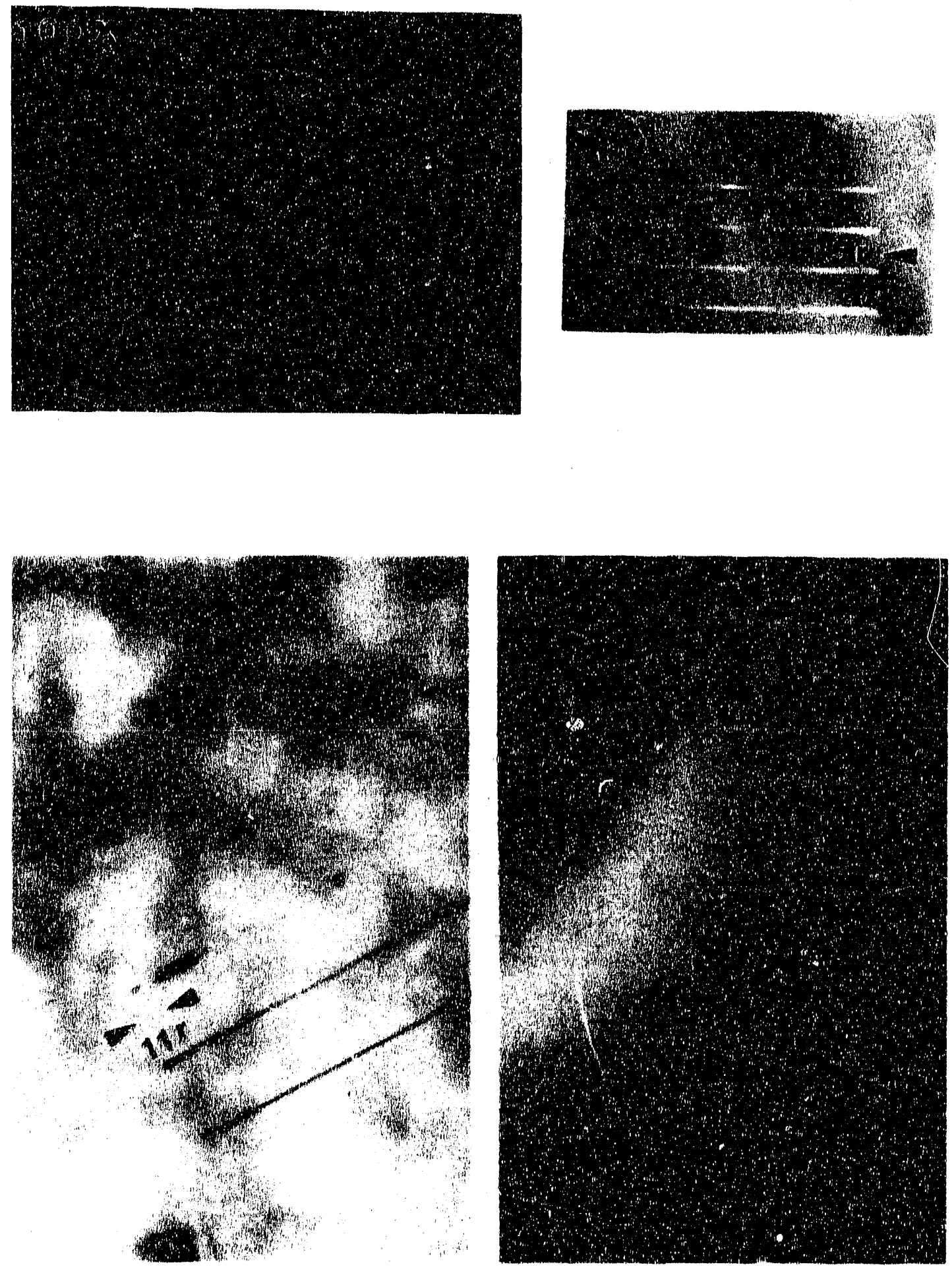

Fig. 2.9

XBB 924-2364 
treatment of artificial pores inside glass wafers. The experimental results showed that the pores disintegrated at a quite broad distribution of wavelengths $\left(7-70 \mathrm{ro}_{0}\right.$, here, $\mathrm{r}_{0}$ is the initial pore radius) but most of the pores broke up at a wavelength of about $10-15$ ro. The possible reasons why there appears a preferential breakup wavelength range (10 - 15 I0) are: the theoretical consideration is only a first order approximation and the artificial pores are not infinitely long. 
References

1. Lord Rayleigh, Proc. Jondon Math. Soc., 10, 4 (1878).

2. F. A Nichols and W.W. Mullins, J. Appl. Phys., 36, 1826 (1965).

3. F. A. Nichols, J. Mater. Sc., 11, 1077 (1976).

4. T. K. Gupta, J. Am. Ceram. Soc., 61, 191 (1978).

5. H. P. Stuwe and O. Kolednik, Acta Metall., 36, 1705 (1988).

6. F. A. Nichols and W.W. Mullins, Trans. AIME, 233, 1840 (1965).

7. Lord Rayleigh, Philos. Mag., 34, 145 (1892).

8. M. I. J. Beale, N.G. Chew, M.J. Uren, A.G. Cullis, and J.D. Benjamin, Appl. Phys. L.ett., 46, 86 (1985).

9. J. Rodel and A.M. Glaeser, Mat. Res. Soc. Symp. Proc., 155, 293 (1989).

10. R. Stengl, T. Tan, and U. Gosele, Jpn. J. Appl. Phys., 28, 1735 (1989).

11. W. P. Maszara, G. Goetz, A Caviglia, and J.B. McKitterick, J. Appl. Phys., 64, 4943 (1988).

12. M. Esashi, A. Nakano, S. Shoji, and H. Hebiguchi, Sensors and Actuators, A2123, 931 (1990).

13. J-P. Colinge, Silicon-on-Insulator Technology: Materials to VLSI, Klumer Academ. Publishers, Boston 1991.

14. W. D. Kingery, H. K. Bowen, and D. R. Uhlmann, Introduction to Ceramics, JohnWiley \& Sons, Inc. New York, 1976.

15. S-Y Shieh and J.W. Evans, J. Appl. Phys., 70, 2968 (1991).

16. R. B. Bird, W. E. Steward, and E. N. Lightfoot, Transport Pheromena, JohnWiley \& Sons, Inc. New York, 1971.

17. O. F. Devereux, Topics in Metallurgical Thermodynamics, 1983

18. I S. Sokolnikoff, Applied Mathematics Series: Tensor Analysis Theory and Applications to Geometry and Mechanics of Continua, 
19. R. Herino, A Perio, K. Barla, and G. Bomchil, Matl. Lett., 2, 519 (1984).

20. H. Ackler private communication. 
Chapter 3 Oxidation of Porous Silicon

\subsection{Introduction}

Since the main interest in porous silicon (PS) is due to its potential to form a thick dielectric insulating layer for integrated circuit (IC) devices, the oxidation reaction is most important for PS. Unagami ${ }^{1}$ conciuded that the oxidation of PS is controlled by the surface reaction at both the external surface of PS and the pore walls in PS. The weight change of PS after two-hour oxidation (W) was measured to examine the amount of oxidation. $W$ is related to the oxidation temperature $(T)$ by the equation, $\mathrm{W}=\mathrm{Ae}^{-\mathrm{E}} \mathrm{a} / \mathrm{T} T$. Here, $\mathrm{A}$ is the coefficient related to the anodization condition and the oxidation conditions, $k$ is the Bolkzman constant, and $E_{a}$ is the activation energy of the oxidation of porous silicon. $\mathrm{E}_{\mathrm{a}}$ is about $0.13 \mathrm{eV}$ for the oxidation in dry oxygen. This value is much smaller than that of direct oxidation of bulk silicon ${ }^{2}(2 \mathrm{eV})$ and can be rationalized by the reactive nature of PS. The oxidation of PS can be completed at a rather low temperature ${ }^{1}\left(\right.$ e.g., $\left.200^{\circ} \mathrm{C}\right)$ from a chemical point of view. Even at room temperature, porous silicon can be fully oxidized after exposed to the air for a few days 3 . The oxidized porous silicon (OPS) has the same properties (e.g., dielectric constant, breakdown strength, etching rate in a buffered HF solution) as the thermally grown silicon dioxide of bulk silicon, if the oxidation is performed at a high temperature $\left(>960^{\circ} \mathrm{C}\right)^{1,4-8}$. When the oxidation temperature is lower than $960^{\circ} \mathrm{C}$, the OPS is still porous as shown in Figure 1.11. And due to those residual pores, the properties of OPS are poor, e.g., the etching rate in a buffered HF solution is much higher than that of thermally grown silicon dioxide of bulk silicon. So a densification step at a higher temperature $\left(>960^{\circ} \mathrm{C}\right)$ is needed to start a viscous flow of silica with a reasonable rate to remove the residual pores. 7 When the temperature is above $960^{\circ} \mathrm{C}$, the viscosity of the 
thermally grown silicon dioxide (silica) is low enough to trigger off a "sensible" viscous flow, 9,10 e.g., the activation energy of silicon oxidation changes when the oxidation temperature across $960^{\circ} \mathrm{C}, 11,12$ where the viscous flow rate of the silicon dioxide is comparable with the oxidation rate. Unagami ${ }^{1}$ also found that the $E_{a}$ of PS oxidation changed remarkably when the vemperature was roughly about $900^{\circ} \mathrm{C}$. The densification of OPS is discussed in Chapter 4. Therefore, in view of forming a "good" oxide, the oxidation process of PS should entail two mechanisms: (1) chemical oxidation of the PS and (2) densification of OPS at a temperature higher than $960^{\circ} \mathrm{C}$. These two mechanisms can take place at the same time when the oxidation temperature is higher than $960^{\circ} \mathrm{C}$ or independently when the oxidation process is performed in two steps, first a low temperature oxidation followed by a high temperature densification.

The pores of PS coarsen under heat treatment 13,14 (temperature $>400^{\circ} \mathrm{C}$ ), resulting in the drastic reduction of the specific surface area and the reactivity of PS ${ }^{1}$, which makes the oxidation rate decrease. Also, the open cylindrical pores may be unstable and disintegrate into isolated pores, then the oxidation task becomes harder because of the difficulty of transporting oxidant species. This adverse effect can be avoided by growing a thin silicon dioxide layer on the pore walls (e.g., oxidized at $300^{\circ} \mathrm{C}$, dry oxygen, 1 hour) to stabilize the pore structure, 6,13 before any high temperature process (e.g., oxidation 6 , epi-growth). The explanation of this stabilization effect has been discussed in Chapter 2. Therefore, in view of a chemical reaction, the PS oxidation process should consist of two steps 6 : (1) preoxidation at $300^{\circ} \mathrm{C}$, dry oxygen, 1 hour to stabilize the pore structure, and (2) oxidation at a higher temperature to fully oxidize PS. To avoid this tedious oxidation process, rapid thermal oxidation, proposed in present study, provides an alternative to the PS oxidation. 


\subsection{Rapid Thermal Oxidation of Porous Silicon}

Rapid thermal processing. (RTP), using incoherent radiation (e.g., tungsten-halogen lamp) as the heating source, has drawn attention in the IC processing industry recently 15 45 It is often used to enhance a desirable process and at the same time suppress an undesirable process, having a different activation energy. 32 For example, rapid thermal annealing is employed for the dopant activation but leaves the dopant profile unchanged because of its very short processing tirue (seconds to minutes). By contrast, prolonged conventional furnace processing (CFP) not only activates the dopants but also alters the dopant profile. There are two key differences between RTP and CFP:

(1) The heating and cooling rates are much higher in the RTP (e.g., as high as $500^{\circ} \mathrm{C} / \mathrm{sec}$ and $50^{\circ} \mathrm{C} / \mathrm{sec}$ for heating rate and cooling rate, respectively).

(2) There is a photoeffect in RTP.15 Although radiation is the operative heat transfer mechanism in both RTP and CFP, the radiation spectra are different. The filament (radiation source) temperature is much higher than the substrate temperature in RTP. In the case of CFP, the furnace wall (radiation source) temperature is approximately the same as the substrate temperature. Therefore, for a given substrate temperature, there are many more photons with shorter wavelength (vacuum ultraviolet to visible regions) in RTP. These photons can provide certain photochemical and photophysical effects in the RTP, e.g., they can excite electrons from the ground state to an excited state. On the other hand, the photons in the CFP are mostly from the infrared region and have less ability to induce such photoeffects.

These two novel properties mean that RTP has several potential applications in the IC processing: formation of dielectric materials ${ }^{15-31}$, activation of dopants (see review articles : reference 32 and 33), gettering $34-37$, formation of silicides (see review article: reference 32), and glass reflow37-45. The rapid thermal oxidation (RTO) of silicon has been proposed to form a thin gate oxide for a MOSFET 22,31 and a thin oxide layer for a 
trench capacitor. 47 The growth kinetics of thin dry oxide by CFP is still unclear, let alone that in RTO, which is more complicated. Compared with CFP, RTO provides a faster oxidation rate $15,17,20-22,24$ and better oxide 16,19 . The faster oxidation rate in the RTO is attributed to the photoeffect, which induces certain physical and chemical processes, e.g., the gas phase oxygen dissociation $\mathrm{O}_{2} \rightarrow 20.15,24$ Figure 3.1 shows the oxide thickness as a function of oxidation time for RTO at different oxidation temperatures (one curve for CFP at $900^{\circ} \mathrm{C}$ for comparison). The RTO technique is expected to fully oxidize porous silicon before the heat treatment effect becomes serious. Then, the tedious two-step conventional oxidation process can be avoided.

\subsection{Experiments and Results}

Two kinds of p-type, (100) oriented silicon wafers with different resistivities were used to study the RTO of PS: 0.02-0.005 ohm-cm ( $\mathrm{p}^{++}$sample) and 5-8 ohm-cm ( $p$ sample). The current densities were $50 \mathrm{~mA} / \mathrm{cm}^{2}$ and $10 \mathrm{~mA} / \mathrm{cm}^{2}$ in the $\mathrm{p}^{++}$and $\mathrm{p}$ silicon wafer cases, respectively. The electrolyte for the PS formation was a solution with $20 \%$ HF, $20 \% \mathrm{H}_{2} \mathrm{O}$, and $60 \% \mathrm{C}_{2} \mathrm{H}_{5} \mathrm{OH}$. The electrolytic cell used to produce PS was a double-cell fixture ${ }^{46}$ as shown in Figure 3.2. The electrical contact was made to the wafer backside through a chamber filled with saturated $\mathrm{KCl}$ solution. The diameter of the O-ring was one inch, therefore the PS patch was an about one-inch diameter disc. The anodization time was 3 minutes. Each sample was equally broken into two pieces: one for the two-step conventional oxidation, the other one for rapid thermal oxidation.

(I) PS Oxidation

- Conventional oxidation of porous silicon (COPS):

To avoid any heat treatment effect, a two-step oxidation was used. The PS was preoxidized in dry oxygen at $300^{\circ} \mathrm{C}$ for 1 hour to stabilize the microstructure of PS, then oxidized in wet oxygen (oxygen bubbled through $85^{\circ} \mathrm{C}$ DI water) at $800^{\circ} \mathrm{C}$ for 1 hour. 

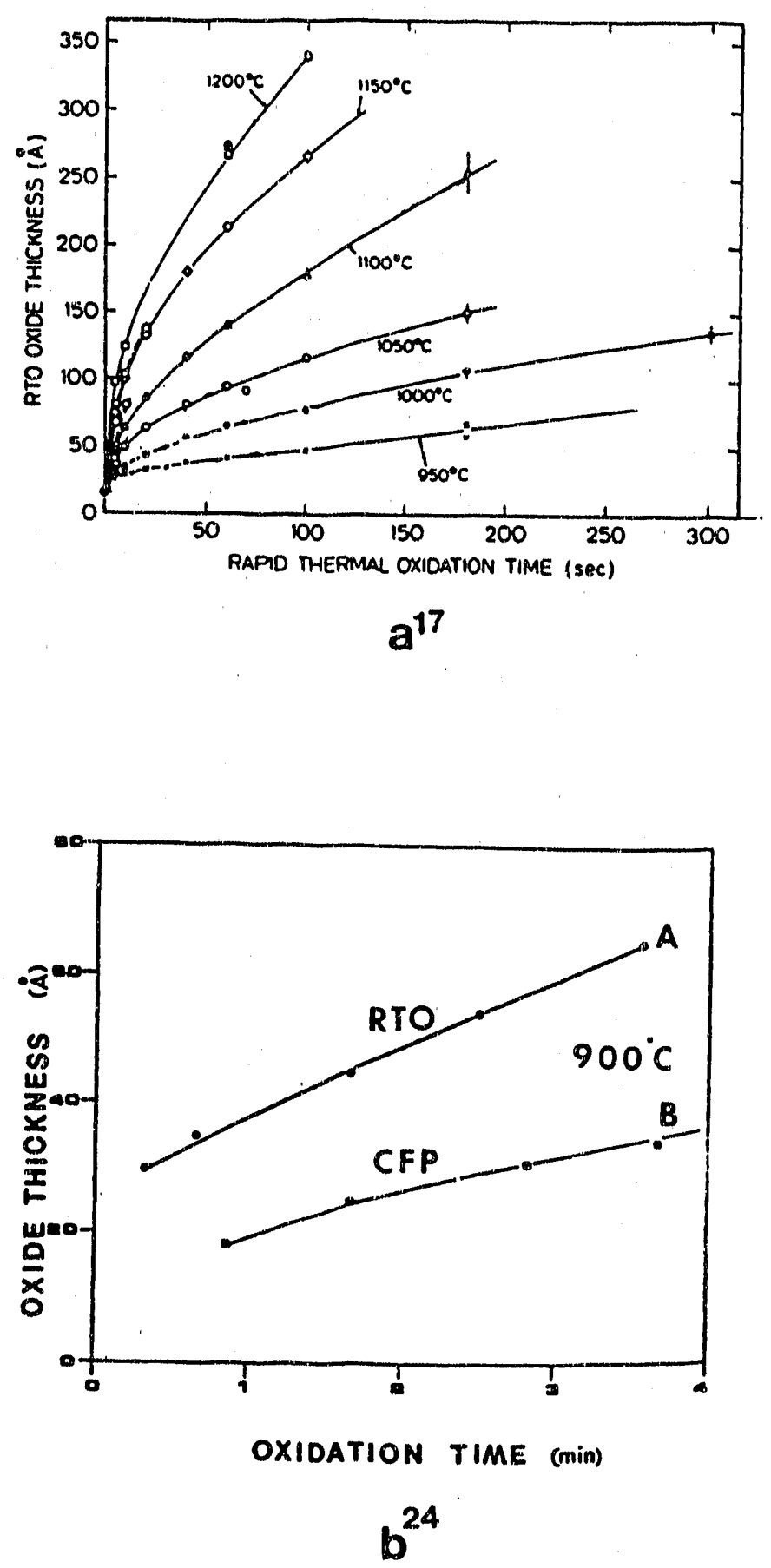

Figure 3.1 (a) RTO oxide thickness vs. oxidation time at different temperature ${ }^{17}$ and (b) oxide thickness vs. oxidation time at $900^{\circ} \mathrm{C}$ for RTO (curve A) and CFP (curveB). ${ }^{24}$ 


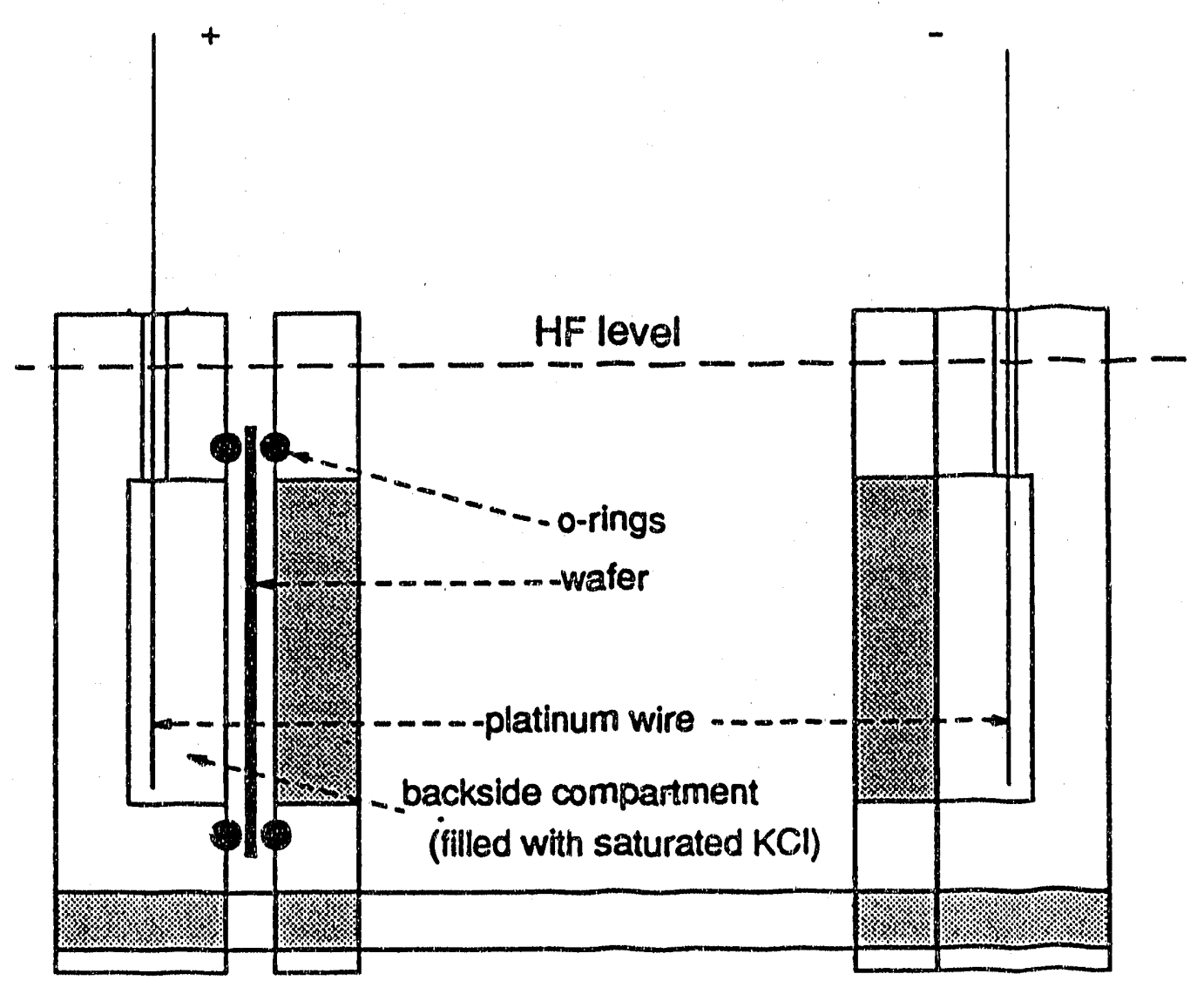

Figure 3.2 Electrolytic cell used for PS formation (Reprinted from Anderson46 1991). 
- Rapid thermal oxidation of porous silicon (RTOPS)

The RTO was performed in a A.G. Heatpulse200. The oxidation conditions were: 6 minutes at $1000^{\circ} \mathrm{C}$ and 9 minutes at $1050^{\circ} \mathrm{C}$ for $\mathrm{p}$ and $\mathrm{p}^{++}$samples, respectively.

\section{(II) OPS Characierization}

- Transmission electron microscopy (TEM) study

Plane-view TEM samples were prepared. After the thickness was reduced to about $20 \mu \mathrm{m}$ by mechanical grinding, ion milling was used to thin the sample until a hole appeared. The Philips EM 301 was used in this research. The TEM results are shown in Figure 3.3 and Figure 3.4 for $p$ and $\mathrm{p}^{++}$cases, respectively. The diffraction patterns of RTOPSs in Figure 3.3(b) and Figure 3.4(b) shaw amorphous rings only. No diffraction pattern from crystalline silicon can be detected. This suggests that the PS might have been fully oxidized by RTO of both $\mathrm{p}^{++}$and $\mathrm{p}$ samples. The bright field images in the Figure 3.3(b) and Figure 3.4(b) show that the RTOPSs are still porous.

-Energy Dispersive Spectroscopy (EDS) study - $\mathrm{p}^{++}$sample only

Energy Dispersive Spectroscopy (EDS)was employed to compare the RTOPS with COPS in the $\mathrm{p}^{++}$case. The two EDS spectra shown in Figure 3.5 (RTOPS) and Figure 3.6 (COPS) are almost the same except for different carbon concentrations, which might be from the carbon films, evaporated onto the sampies to avoid surface charge buildup during the EDS study. The two peaks are due to silicon and oxygen, respectively. The left shoulder of the oxygen peak is due to the presence of nitrogen. The reason why there is nitrogen incorporation into the sample is unknown. Nevertheless, the OPS formed by RTO is exactly the same as that formed by the tedious conventional two-step process. 


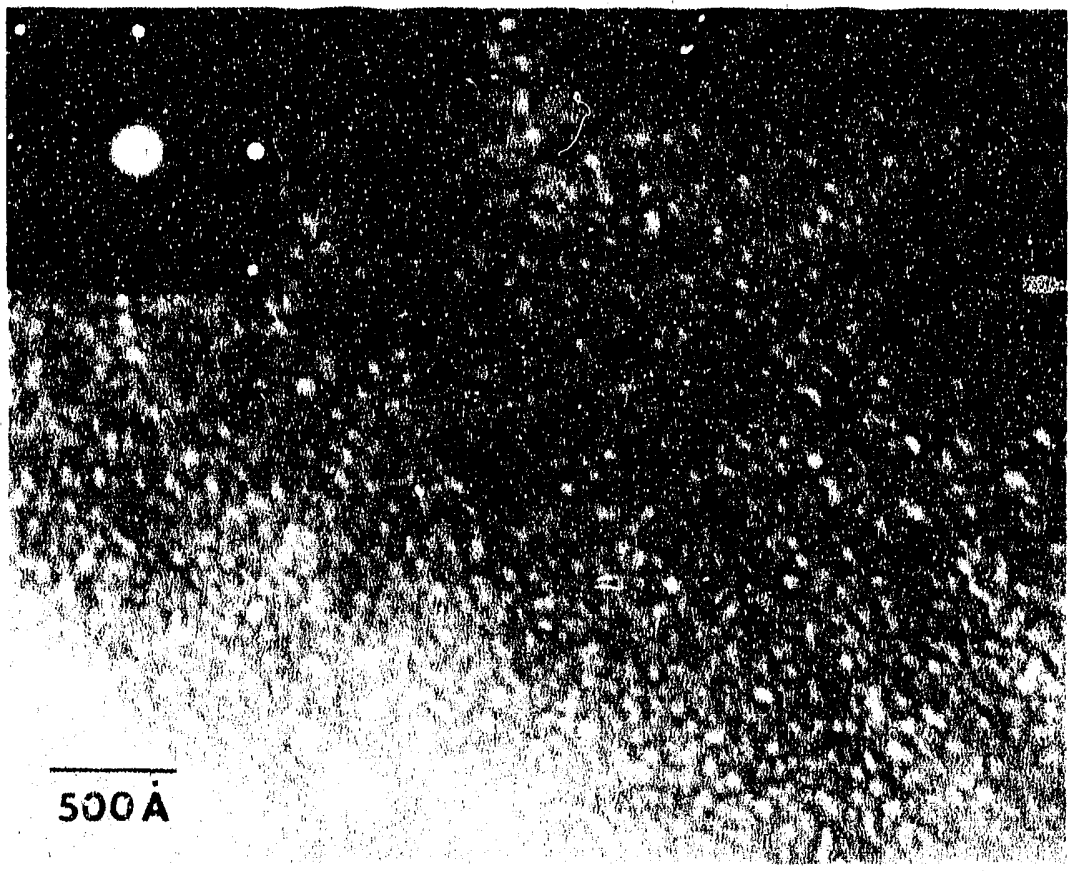

a

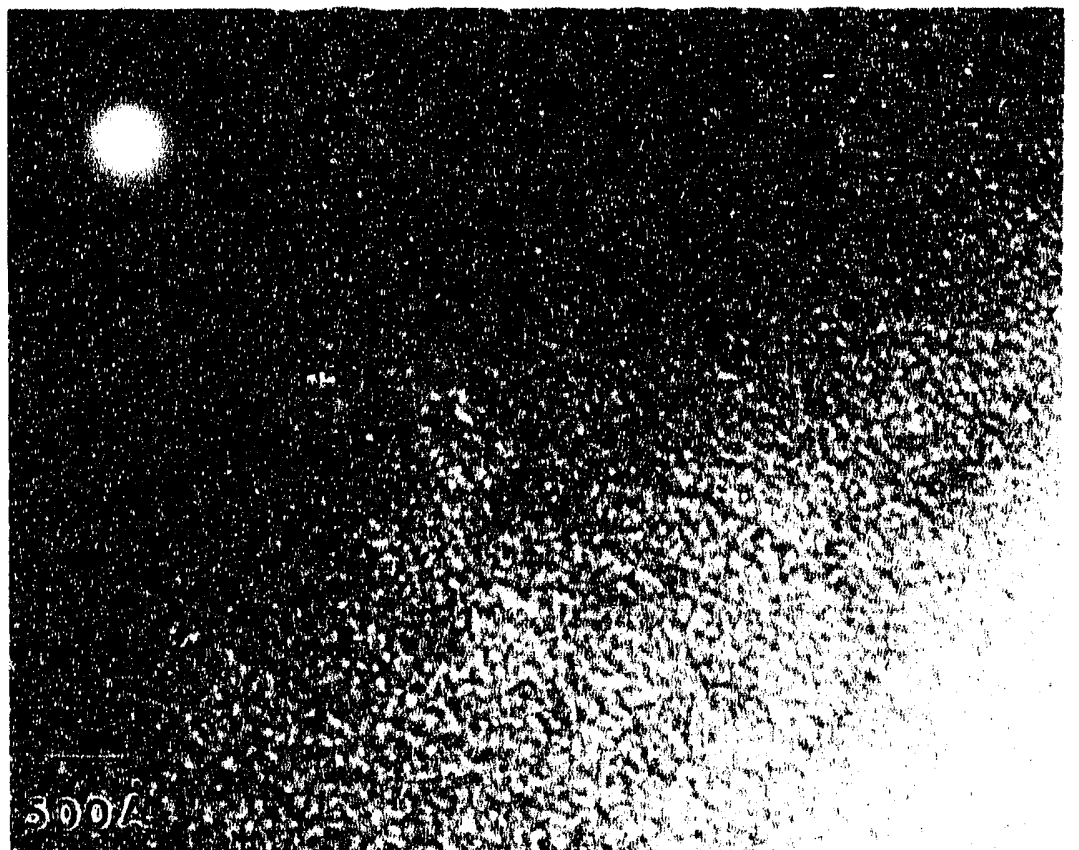

b

XBB 924-2496

Fig. 3.3 


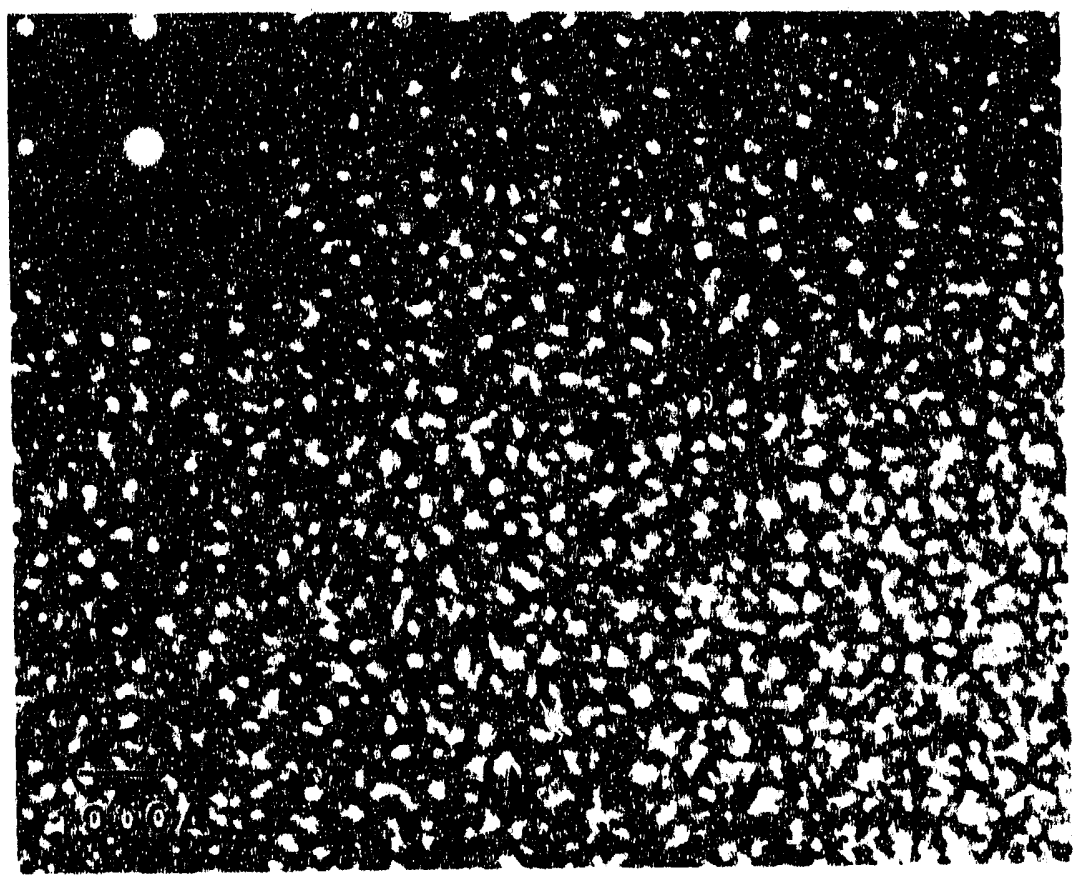

a

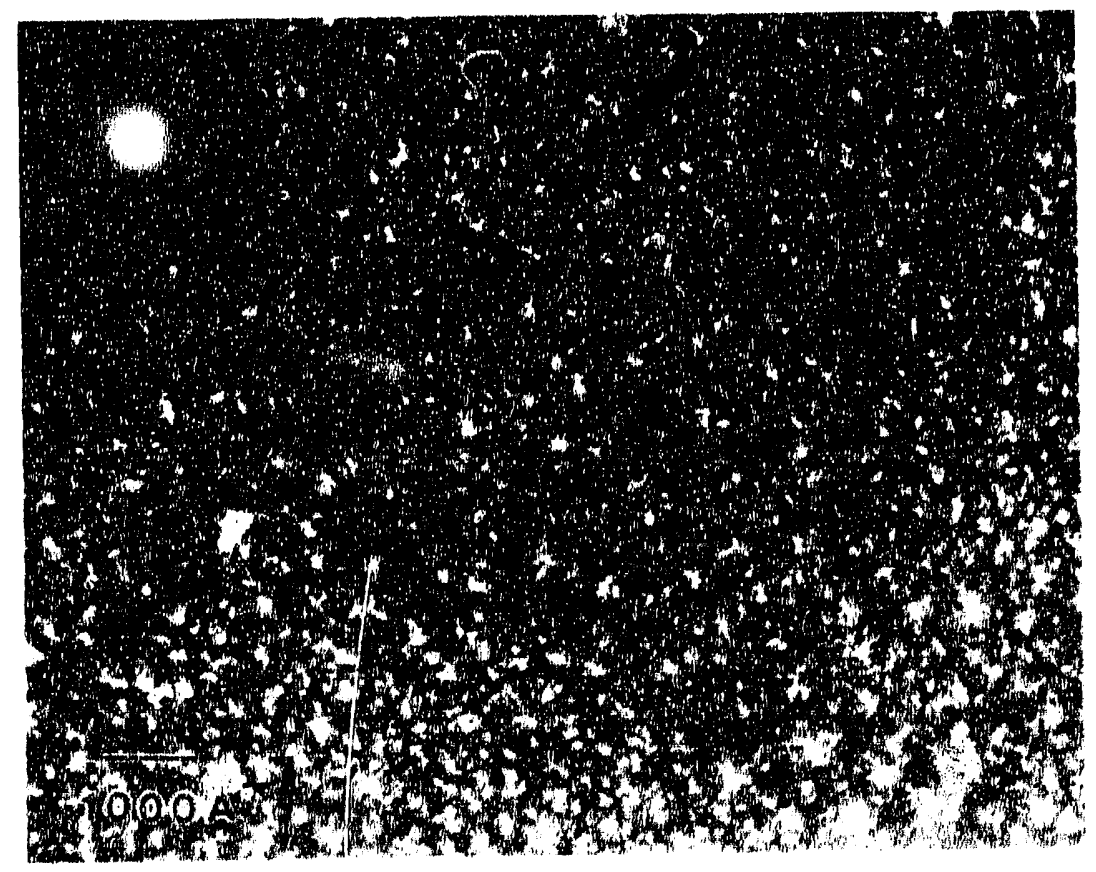

b

Fig. 3.4 


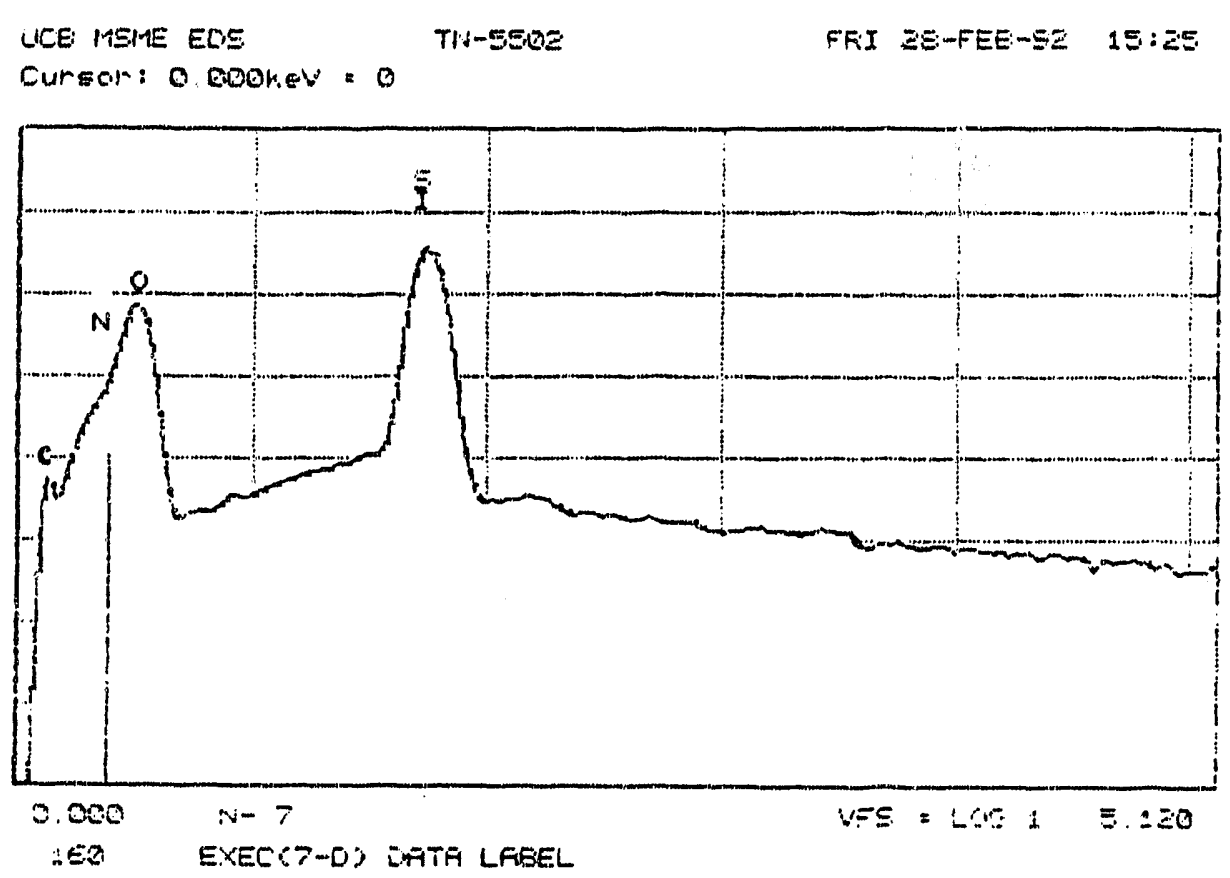

Figure 3.5 EDS spectrum for RTOPS.

LRE MEME EDS $\operatorname{rin}-5002$

FRI Z8-FEE-92 $15: 5 E$

Cursor: $0.000 k$ KV $=0$

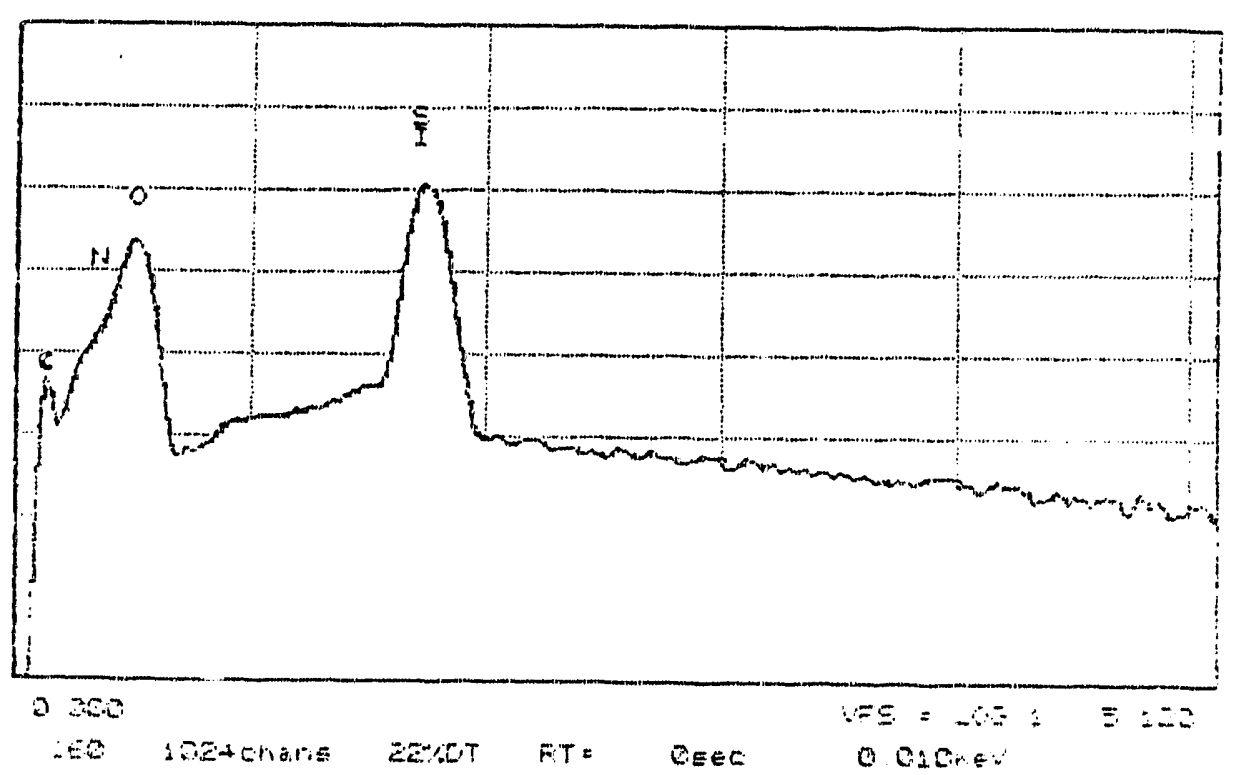

Figure 3.6 EDS spectrum for COPS. 
-Electron Spectroscopy for Chemical Analysis (ESCA) ${ }^{*}-\mathrm{p}^{++}$sample only

Electron Spectroscopy for Chemical Analysis (ESCA), sometimes also known as X-ray Photoelectron Spectroscopy (XPS), was employed to compare the RTOPS with COPS in the $\mathrm{p}^{++}$case. To avoid the surface contamination, the samples were sputtered in-situ to remove the top 1,000 angstroms of material. The compositions of RTOPS and COPS are the same within the experimental error as shown in Figure 3.7 and 3.8. There is about 3\% nitrogen incorporated into the OPS in both processes. This is consistent with the observation in the EDS study.

\subsection{Discussion}

It has been confirmed by using TEM, EDS, and ESCA that the rapid thermal oxidation process can fully oxidize porous silicon just as the two-step conventional oxidation process does. The following reasons make RTO of PS feasible:

(1) Once the oxidation rate is high enough to fully oxidize one half of the silicon pore wall (generally hundreds of angstroms) within the oxidation time, oxidation of PS can be completed. From the TEM study shown in Figure 3.3(a) and Figure 3.4(a), one half of the average pore wall thicknesses of $\mathrm{p}^{++}$and $\mathrm{p}$ samples are about $75 \AA$ and smaller than $60 \AA$, respectively. Fmm Figure 3.1, the extrapolated thicknesses of oxide from R'rO of bulk silicon at $1050^{\circ} \mathrm{C}$ for 9 minutes ( $\mathrm{p}^{++}$sample) and $1000^{\circ} \mathrm{C}$ for 6 minutes (p sample) are about $250 \AA$ and $130 \AA$, respectively (about $120 \AA$ and $60 \AA$ thickness silicon consumed, respectively). In both cases ( $\mathrm{p}$ and $\mathrm{p}^{++}$samples), the amount of silicon which can be oxidized at these oxi' 'ation conditions, is greater than that of the half of the silicon pore walls. So the oxidation of PS can be accomplished theoretically for these samples under these RTO conditions.

\footnotetext{
* The autbo: gratefully acknowledge the assistance of Dr. Frank Ogletree in the ESCA measurements
} 


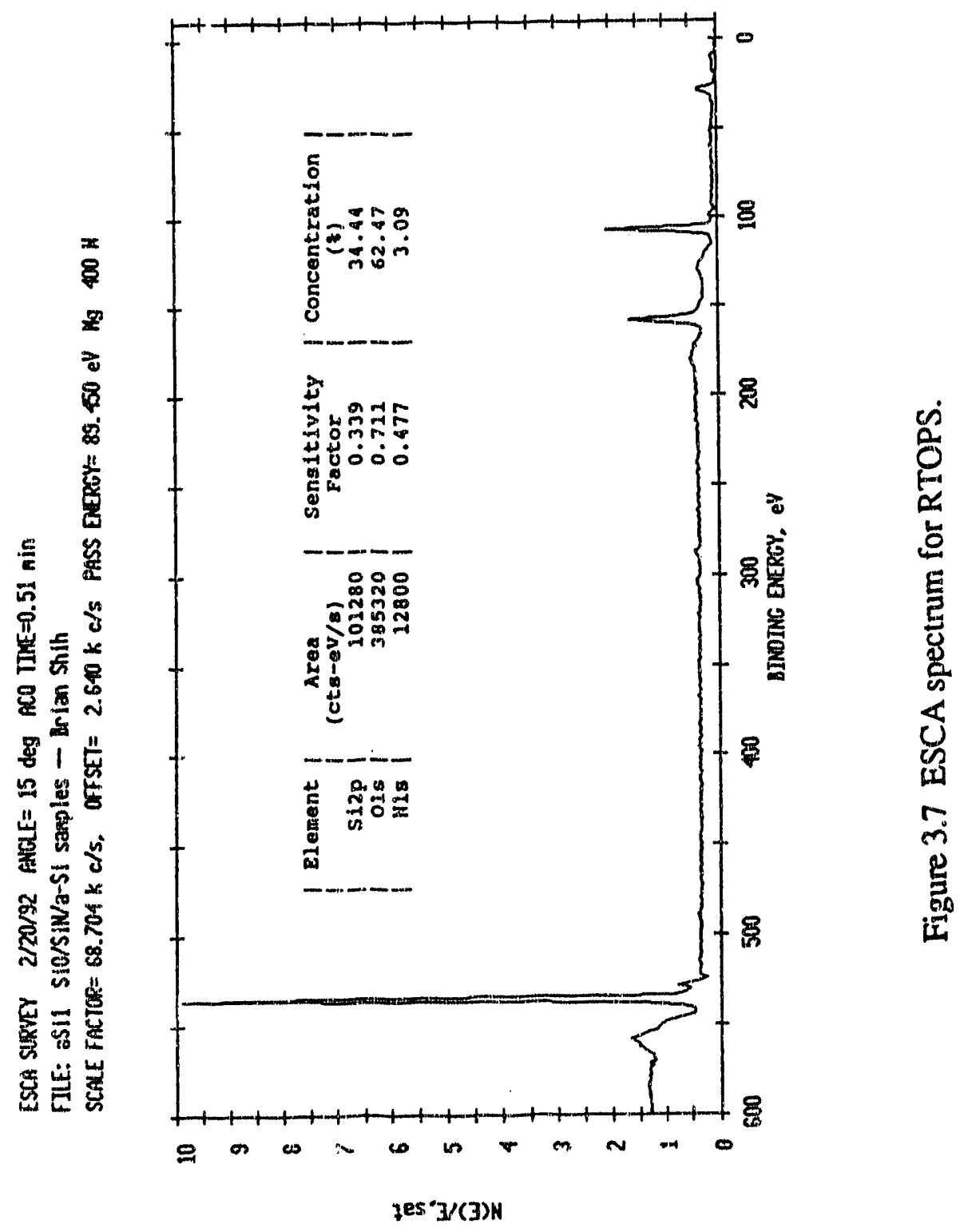




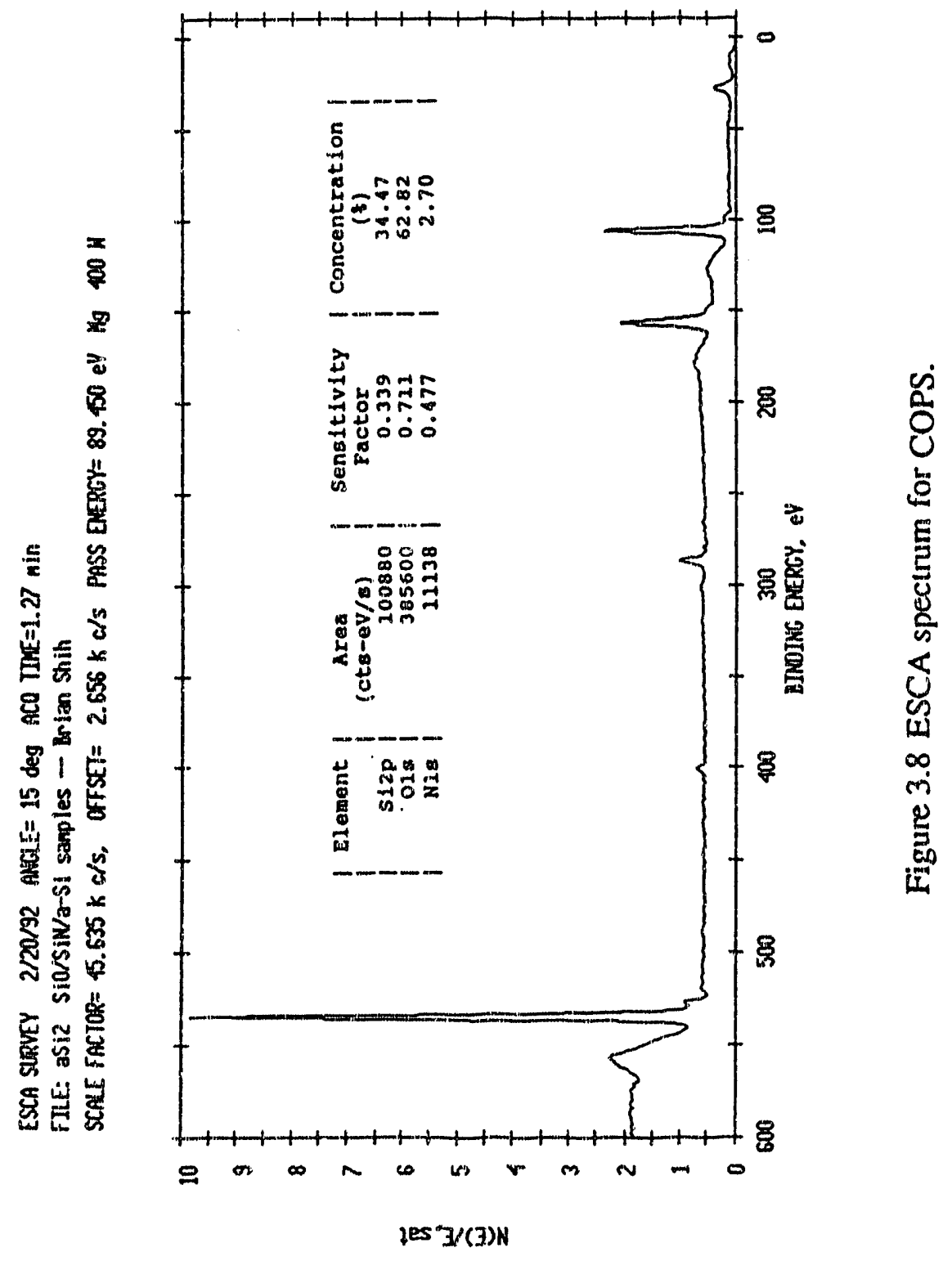


(2) Porous silicon is more reactive than bulk silicon, so the above estimation is a conservative one.

(3) The oxidiation time (especially, the heating time) is so short that the heat treatment effertis still not serious enough to hinder the oxidation. The TEM images in Figure 3.3(b) and 3.4(b) show that the pores did not coarsen during RTO. The oxidant species $\left(\mathrm{O}_{2}\right.$ or/and $\left.\mathrm{O}\right)$ can diffuse deeply to the PS/Si interface. So the oxidation takes place from top to bottom of the PS at the same time.

Sometimes a prolonged oxidation time (tens of minutes) is still necessary for the RTO of PS, e.g., the thickness of silicon pore wall is order of tenths of micrometers and RTO is employed to oxidize the PS under the epi-silicon island in the silicon-on-insulator (SOI) structure as shown in Figure 1.6. In the latter case, a prolonged oxidation time is necessary to allow the oxidant species to diffuse laterally underneath the epi-silicon island (the diffusion path is about tens of micrometers long and about half of it is solid state diffusion).

\subsection{Summary}

The rapid thermal oxidation process can be an alternative to the oxidation of porous silicon. Due to the very rapid heating rate of rapid thermal oxidation (RTO), the enhancement of oxidation rate by the photoeffect of RTO, reactive nature of PS, and oniy a very thin silicon pore wall (hundreds of angstroms) to be oxidized, the oxidation time can be so short that the PS is fully oxidized before the heat treatment effect becomes serious. In some unusual cases, e.g., the thickness of silicon pore wall is thick (tenths of micrometers), a prolonged oxidation time is still needed for the RTO of PS. 
References

1. T. Unagami, Jpn. J. Appl. Phys., 19, 231 (1980).

2. B. E. Deal and A.G. Grove, J. Appl. Phys., 36, 3770 (1965).

3. R. L. Smith and S. D. Collins, Sensors and Actuators, A21, 830 (1990).

4. Y. Watanabe, Y. Arita, T. Yokoyama, and Y. Igarashi, J. Electrochem. Soc. 122, 1351 (1975).

5. T. C. Teng, J. Electrochem. Soc. , 126, 870 (1979).

6. T. L. Lin and K. L. Wang, Appl. Phys. Lett. , 49, 1104 (1986).

7. K. Barla, J. J. Yon, R. Herino, and G. Bomchil, Insulating Films on Semiconductors (edited by J. J. Simonne, p53, Elsevier Sci. Pub. 1986).

8. T. Unagami and K. Kato, Japan J. Appl. Phys. , 16, 1635 (1977).

9. E. P. EerNisse and G. F. Derbenwick, IEEE Trans. Nucl. Sci, NS-23, 1534 (1976).

10. E. P. EerNisse, Appl. Phys. Lett., 30, 290 (1977).

11. E. A. Irene, J. Appl. Phys., 54, 5416 (1983).

12. H. Z. Massoud, J. D. Plummer, and E. A. Irene, J. Electrochem. Soc., 132, 1645 (1985).

13. R. Herino, A. Perio, K. Barla, and G. Bomchil, Materials Lett. , 2, 519 (1984),

14. T. Unagami and M. Seki, J. Electrochem. Soc., 125, 1339 (1978).

15. R. Singh, S. Sinha, R. I: S. Thakur, and P. Chou, Appl. Phys. Lett., 58, 1217 (1991).

16. J. Nulman, J.P. Krusius, and A. Gat, IEEE EDL, 6, 205 (1985).

17. M. M. Moslehi, S. C. Shatas, and K. C. Saraswat, App. Phys. Lett., 47, 1353 (1985).

18. A. G. Associates, Solid State Tech., 29, 167 (1986). 
19. J. Nulman, J.P. Krusius, N. Shah, A. Gat and A. Baldwin, J. Vac. Sci. Tech. A, 4, 1005 (1980).

20. J. P. Ponpon, J. J. Grob, A. Grob, and R. Stuck, J. Appl. Phys., 59, 3921 (1986).

21. V. Murali and S. P. Murarka, J. Appl. Phys., 60, 4327 (1986).

22. Y. Sato and K. Kiuchi, J. Electrochem. Soc., 133, 652 (1986).

23. S. T. Ang and J.J. Wortman, J. Electrochem. Soc., 133, 2361 (1986).

24. R. Singh, F. Radpour, and P. Chou, J. Vac. Sci. Tech. A, 7, 1456 (1989).

25. J. Nulman, J. P. Krusius, and L. Rathbum, Technical Digest, IEDM, 169 (1984).

26. J. Nulman, and J.P. Krusius, Appl. Phys. Lett., 47, 148 (1986).

27. C. C. Chang, A Kamgar, and D. Kahng, IEEE EDL, 6, 476 (1986).

28. M. M. Moslehi, K. S. Saraswat, and S. C. Shatas, Appl. Phys. Lett., 47, 113 (1986).

29. T. Hori, Y. Naito, H. Iwasaki, and H. Esaki, IEEE EDL, 6, 669 (1986).

30. H. Hwang, W. Ting, B. Maiti, D-L Kwong, and J. Lee, Appl. Phys. Lett., 57, 1010 (1990)。

31. M. M. Moslehi, K. C. Saraswat, and S. C. Shatas, Appl. Phys. Letto, 47, 1113 (1985).

32. R. Singh, J. Appl. Phys., 63, R59 (1988).

33. T. E. Seidel, D. J. Kischner, C. S. Pai, R. V. Knoell, D. M. Maher, and D. C. Jacobson, Nucl. Instrum. Methods Phys. Res. B, 178, 251 (1985).

34. D. R. Sparks, R. G. Chapman, and N. S. Alvi, Appl. Phys. Lett., 49, 525 (1986).

35. B. Hartiti, Vu-Thuong-Quat, W. Eichhammer, J-C Muller, and P. Siffert, Appl. Phys. Lett., 55, 873 (1989).

36. B. Hartiti, A Slaoui, M. Loghmarti, J-C Mulier, and P. Siffert, Appl. Phys. Lett., 59, 3446 (1991).

37. B. Hartiti, J-C Muller, and P. Siffert, Appl. Phys. Lett., 59, 425 (1991). 
38. D. F. Downey, C.J. Russo, and J.T. White, Solid State Technol., 25, 87 (1982).

39. T. Hara, H. Suzuki, and M. Furukawa, Jpn. J. Appl. Phys., 23, LA52 (1984).

40. J. Kato and Y. Omo, J. Electrochem. Soc., 132, 1730 (1985).

41. W. Kern and R. W. Smeltzer, Solid State Technol., 26, 171 (1985).

42. J. S. Mercier, I D. Calder, R. P. Beerkens, and H. M. Naguib, J. Electrochem. Soc., 132, 2432 (1985).

43. N. S. Alvi and D. L. Kwong, J, Electrochem. Soc., 133, 2026 (1986).

44. I Barsony, H. Anzai, and J. Nishizawa, J. Electrochem. Soc., 133, 156 (1986).

45. J. S. Mercier, Solid State Technol., 30, 85 (1987).

46. R. C. Anderson, Ph.D. Thesis, University of California at Berkeley, May, 1991.

47. K. Yoneda, Y. Todokoro, and M. Inoue, J. Mater. Res., 6, 2362 (1991). 
Chapter 4 Densification and Nitridation of Oxidized Porous Silicon

\subsection{Introduction}

To be a dielectric insulator material for integrated circuited (IC) devices, porous silicon (PS) is oxidized to form oxidized porous silicon (OPS). When the oxidation temperature is low (e.g., $<960^{\circ} \mathrm{C}$ ), OPS is still porous as shown in Figure 1.11 and the residual pores keep the "tube" shape of that of PS as shown in Figure 1.11(b). Because of these residual pores, the property of the OPS is poor, e.g., its resistance to the attack of a buffered HF solution is much weaker than that of thennally grown silicon dioxide of bulk silicon. ${ }^{1,2}$ Since a buffered HF solution is frequently used in an IC production line, the as-formed OPS is susceptible to being etched away totally. Therefore, enhancing the OPS's durability in the HF solution is very critical for the application of OPS in the IC technology2,3,4. Three possible ways to do this are: densifying at a higher temperature $\left(>960^{\circ} \mathrm{C}\right)^{2,3}$ to remove the residual pores, nitridizing to incorporate nitrogen, and depositing a protective film (e.g., silicon nitride). The first two methods are studied here.

\subsection{Densification of Oxidized Porous Silicon}

OPS is merely a porous silica glass, which is an undercooled liquid 5 formed by cooling down from temperatures above the melting temperature of cristobalite (a polymorphous state of silicon dioxide 6 ). Viscous flow of the undercooled liquid is the operative transport mechanism for the densification of porous glass. ${ }^{7-16}$ Yon $^{2}$ found the activation energy of OPS densification process by studying the necessary densification time (when the OPS had the same etching rate in a buffered HF solution as bulk thermal oxide did) in steam ambient at different temperatures, was about $3 \mathrm{eV}$. This value could be related to the reported values for viscous flow of bulk silica $(5-7 \mathrm{eV})^{24}$ and Yon ${ }^{2}$ 
concluded that the viscous flow, as expected, was the operative transport mechanism for the densification of the OPS. The possible reason why the activation energy of OPS densification process is smaller than that of the viscous flow of bulk silica, is due to the densification ambient (steam), which can effectively reduce the activation energy of the viscosity of silica as discussed later. The driving force for the densification process is to reduce the total surface energy. Frenkel17 proposed a hypothesis for the theory of viscous densification by equating the energy dissipated in the viscous flow to the energy change resulting from the reduction in total surface area. Many mathematical models9,12,17-19, based on Frenkel's assumption, work quite well to describe the evolution of the densification of porous glass. One of the best known was proposed by Mackenzie and Shuttleworth ${ }^{20}$ (M-S model). The other main assumptions of the M-S model are: (1) both spherical and monosized pores inside the glass distribute uniformly, and (2) there is no gas trapped inside the pores. The model provides the following equation to predict the evolution of the desification of porous glass:

$$
\begin{aligned}
2.418(\gamma \mathrm{t} / \mu) \mathrm{m}^{1 / 3}= & 0.5 \ln \left[\left(1+\mathrm{x}^{3}\right) /(1+\mathrm{x})^{3}\right]-\sqrt{3} \tan ^{-1}[(2 \mathrm{x}-1) / \sqrt{3}] \\
& -0.5 \ln \left[\left(1+\mathrm{x}_{0}^{3}\right) /\left(1+\mathrm{x}_{0}\right)^{3}\right]-\sqrt{3} \tan ^{-1}\left[\left(2 \mathrm{x}_{0}-1\right) / \sqrt{3}\right]
\end{aligned}
$$

where $\gamma$ is the specific surface energy' $\mu$ is the viscosity, $t$ is the densification time, $D$ is the relative density of OPS, $D_{0}$ is the initial relative density, $x^{3}=(1-D) / D, x_{0}^{3}=(1$ $\left.D_{0}\right) / D_{0}$, and $m$ is the number of pores per unit volume of real material. When the pores are cylindrical voids, Scherer's model ${ }^{19}$ is applicable. His development of the equations was based on solid mechanics. An identical result can be obtained by using fluid mechanics, which presents a clearer physical picture. The Navier-Stokes equations ${ }^{21}$ with the inertia and gravity terms omitted are applied to solve this viscous flow problem as shown in Appendix 1. The result is 


$$
\gamma t / \mu=4 r_{2}\left[\tan ^{-1}\left(r_{1} / r_{2}\right)-\tan ^{-1}\left(r_{1} / r_{2}\right)\right]+\sigma\left(r_{10}-r_{1}\right)
$$

where $r_{10}$ is the initial pore radius, $r_{1}$ is the pore radius at time $t$, and $r_{2}$ is the outside radius of the glass tube as shown in Figure 4.1.

From the models above, it is quite obvious that the necessary densification time (i.e., the time needed to remove all pores) for a given pore structure (porosity, pore size, pore shape), depends on the specific surface energy and viscosity. The necessary densification time decreases with increasing specific surface energy and decreasing viscosity. For glass materials, the specific surface energy may be altered by the environment gas. For soda-lime-silica glass (Corning 0080), nonpolar gases (e.g., He, $\mathrm{N}_{2}, \mathrm{H}_{2}, \mathrm{O}_{2}$ ) have virtually no effect on the specific surface energy, whereas polar gases (e.g., $\mathrm{H}_{2} \mathrm{O}, \mathrm{HCl}, \mathrm{NH}_{3}, \mathrm{SO}_{2}$ ) can lower the specific surface energy 22 . For silica glass, the specific surface energy is unaffected by water vapor and nitrogen 22 , but lowered by $\mathrm{HCl}$ gas ${ }^{16}$. The viscosity of glass depends on its composition, 23-26 temperature, 6,24 and thermal history $6,23,24,27$. Those species, that can effectively break the Si-O-Si bond, lower the viscosity, e.g., $\mathrm{OH}^{23-26}$ and $\mathrm{Cl}^{23}$ can open Si-O-Si bond and form:

$$
-\mathrm{Si}-\mathrm{OH}+\mathrm{HO}-\mathrm{Si}-\quad-\mathrm{Si}-\mathrm{Cl}+\mathrm{Cl}-\mathrm{Si}-
$$

Hence the viscosity of the glass is dependent on the water vapor content of the gas with which it is in contact. The glass network modifiers (e.g., $\mathrm{Na}_{2} \mathrm{O}$ and $\mathrm{B}_{2} \mathrm{O}_{3}$ ), which break the $\mathrm{Si}-\mathrm{O}-\mathrm{Si}$ bond, also reduce the viscosity. In the glass industry, the $\mathrm{Na}_{2} \mathrm{O}$ is often used to reduce the viscosity of glass to facilitate the working of glass. ${ }^{6}$ Generally, glass is a Newtonian fluid 12 and its viscous flow is a thermally activated mechanism. The viscosity of silica can be expressed by 24 : 


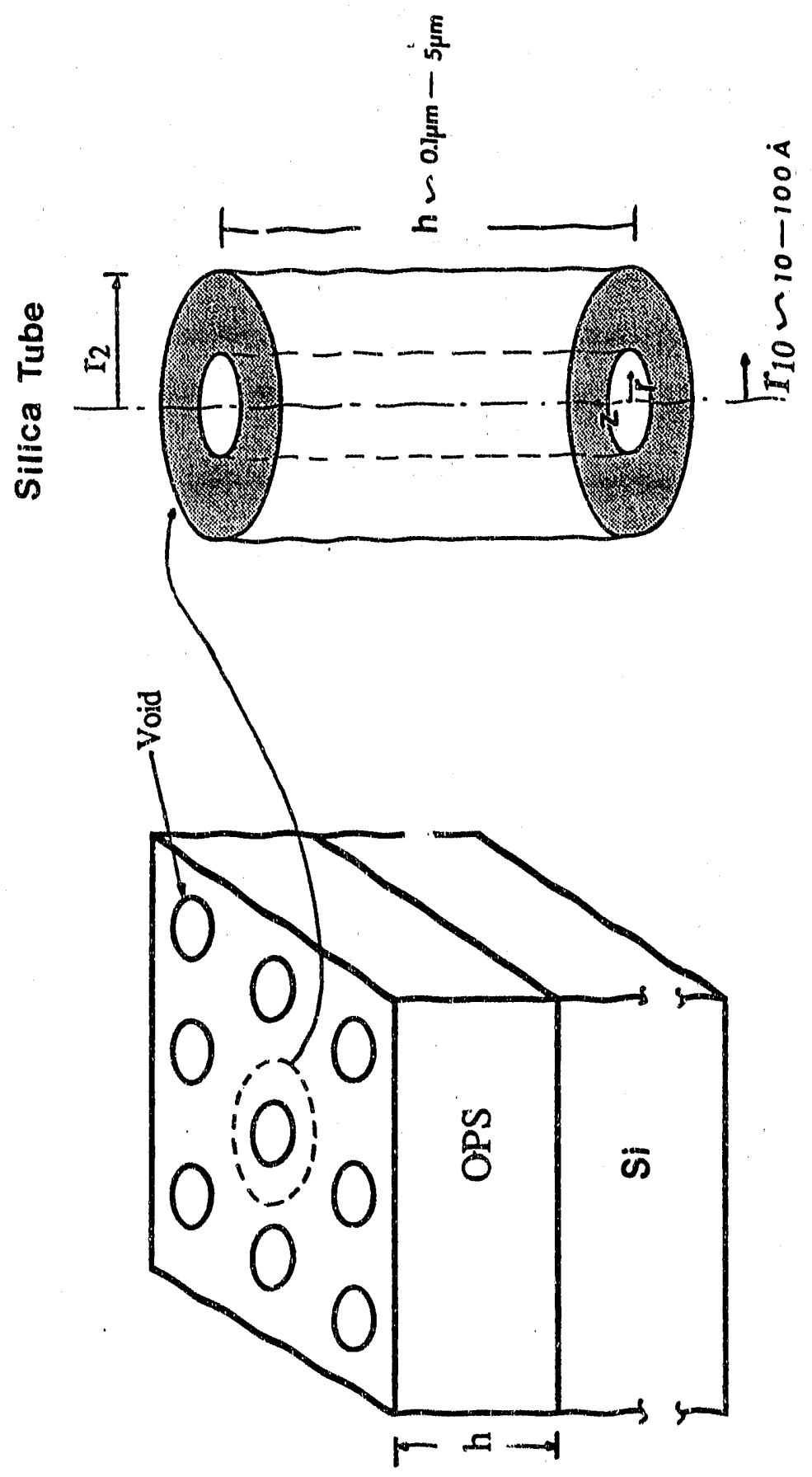

O⿱ 


$$
\mu=3 \times 10^{-13} \exp (171 \mathrm{kcal} / \mathrm{RT})
$$

where $R$ is the gas constant.

The activation energy decreases with increasing concentrations of impurities (e.g., OH) effective in breaking Si-O-Si bond. ${ }^{24}$ The viscosity of silica with different $\mathrm{OH}$ contents is shown in Figure 4.2(a). In addition to the composition and temperature, the thermal history (e.g., fictive temperature 6 ) has effect on the viscosity of glass. 6,24 The fictive temperature is the temperature at which the existing structure of a glass material would be in equilibrium. The viscosity decreases with increasing fictive temperature. 24 A typical viscosity of silica glass with different fictive temperatures is shown in Figure 4.2(b).

The ambient gas not only has effect on the viscosity and specific surface energy (chemical effect) but also may cause a "trapped gas" problem20,27-34, which reduces the densification rate or the limiting density (mechanical effect). Coble ${ }^{30}$ did a very detailed analysis of the trapped gas problem during densification process:

During the course of densification, the open pore channels are pinched off at the specimen surface first (because of faster sintering there) and the trapped gas can no longer escape to the atmosphere. At the pinch-off the gas is trapped at the ambient pressure and is compressed as further shrinkage takes place. Shrinkage stops when the internal gas pressure $(P)$ counterbalances the surface tension $(\gamma)$ driving force as given by $P=2 \gamma / r$, where $r$ is the effective radius of curvature at the pore surface. Shrinkage stops if no gas diffusion occurs. At the opposite extreme, ie., at relatively high gas diffusivity, the final shrinkage is not impeded by the presence of the gas; it simply continues at a speed dependent on the transport of the solid. At an intermediate gas diffusivity, the kinetics of gas diffusion to the specimen surface control the rate of final pore shrinkage. At a slightly lower diffusivity (still intermediate) in the range of values where the surface is essentially inaccessible within the sintering time, only exchange between adjacent pores is allowed. The shrinkage of all pores is not possible because while some shrink other near-neighbor pores must grow. The gas moving from the small pores to the larger ones expands because the equilibrium pressure in the larger pores is lower; i.e., after a density 


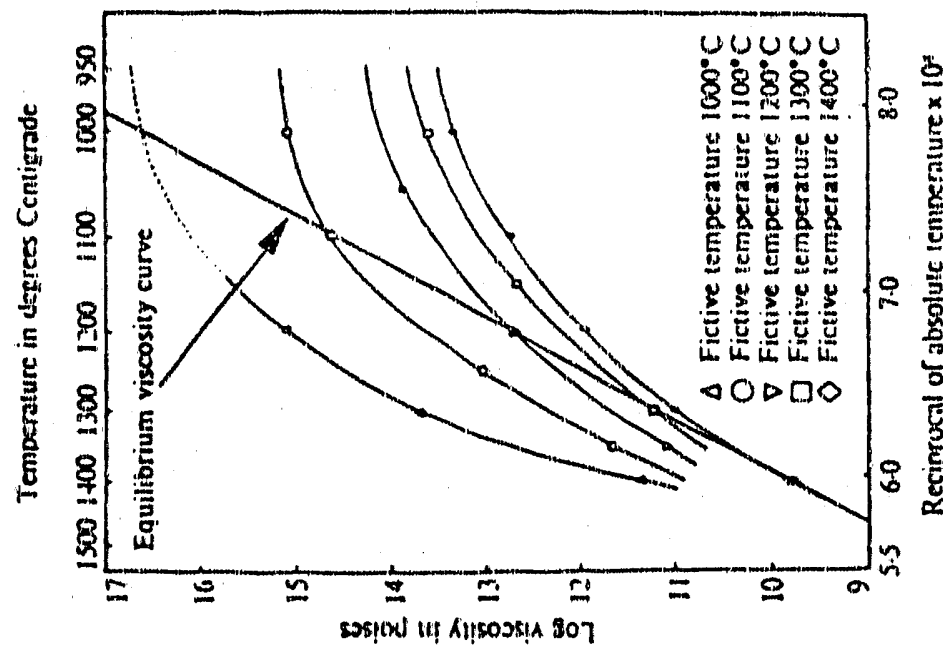

胥
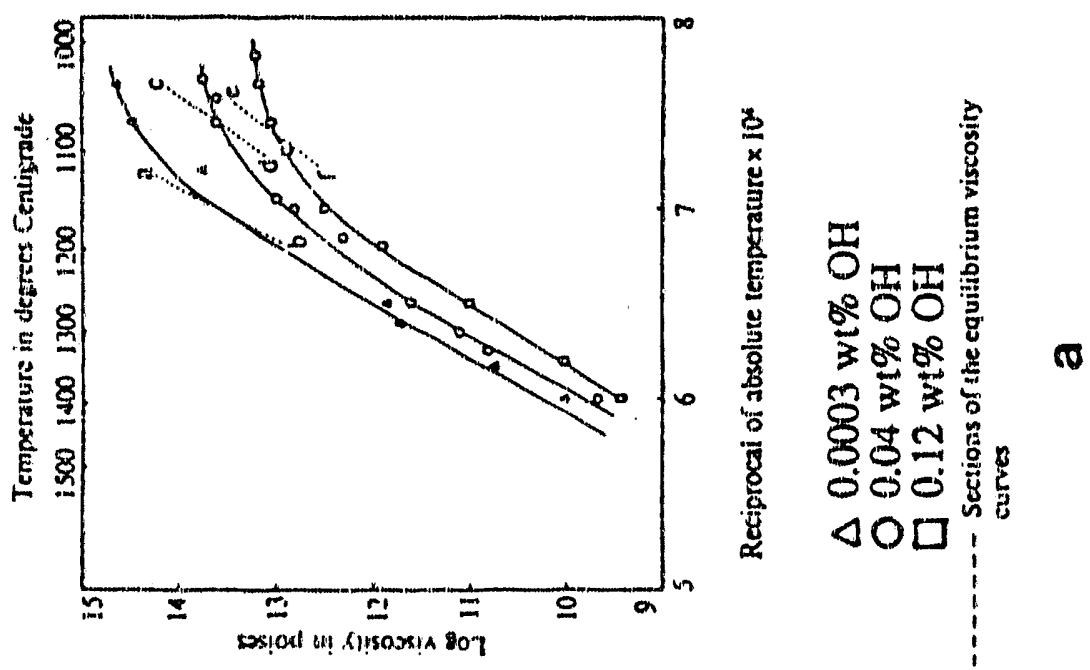

岕

羿 
limit is reached continued growth of larger pores at the expense of their smaller neighbors occurs by a diffusion process and the gas exchanged between pores must expand, causing the specimen density to decrease. This decrease in density is called "bloating" effect.

Therefore, how the trapped gas affects the densification process depends on the relative rate of the removal of trapped gas and the transport of solid (e.g., visious flow of silica). Both rates depend on the pore structure and some physical properties (the gas removal rate: the gas diffusivity and solubility in the solid; the solid transport rat: specific surface energy and viscosity of the solid as discussed in the previous paragraph). For a gas to diffuse through a solid, it must be soluble in the solid. So a gas with high diffusivity and solubility in a solid can be removed quickly from isolated pores and has less or even no trapped gas problem. Coble 30 did alumina sintering experiments and found that the theoretical density can be obtained if the ambient gas was $\mathrm{H}_{2}$ or $\mathrm{O}_{2}$, but not in the $\mathrm{Ar}, \mathrm{N}_{2}$ and He. His explanation was: compared with $\mathrm{H}_{2}$ and $\mathrm{O}_{2}$, the $\mathrm{Ar}$ and $\mathrm{N}_{2}$ have smaller diffusivity and solubility in the alumina. Helium has high diffusivity in alumina, but it's solubility is very low. Thenefore, porosity cannot be completely eliminated in a $\mathrm{Ar}, \mathrm{He}$, or $\mathrm{N}_{2}$ environment.

For silica glass, the dominant gas diffusion path is interstitial 35,36 because of its open structure ${ }^{37}$. The gas diffusivity increases with decreasing molecular/atom size. The activation energy $Q$ for gas diffusion in silica can be given by 36 :

$$
\mathrm{Q}^{0.5}=\mathrm{a}+\mathrm{br}
$$

where $\mathrm{a}$ and $\mathrm{b}$ are constants, $\mathrm{r}$ is the gas molecular radius.

The experimental data $23,33,38,3967,68$ also show that the order of different gas diffusivity in silica is $\mathrm{He}>\mathrm{H}_{2} \gg \mathrm{H}_{2} \mathrm{O}, \mathrm{Ar}, \mathrm{O}_{2}, \mathrm{~N}_{2}$ as shown in Figure 4.3. The order of gas 


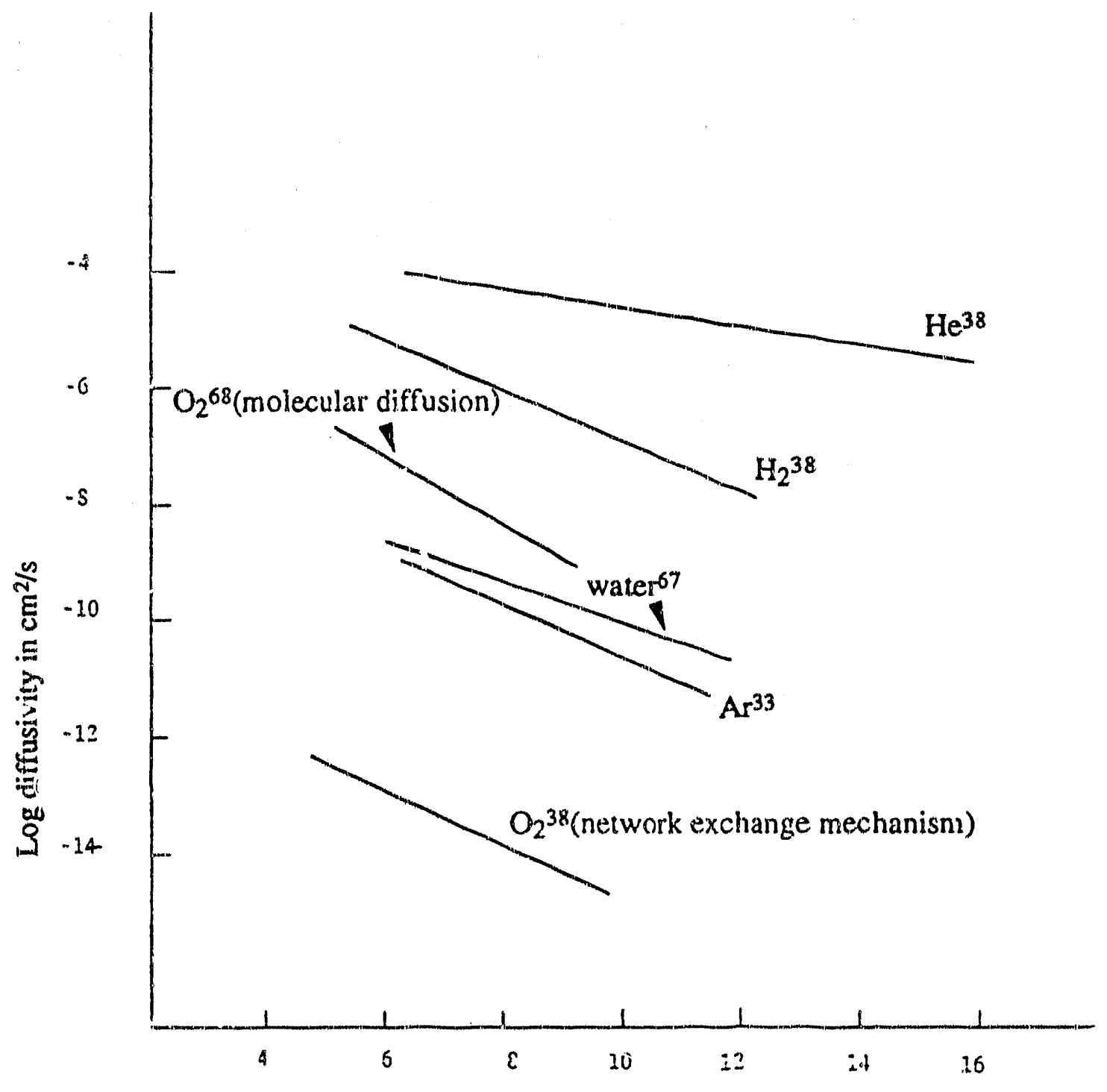

Reciprocal of absolute temperature $\times 10^{4}$

Figure 4.3 Diffusivity vs. temperature for different gases in silica 
solubility 35,38-40 in a silica is $\mathrm{H}_{2} \mathrm{O}>\mathrm{H}_{2}>\mathrm{He}>\mathrm{Ar}, \mathrm{O}_{2}, \mathrm{~N}_{2}$. The reason why the water vapor and hydrogen have high solubility in silica is due to the following reactious:

$$
\begin{aligned}
& \mathrm{Si}-\mathrm{O}-\mathrm{Si}+\mathrm{H}_{2} \mathrm{O} \rightarrow 2 \mathrm{Si}-\mathrm{OH} \\
& \mathrm{Si}-\mathrm{O}-\mathrm{Si}+\mathrm{H}_{2} \rightarrow \mathrm{Si}-\mathrm{OH}+\mathrm{Si}-\mathrm{H}
\end{aligned}
$$

The gas permeability $(P)$ is the suitable paraneter to represent the overall effect of gas diffusivity and solubility in a condensed material. The onder of permeabilities of different gases in silica glass ${ }^{38}$ is $\mathrm{He}>\mathrm{H}_{2} \gg \mathrm{Ar}, \mathrm{O}_{2}, \mathrm{~N}_{2}$ (e.g., at $700 \mathrm{C}, P_{\mathrm{He}}=210, P_{\mathrm{H} 2}=21$, $P_{\mathrm{Ar}}, P_{\mathrm{O} 2}, P_{\mathrm{N} 2}<0.00001$, unit: $\left.10^{10} \mathrm{~cm}^{3}(\mathrm{STP}) \mathrm{mm} /\left(\mathrm{cm}^{2} \mathrm{sec} \mathrm{cmHg}\right)\right)$. According to the above argument and data, a strategy is proposed to do the densification of OPS to reduce the densification time: a wet $\mathrm{He}$ or $\mathrm{H}_{2}$ (He or $\mathrm{H}_{2}$ bubbled through water) is chosen as the densification ambient gas. The wet environment enhances the $\mathrm{OH}$ content and then decreases the viscosity of OPS. The He or $\mathrm{H}_{2}$ gas reduces or even eliminates the trapped gas problem. So the strategy is expected to provide a faster densification rate and a bigher limiting density.

\subsection{Ixperiments: Densification of Oxidizal Porous Silicon}

P-type, (100) oriented silicon wafers with resistivity $0.02-0.005$ ohm- $\mathrm{cm}$, were used to study the ambient gas effect on the densification of OPS. The current densities was 50 $\mathrm{mA} / \mathrm{cm}^{2}$. The elictrolyte for the PS formation was a solution with $20 \% \mathrm{HF}, 20 \% \mathrm{H}_{2} \mathrm{O}$, and $60 \% \mathrm{C}_{2} \mathrm{H}_{5} \mathrm{OH}$. The anodization time was 3 minutes to form an approximately $3 \mu \mathrm{m}$ thick PS layer. To avoid heat treatment effects, a two-step oxidation was used. The PS was preoxidized in dry oxygen at $300^{\circ} \mathrm{C}$ for 1 hour to stabilize the microstructure of PS, then oxidized in a wet oxygen at $800^{\circ} \mathrm{C}$ (oxygen bubbled through $85^{\circ} \mathrm{C}$ DI water) for 1 bour. Then the OPS was densified in different ambient gases. 
(1) Dry environment

To facilitate the comparison, one OPS/Si (OPS patch on silicon substrate) wafer was broken into four pieces: three of them were densified in dry He, dry Ar, and vacuum, and the fourth one was left as-formed. The densification temperature was $1100^{\circ} \mathrm{C}$ and densification time was one hour. Both the heating and cooling times were one hour too. Transmission electron microscope (TEM) was used to characterize the pore structures. The results are shown in the Figure 4.4. A second OPS/Si wafer was also broken into four pieces. Three of them were densified in dry Ar, $\mathrm{O}_{2}$, and $\mathrm{N}_{2}$. The densification temperature was $1090 \mathrm{C}$ and densification time was one hour. The heating and cooling times were 5 and 7 minutes, respectively. The results are shown in Figure 4.5.

(2) Wet environment (gas bubbled through $85^{\circ} \mathrm{C}$ DI water)

One OPS/Si wafer was broken into two pieces. They were densified in wet He aud wet $\mathrm{Ar}$, respectively. The densification temperature was $1090^{\circ} \mathrm{C}$ and densification times were $5,20,40$, and 60 minutes respectively. The heating and cooling times were 5 and 7 minutes, respectively. The results are shown in Figure 4.6.

\subsection{Results and Discussion: Densification of Oxidized Porous Silicon}

The pore structures were almost unchanged after 1-hour densification in dry ambient atmospheres as shown in Figures 4.4 and 4.5. It implies that the densification rate of OPS is quite slow in a dry environment because of high viscosity. On the contrary, the OPSs were fully densified in the wet ambient atmospheres for the same densification time (one hour) as strown in Figure 4.6(d). This faster densification rate is attributed to the higher $O H$ concentration in a wet environment, which reduces the viscosity. There are three other observations to be made in Figure 4.6. (1) The pores disintegrated and became very large (about $0.5 \mu \mathrm{m}$ in radius) after 20 -minute densification as shown in 


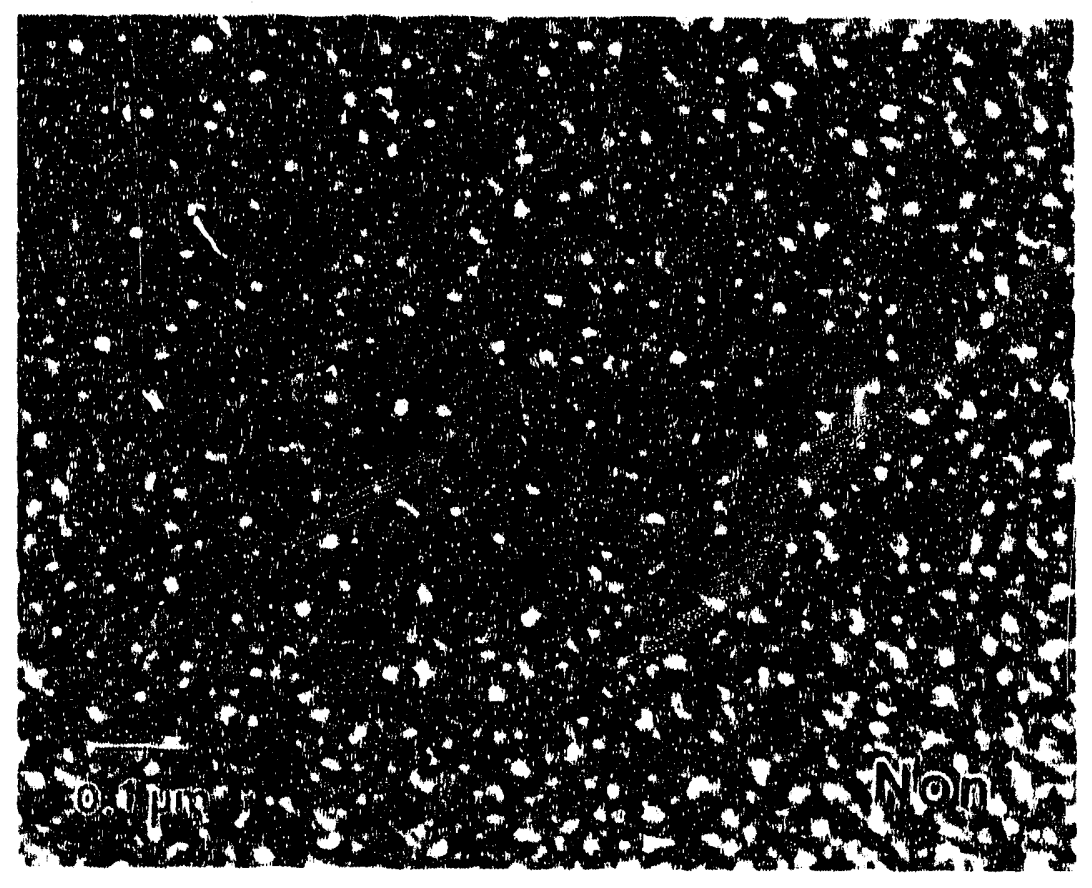

a

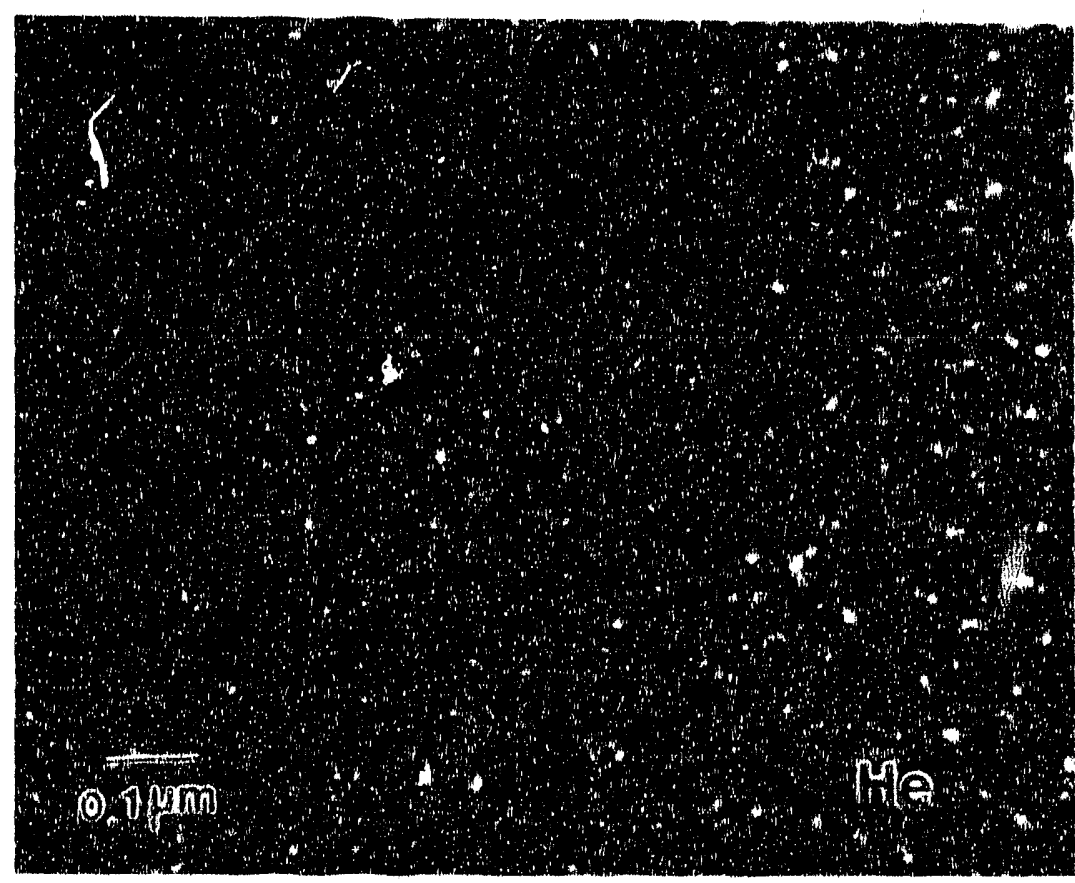

b

Fig. 4.4

XBB 924-2494 


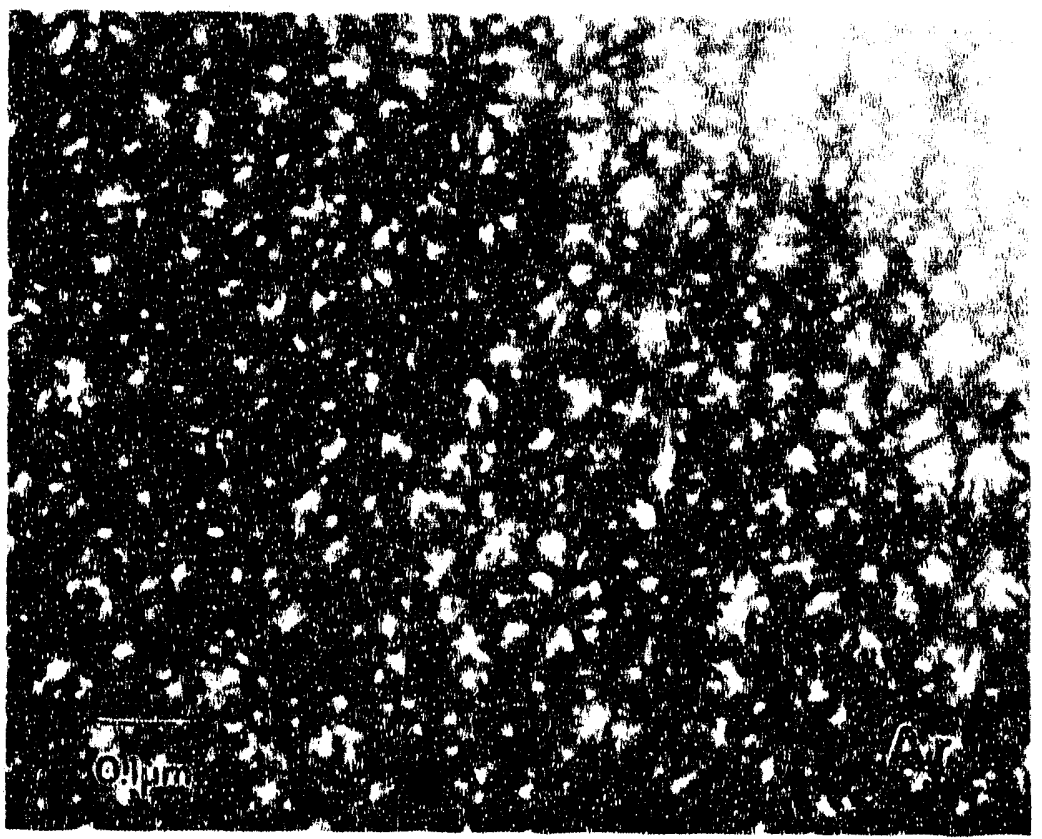

C

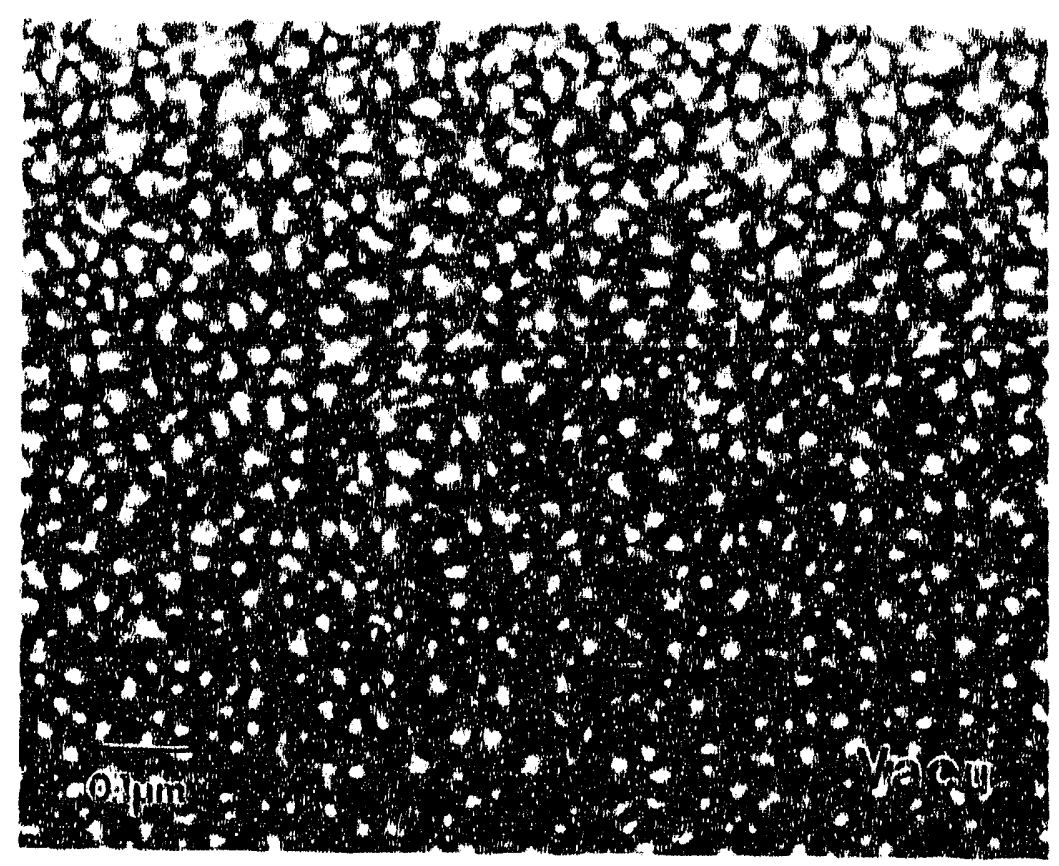

$d$

Fig. 4.4 cont.

XBB $924-2493$ 


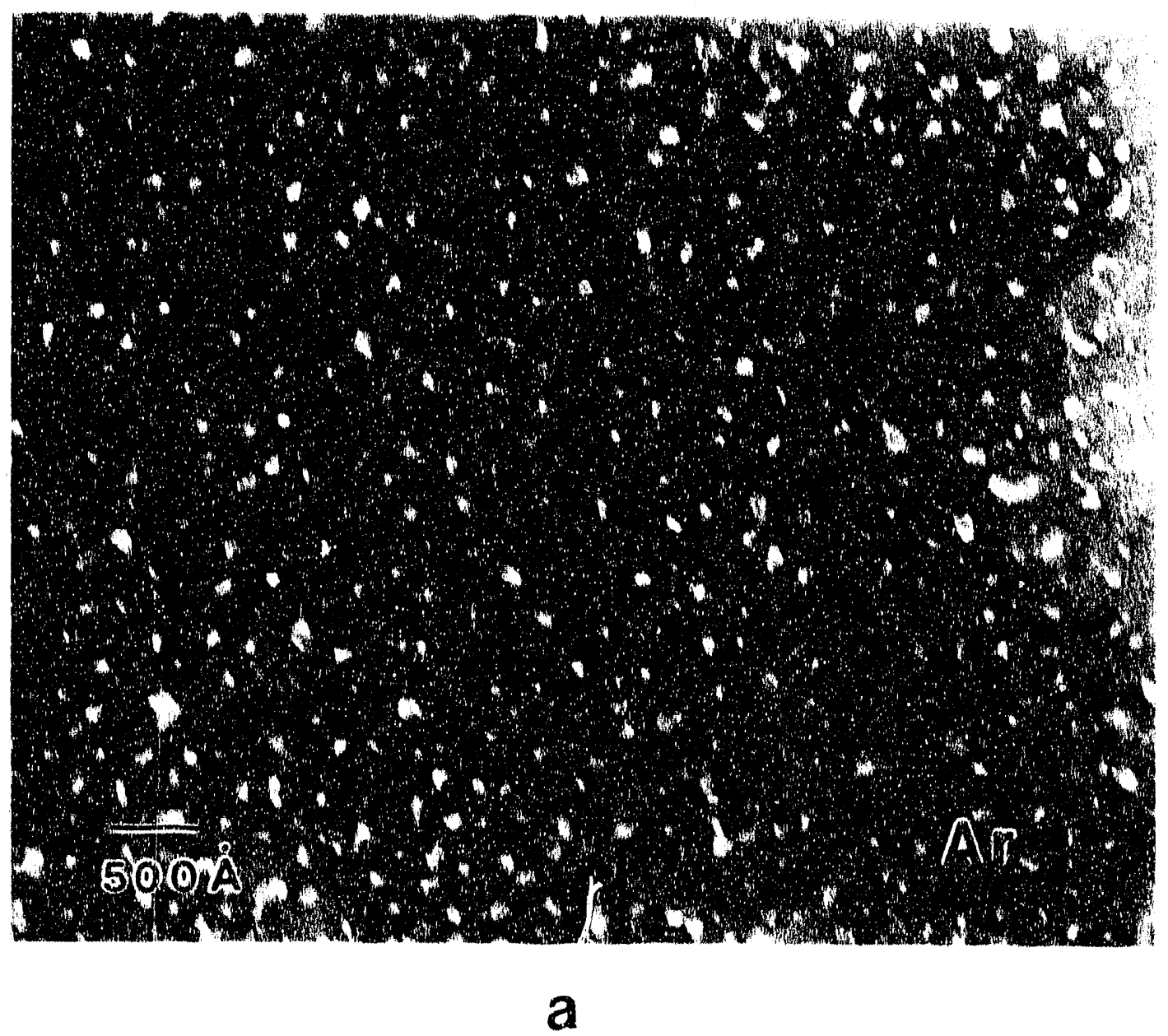

Fig. 4.5 


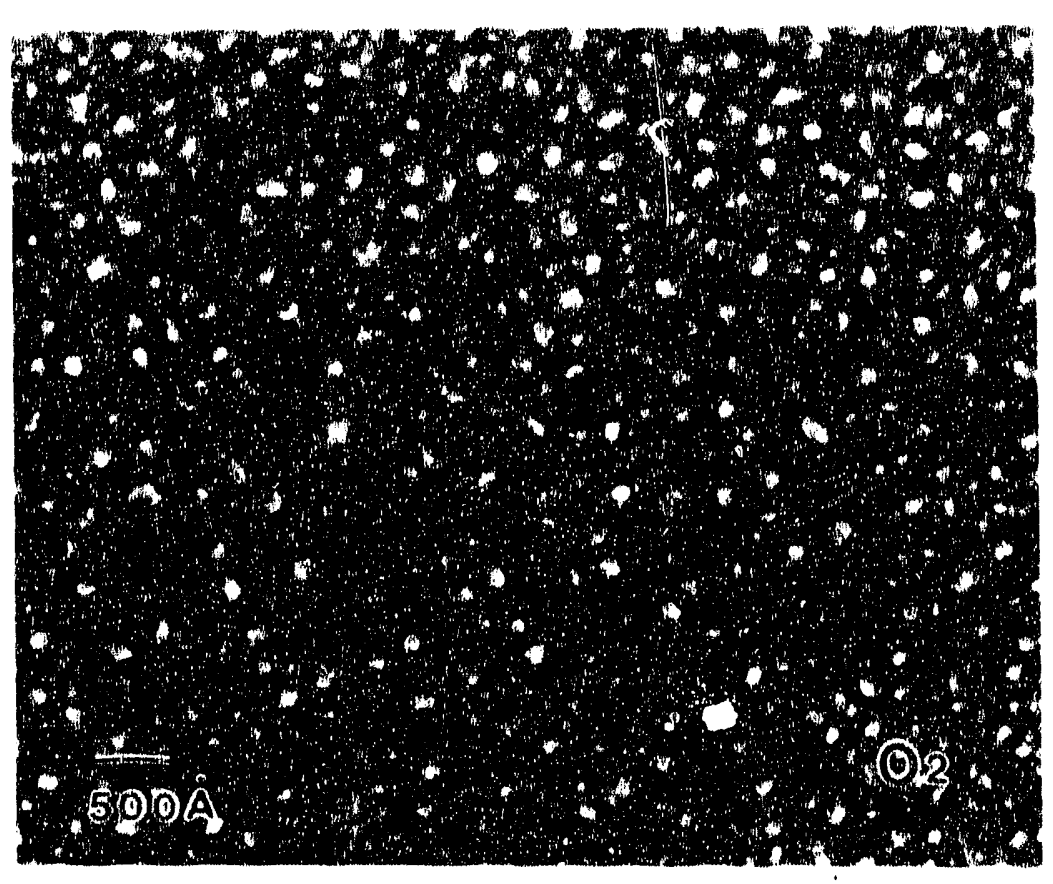

b

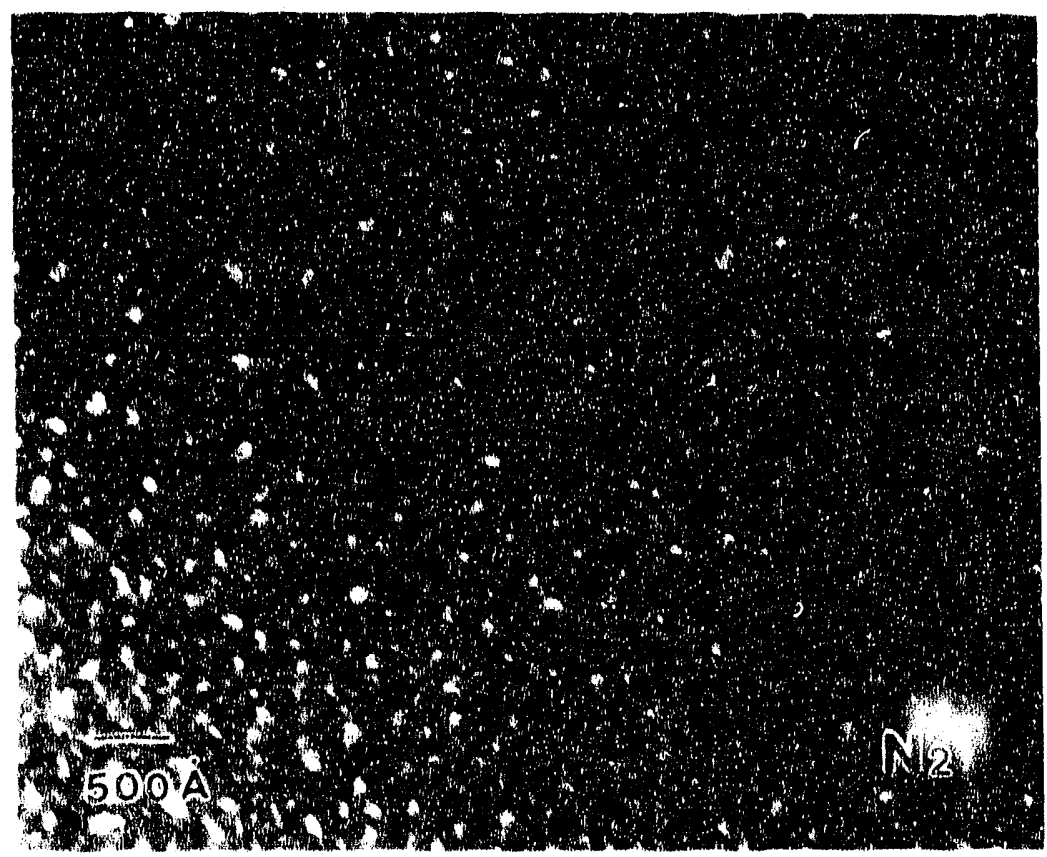

C

Fig. 4.5 cont. 

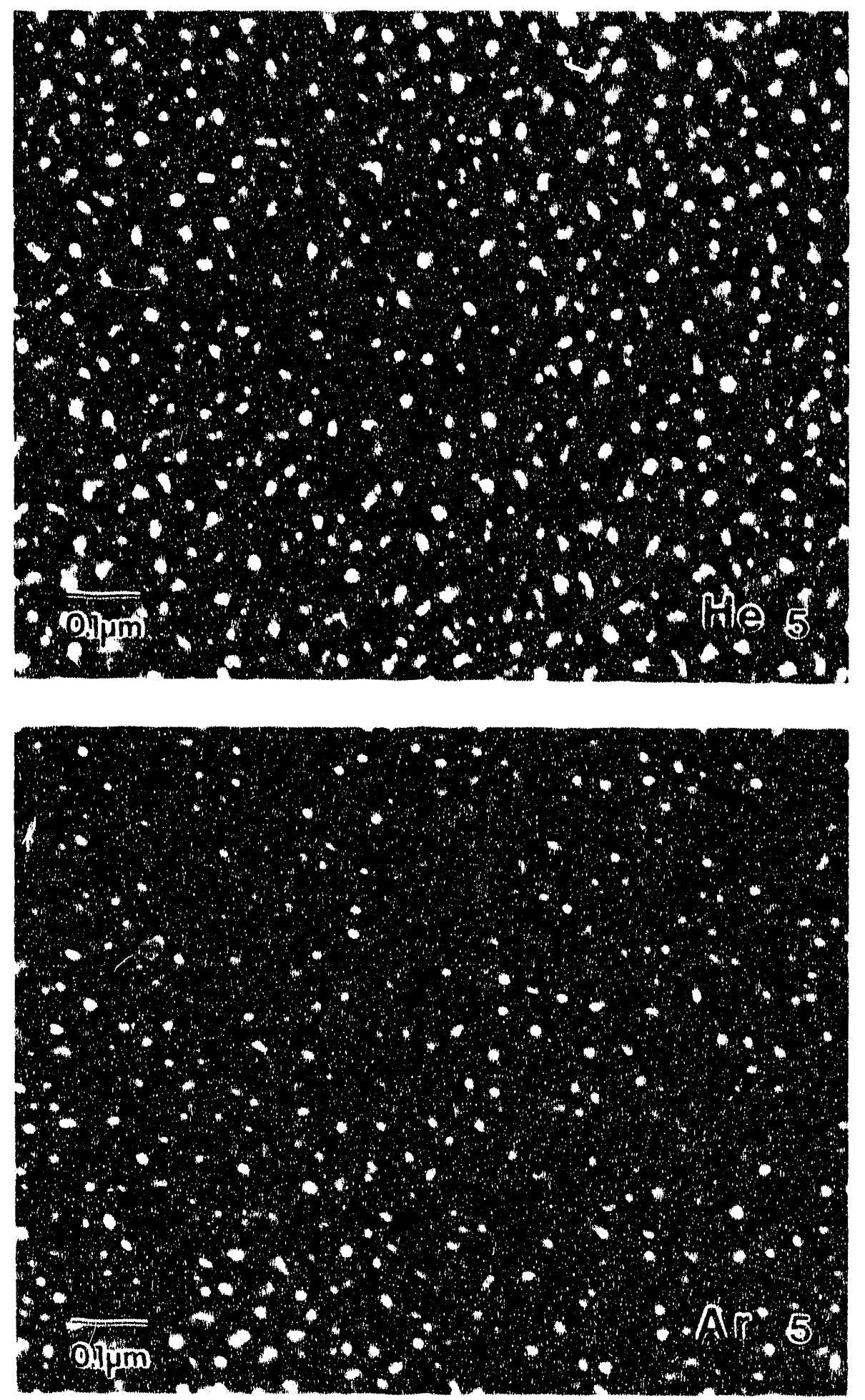

a 2

Fig. 4.6(a)

XBB 924-2490 

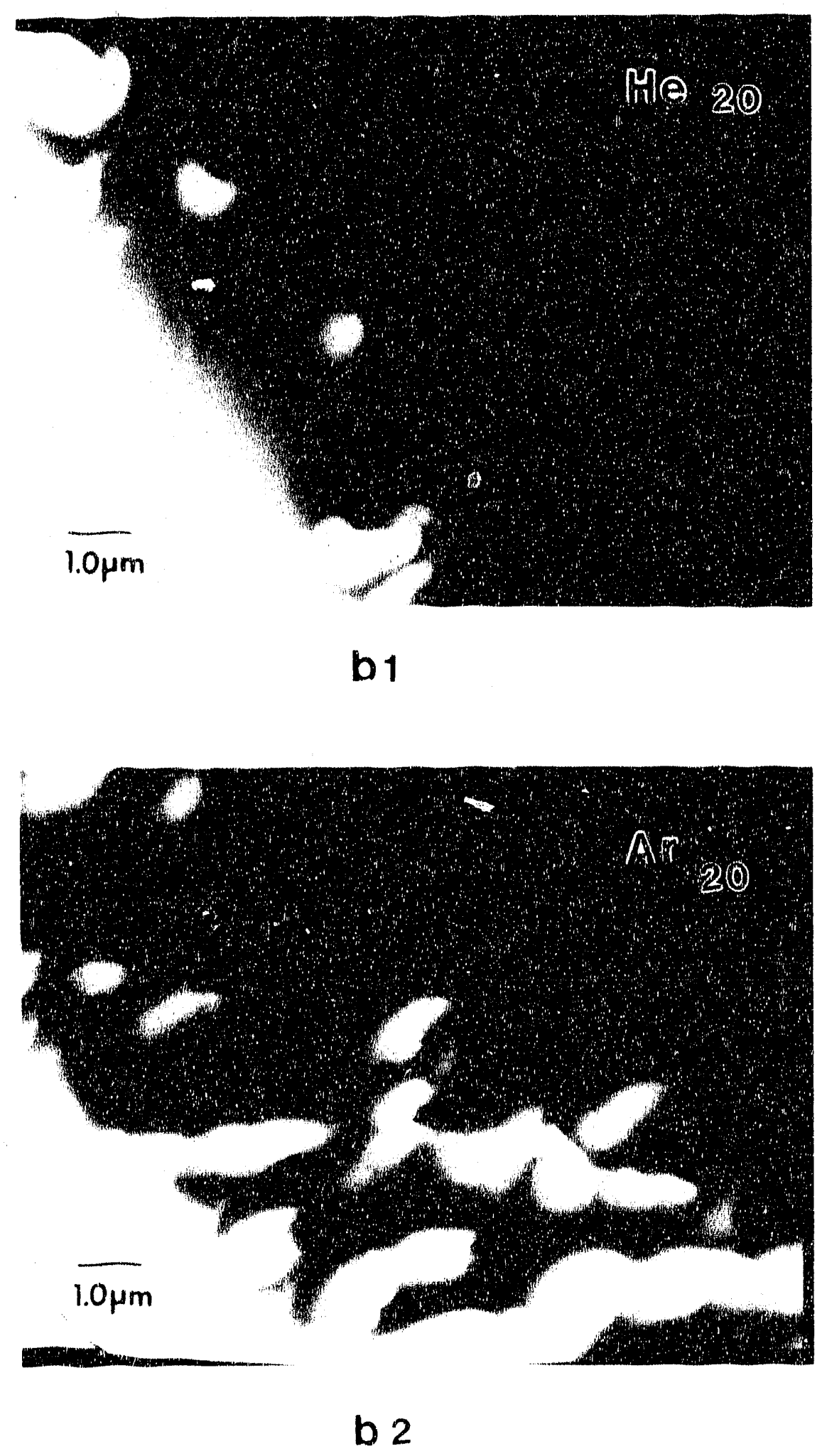

Fig. $4.6(\mathrm{~b})$

XBB 924-2489 

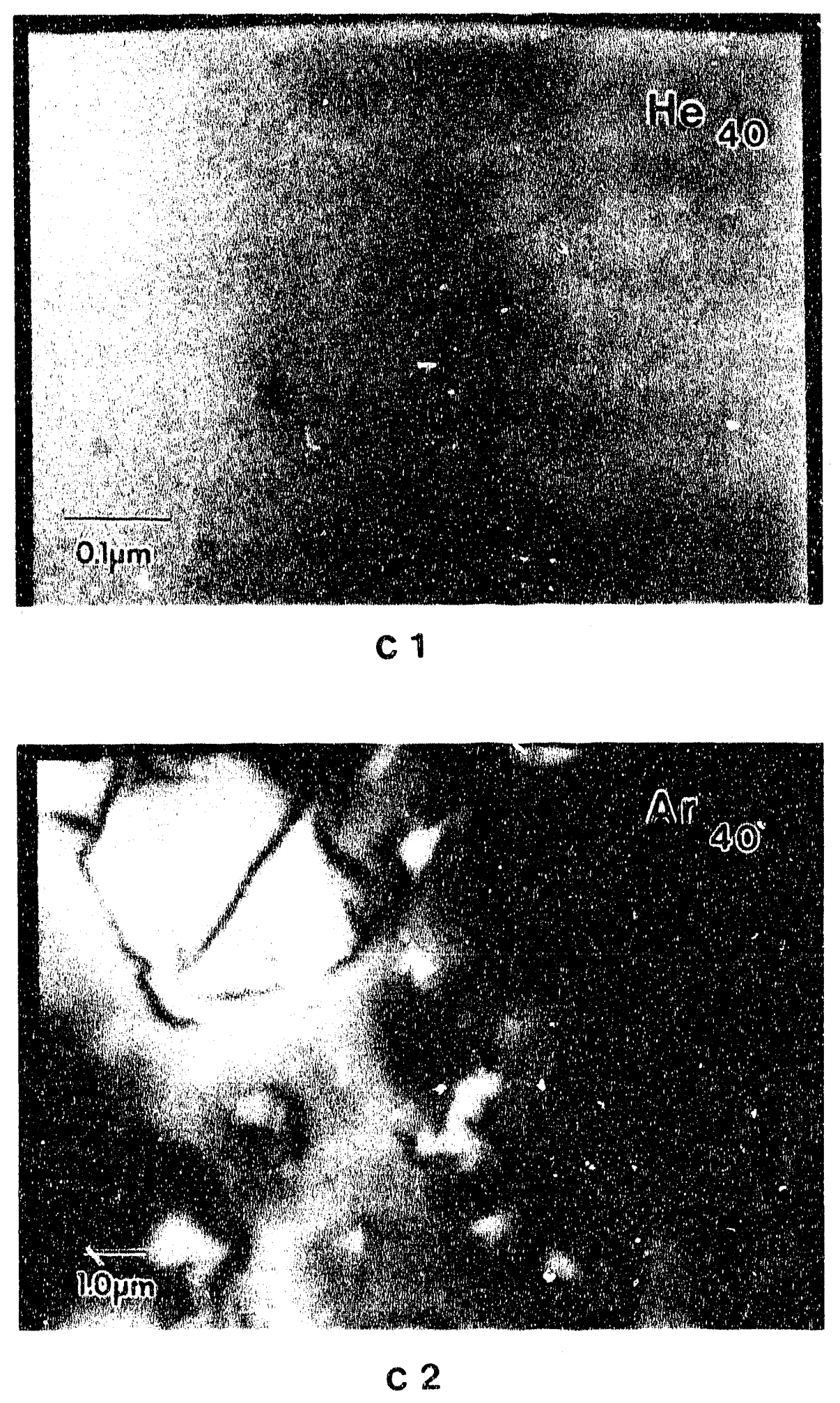

Fig. $4.6(c)$

XBB 924-2488 

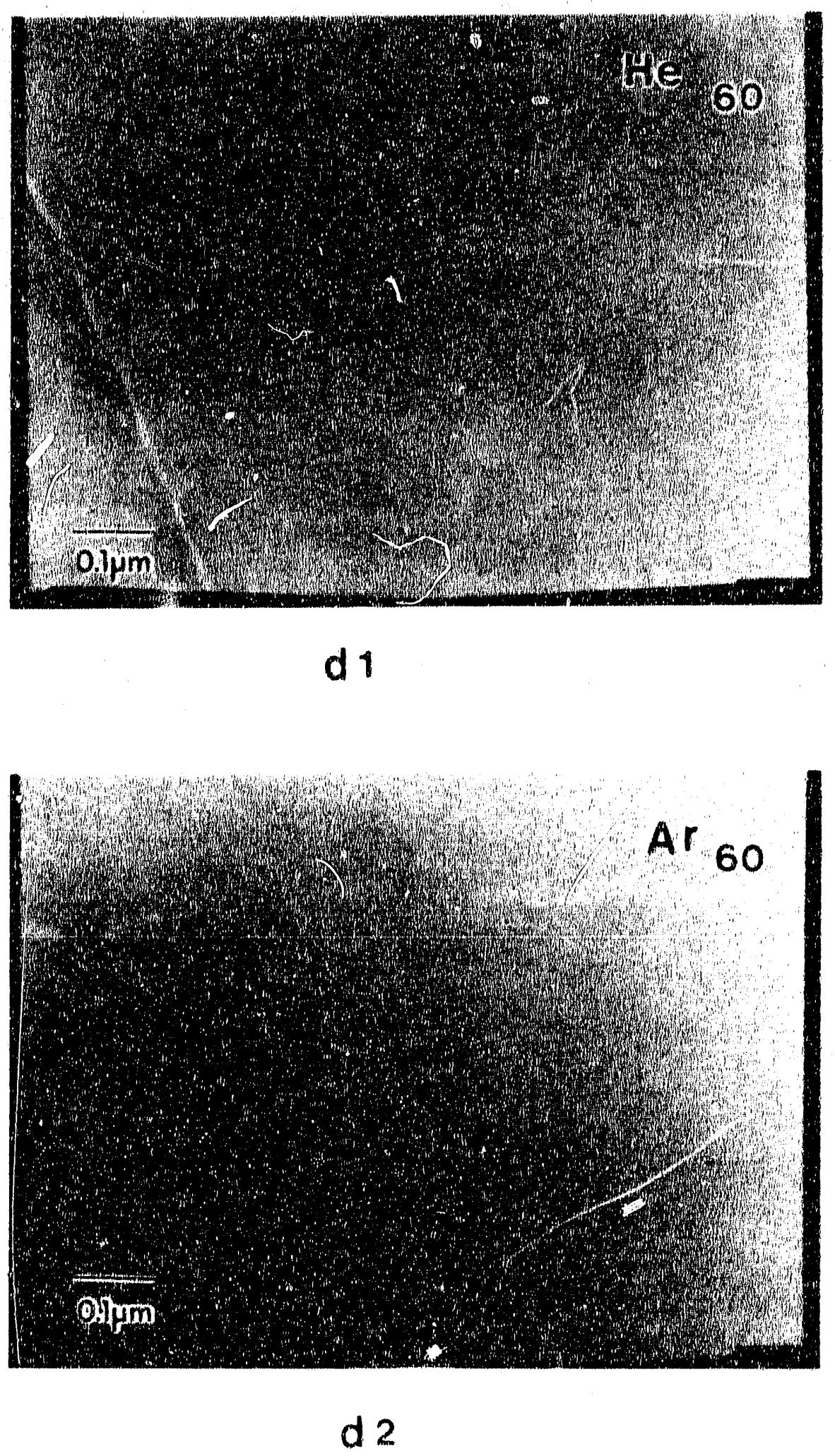

Fig. $4.6(d)$

XBB $924-2487$ 
Figure 4.6(b). This phenomenon is consistent with the prediction in Chapter 2 The pores do not have preference for breaking at the zig-zag point and the theoretical value for the most unstable breakup wavelength is infinite, the after-breakup pores are expected to be large. Also, the distance between two pores is so short that two after-breakup pores can merge together to form a bigger one. As discussed by Coble ${ }^{30}$, the large pores grow at the expense of their smaller neighbors. Therefore, it is not surprising to see such large pores. (2) The wet He environment provides a little bit faster densification rate than the wet Ar environment does (see 40-minute desification results as shown in Figure 4.6(c)), (3) There is no limiting density observed for OPS densification in a wet environment, i.e. OPS can be densified to zero porosity (see 60-minute densification results as shown in Figure 4.6(d)).

The trapped gas problem during OPS densification is not as significant as that in the alumina sintering case ${ }^{30}$, e.g., no limiting density observed for the OPS densification. This can be rationalized by the open structure of silica. Therefore, most of the gases have resonably high permeability in silica, ie., less trapped gas effect.

\subsection{Nitridation of Oxidized Porous Silicon}

Nitridation OPS to form silicon oxynitride $\left(\mathrm{SiO}_{x} \mathrm{~N}_{y}\right)$ is another way to enhance the OPS resistance to the HF solution. Recently, silicon oxynitride has received much atrention $42-45,47,48,5-64$ because of its unique dielectric, chemical, and thermal properties. Compared with silicon dioxide, silicon oxynitride has higher dielectric constant and dielectric breakdown strength, and provides a better impurity diffusion barrier, chemical, and oxidation resistance. So it has been proposed to be a more reliable gate insulator than conventional thermal oxide, e.g., in the scalingudown of MOS devices. The silicon oxynitride can be formed by the thermal nitridation of silicon or silicon dioxide in nitrogen $\left(\mathrm{N}_{2}\right)$ or ammonia $\left(\mathrm{NH}_{3}\right)$. It is easier to control the formation 
of silicon oxynitride by the nitridation of silicon dioxide than that of silicon. 42 In contrast to in ammonia, the nitridation process in nitrogen needs higher process temperature and prolonged process time, which are not acceptable in the IC industry. ${ }^{43}$ The nitridation of silicon in nitrous oxide $\left(\mathrm{N}_{2} \mathrm{O}\right)$ can also form silicon oxynitride for thin gate insulator ${ }^{44}$, but the amount of nitiogen incorporation is low. Therefore, most of the effort in the present study focuses on the nitridation of silicon dioxide in an ammonia gas. Pantano 45 used the SOIGASMIX computer program, developed by Eriksson ${ }^{46}$, to calculate the high temperature thermodynamic equilibria in the Si-O-N-H system and proposed that the $\mathrm{Si}_{2} \mathrm{~N}_{2} \mathrm{O}$ is the thermorilynamic equilibrium product when silica is nitridized in ammonia at $1000^{\circ} \mathrm{C}$. The nitridation of the silicon dioxide proceeds via the replacement of oxygen atom on the silica tetrahedral by nitrogen atom, which then is coondinated by three silicon atoms. The nitrogen concentration is not uniform but U-shape across the silicon oxynitride film with a high nitrogen concentration at the surface (up to 40\%) and the $\mathrm{SiO}_{x} \mathrm{~N}_{y} / \mathrm{Si}$ interface. The silicon oxynitride etching rate in a HF solution decreases with increasing nitrogen content. Therefore, the etching rate is not uniform across a film. For example, Ito 47 found that the etching rate in solution of $\mathrm{NH}_{4} \mathrm{~F}: \mathrm{HF}=10: 1$ was as low ws that of silicon nitride at the surface of the film and about one-third that of the thermally grown $\mathrm{SiO}_{2}$ in the central part of the film. To ovencome this uniformity problem, Brow48 nitridized microporous silicon dioxide thin film, prepared by using sol/gel technology, in ammonia to form silicon oxynitride. Because of its initial interconrected microporasity, the porous film rapidly incorporates a high concentration of nitrogen and transforms into a compositionally uniform silicon oxynitride film 45,48 . According to its very fine pore structure, OPS should also be easily nitridized by ammonia to form silicon oxynitride with uniform nitrogen distribution. To avoid the heat treatment effect, a rapid thermal witridation (RTN) was employed to incorporate nitrogen into OPS. The etching rates in a buffered $\mathrm{HF}$ solution $\left(\mathrm{NH}_{4} \mathrm{~F}: \mathrm{HF}=10: 1\right)$ was measured to examine the effect of RTN. 
The ESCA (electron spectroscopy for chemical analysis) was used to analyze the composition of the nitridized OPS film.

\subsection{Experiments: Nitridation of Oxidized Porous Silicon}

P-type, (100) oriented silicon wafers with resistivity $0.02-0.005$ ohmi-cm were used to study the nitrogen incorporation effect on the chemical durability of OPS. The electrolyte for the PS formation was a solution with $20 \% \mathrm{HF}, 20 \% \mathrm{H}_{2} \mathrm{O}$, and $60 \% \mathrm{C}_{2} \mathrm{H}_{5} \mathrm{OH}$. The current density was $50 \mathrm{n}: \mathrm{A} / \mathrm{cm}^{2}$. The anodization time was 1 minutes to form an approximately $1 \mu \mathrm{m}$ thick PS layer. To avoid heat treatment effects, a two-step oxidation was used. The PS was preoxidized in dry oxygen at $300^{\circ} \mathrm{C}$ for 1 hour to stabilize the microstricture of porous silicon, then oxidized in wet oxygen at $800^{\circ} \mathrm{C}$ (oxygen bubbled through $85^{\circ} \mathrm{C} \mathrm{DI}$ water) for 1 -hour.

(1) Etching rate measurements:

One OKS/Si wafer was brokein into four piec:s (named A, B, C, and D). Sample A was untreated. Sample B was densified in dry He 1 hour at $1100^{\circ} \mathrm{C}$. Sample C was densified in wet $\mathrm{He}\left(\mathrm{He}\right.$ bubbled through $85^{\circ} \mathrm{C} \mathrm{DI}$ water) 2 hours at $1100^{\circ} \mathrm{C}$. Sample D was R'TN in ammonia gas for 8 minutes at $1000^{\circ} \mathrm{C}$. The standard photolithography method as described in Chapter 2 was employed to only allow certain area to be exposed to the etching solution (buffered HF solution; $\mathrm{NH}_{4} \mathrm{~F}: \mathrm{HF}=10: 1$ ). After the protective photoresist was removed, the etching step was measured by using a Tencor, Alphastep 200 Profiler. Then the etching rate was obtained by dividing the step height by the etching time.

(2) Film composition measurement:

The composition of the R'TN sample (i.e, sample C) was analyzed by using ESCA 
4.7 Results and Discussion: Nitridation of Oxidized Porous Silicon

The average etching rates for sample A, B, C, and D are about 8.9, 5.2, 0.1 , and 1.7 $\mu \mathrm{m} / \mathrm{min}$, respectively as shown in Figure 4.7. The nitridation process really can enhance the chemical resistance of OPS. The result of the 8-minute, $1000^{\circ} \mathrm{C}$ RTN treatment in ammonia (sample $D$ ) is better than that of $i$-hour densification treatment in dry He at $1100^{\circ} \mathrm{C}$ (sample B). It can be rationalized by examining the microstructure of saraple B as shown in Figure 4.4(b), which shows that there is very little densification effect after that treatment. The ESCA result is shown in Figure 4.8. It shows that there are certain amount of nitrogen atoms incorporated into the OFS but the composition is still not a stoichiometric one $\left(\mathrm{Si}_{2} \mathrm{~N}_{2} \mathrm{O}\right)$. Figure 4.9 shows that the nitridized OPS is still porous, which provides an explanation why the etching rate of the nitridized OPS is higher than that of smple $\mathrm{C}$ (densified in wet He 2 hours at $1100^{\circ} \mathrm{C}$ ), which is expected to be fully densified.

The ammonia treatment really provides an alternative to enhance the OPS resistance to the HF solution. Also, nitridation of OPS is a promising method to form thick and compositionally uniform silicon oxynitride. The nitridation process for PS to form NPS (nitridized porous silicon) might have another potcntial application: microfilter. The processing flow chart is shown in Figure 4.10. Compared with OPS, NPS is much more inert to most of the silicon etchants (e.g., $\mathrm{HF}+\mathrm{HNO}_{3}+\mathrm{CH}_{3} \mathrm{COOH}$ ). It makes the silicon etching step can stop itself when the silicon substrate is totally removed. The microfilter process described here is superior to Parker's proposed process ${ }^{49}$, in which the PS is removed from the silicon substrate before attached with a supporting porous substrate. The mechanical strength of PS thin film after silicon substrate is removed, is a big problem in Parker's proposed process. Also, the nitridized PS and OPS might find the same application in the microsensor as the PS 65 and OPS $^{66}$ do. 


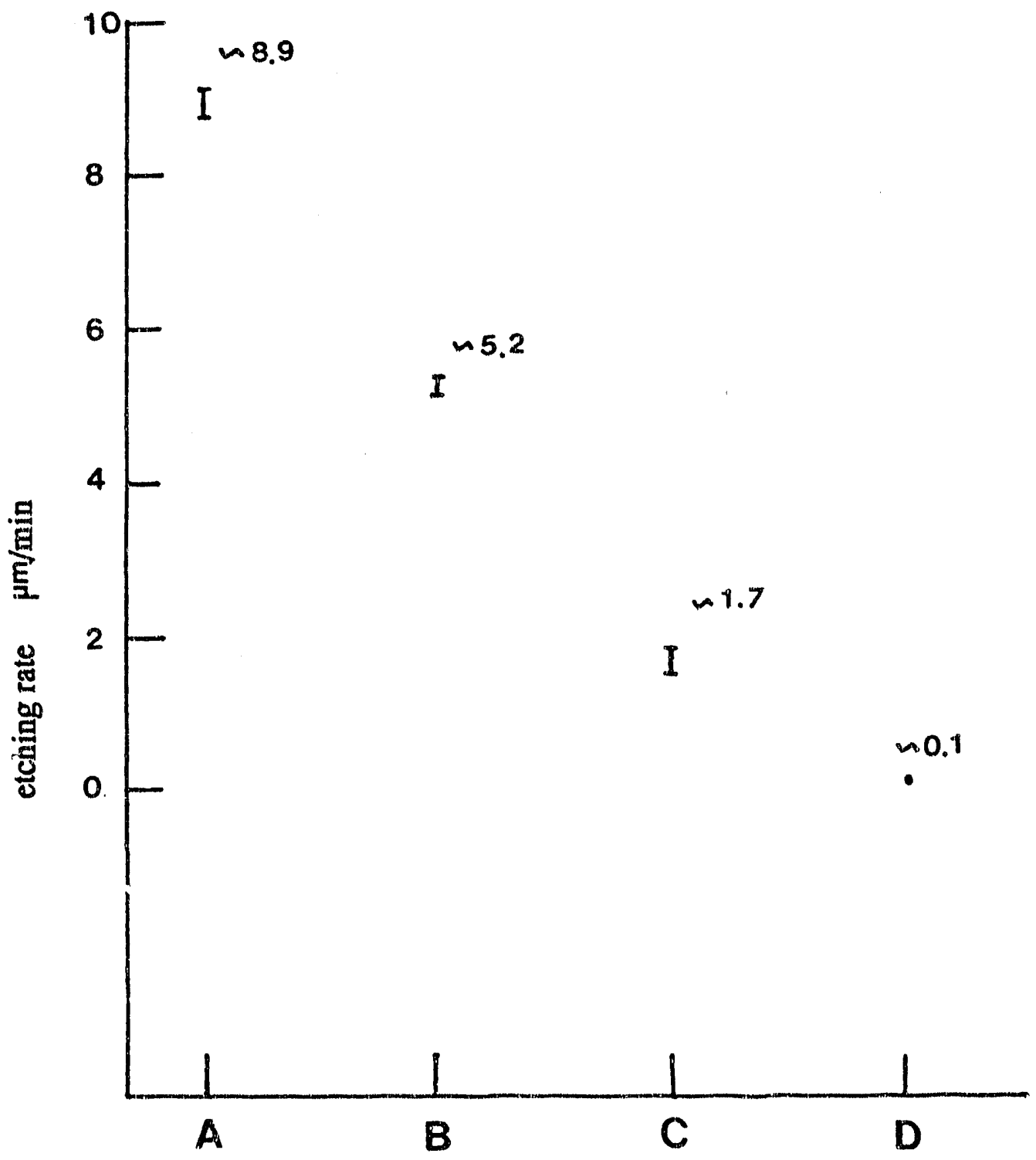

sample

Figure 4.7 Etching rates in a buffered HF solution of OPSs after different processes 


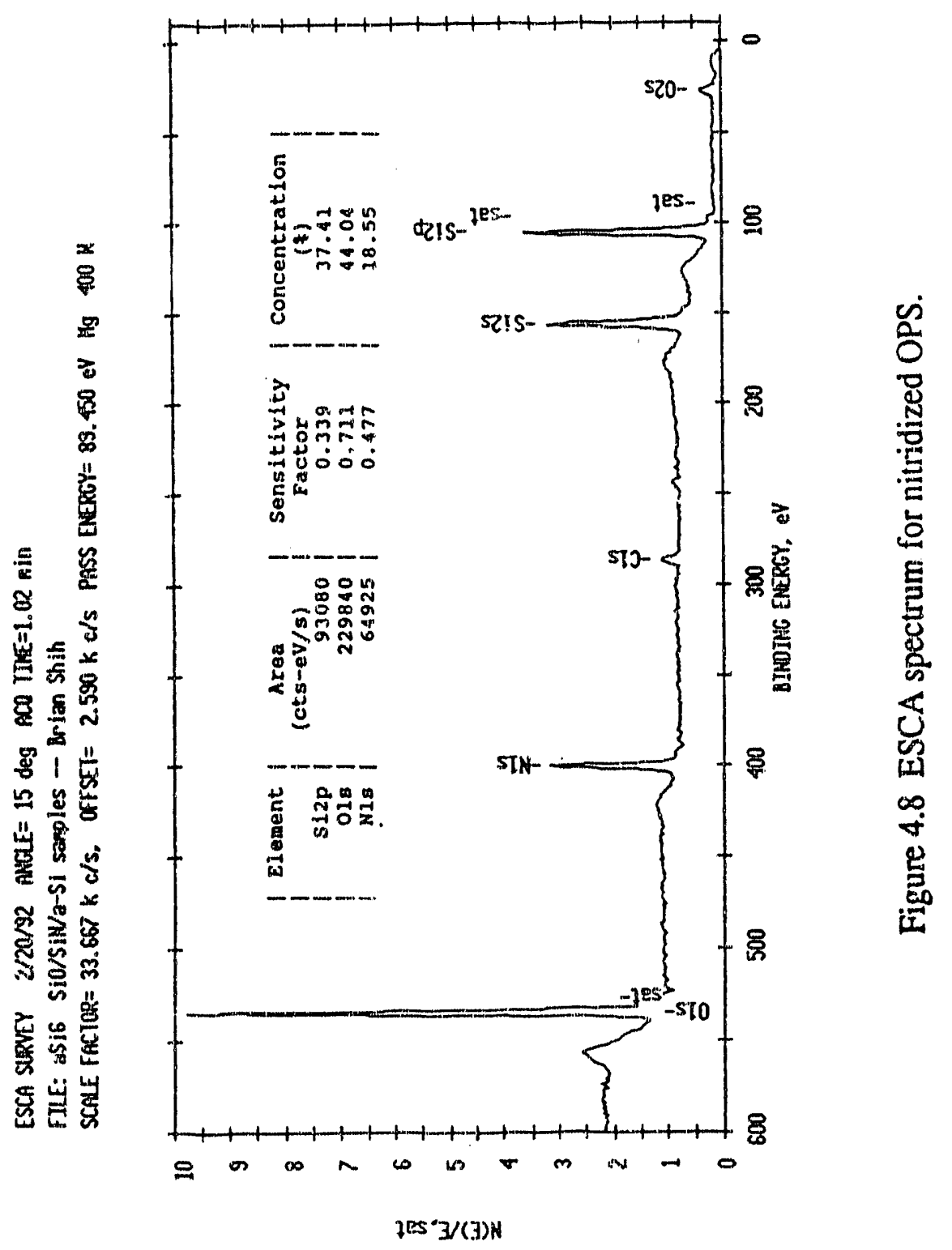




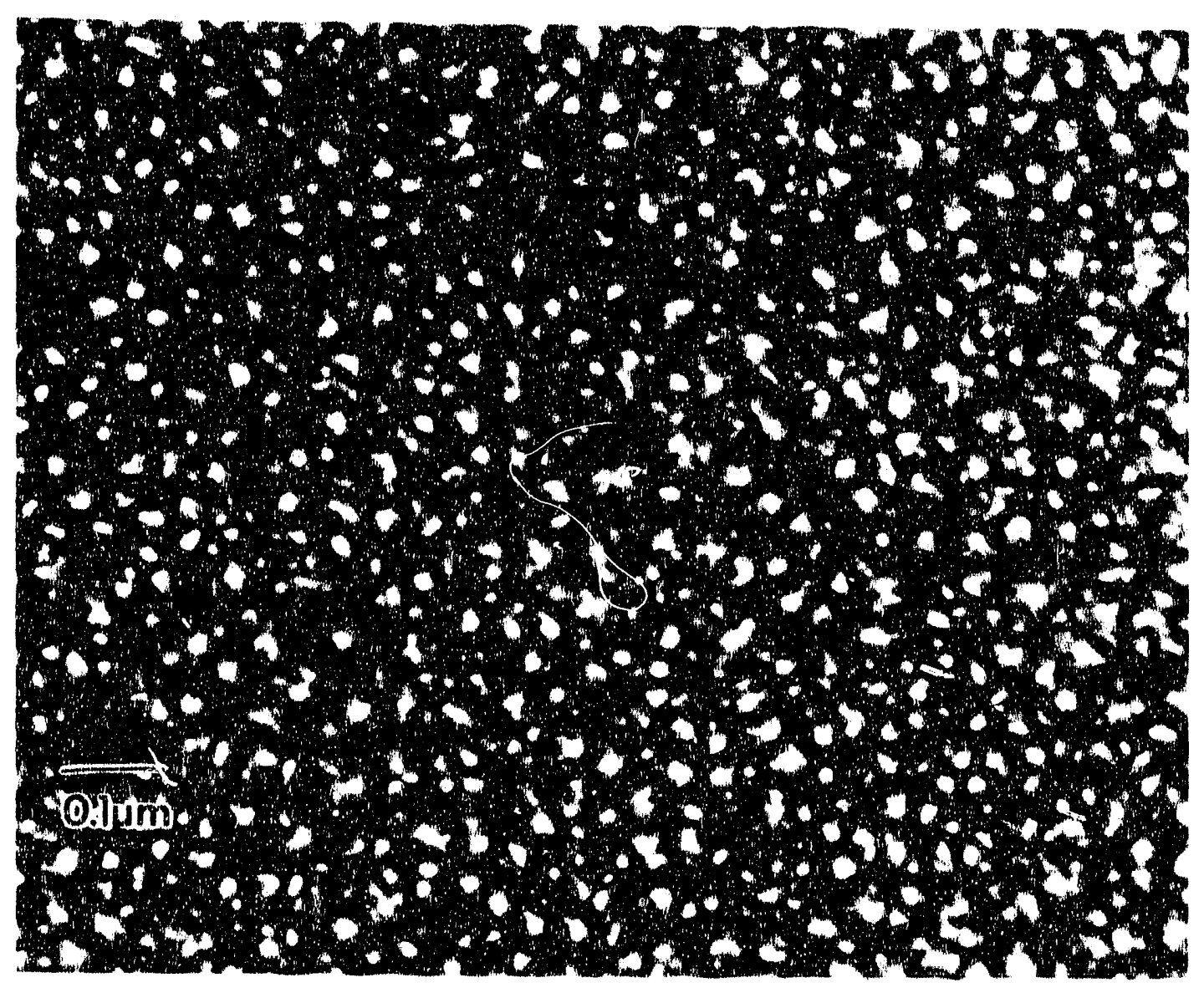

Fig. 4.9 


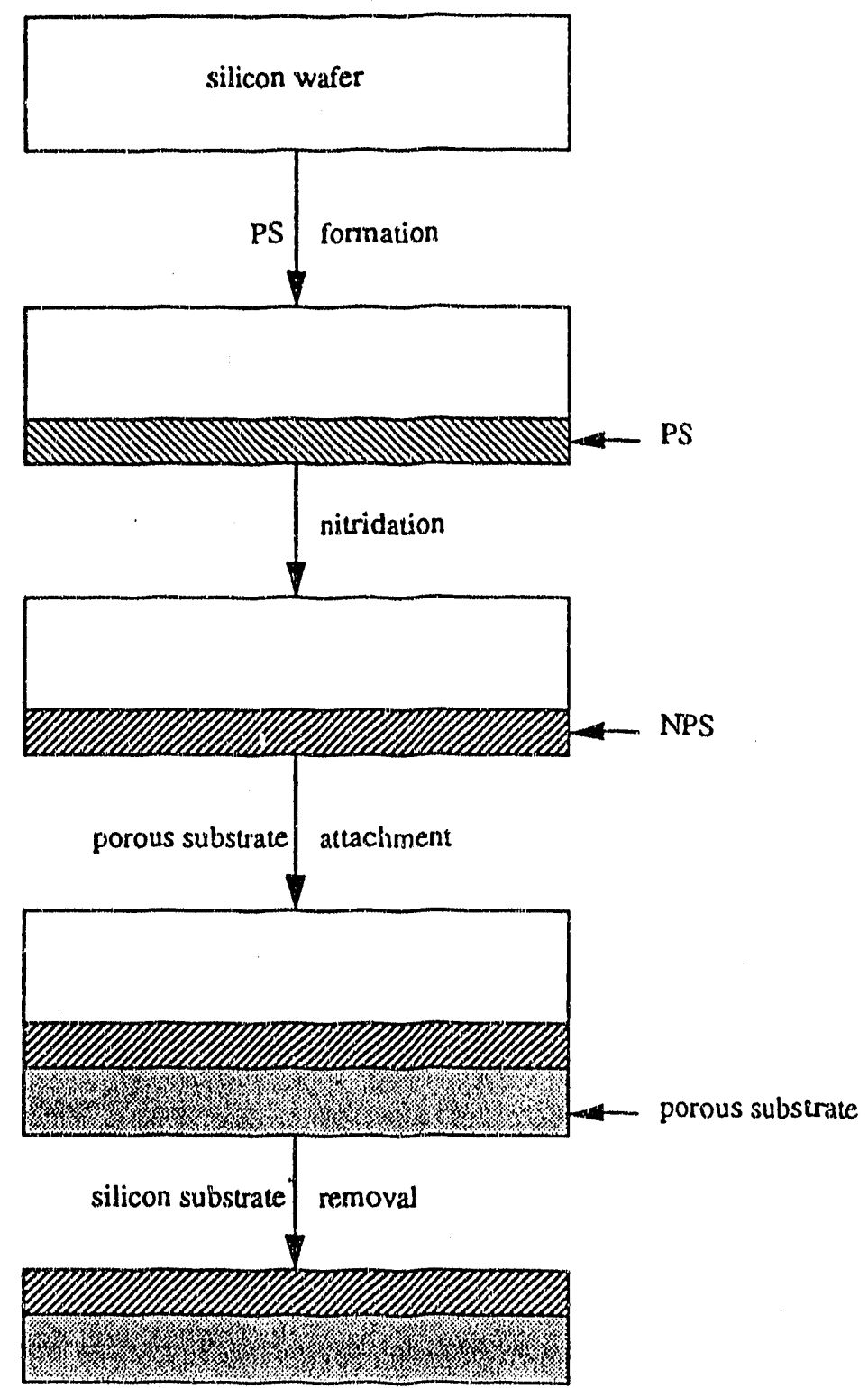

Microfilter

Figure 4.10 Fabrication process for microfilter. 


\subsection{Summary}

The densification rate of OPS can be greatly enhanced in wet ambient. Although the trapped gas effect during OPS densification is not as significant as that during alumina densification, wet He (He bubbled through water) is still recommended as the densification ambient. Since the potential application of OPS is not for the gate oxide or capacitor oxide, the wet ambient process is acceptable. Nitridation of OPS in ammonia really enhances OPS's resistance to the HF solution but the nitridized OPS is still porous. 
References

1. R. Herino, G. Bomchil, K. Barla, and C. Bertrand, J. Electrochem. Soc., 134, 1994 (1987).

2. J. J. Yon, K. Barla, R. Herino, and G. Bomchil, J. Appl. Phys., 62, 1042 (1987).

3. N. Cheung, EECS243 Classnote, UC Berkeley, 1991 Spring.

4. F. Goodenough, Electronic Design, Nov., 88 (1984).

5. R. Bruckner, J. of Non-cryst. Solids, 5, 123 (1970).

6. W. D. Kingery, H. K. Bowen, and D. R. Uhlmann, Introduction to Ceramics, JohnWiley \& Sons, Inc., New York 1976.

7. W. D. Kingery and M. Berg, J. of Applied Physics, 26, 1205 (1955).

8. L. Zagar, Science of Sintering, 7, 35 (1975).

9. M. M. Ristic and M. J. Dragojevic-Nesic, J. of Mater. Sci. Lett., 6, 1091 (1987).

10. T. J. Clark and J. S. Reed, J. Am. Ceram. Soc., 69, 837 (1986).

11. T. H. Elmer, Am. Ceram. Bull, 62, 513 (1983).

12. G. C.Kuczynski, J. Appl. Phys., 20, 1160 (1949).

13. G. W. Scherer, J. Am. Ceram. Soc。, 60, 236 (1977).

14. G. W. Scherer and D.L. Bachman, J. Am. Ceram. Soc., 60, 239 (1977).

15. G. W. Scherer, J. Am. Ceram. Soc., 60, 243 (1977).

16. T. Y. Tseng and J. J. Yu, J. of Mat. Sci, 21, 3615 (1986).

17. J. Frankel, J. of Phys. U.S.S.R., 9, 385 (1945).

18. C. Herring, J. Appl. Phys., 21301 (1950).

19. G. W. Scherer and T. Garino, J. Am. Cera. Soc., 68, 216 (1985).

20. J. K. Mackenzie and R. Shuttleworth, Proc. Phys. Soc., LXII, 12-B, 833 (1949).

21. R. B. Bird, W. E. Stewart, and E. N. Lightfoot, Transport Phenomena, p 80, John Wiley \& Sons, Inc, 1978.

22. N. M. Parikh, J. Am. Ceram. Soc., 41, 18 (1958). 
23. R. Bruckner, J. of Non-cryst. Solid, 5, 177 (1970).

24. G. Hetherington, K.H. Jack, and J.C. Kennedy, Phys. and Chem. of Glasses , 5, 130 (1964).

25. G. Hetherington and K.H. Jack, Phys. and Chem. of Glasses, 3, 129 (1962).

26. V. K. Leko, E. V. Meshcheryakova, H. K. Gusakova, and P. B. Lebedeva, Steklo i Keramika, 8, 16 (1973). translated by Scientific-Research Institute of Silica Glass, p528 (1974).

27. R. W. Douglas and I. O. Isard, J. Soc. Glass Tech., 35, 206 (1951).

28. R. F. Vines, J. O. Semmelman, P. W. Lee, and F. P. Fonvielle, Jr., J. Am. Ceram. Soc., 41, 304 (1958).

29. A. J. Shaler, Metals Trans., 185, 796 (1949).

30. R. L. Coble, J. Am. Ceram. Soc.,45, 123 (1962).

31. S. Satoh, K. Susa, I. Matsuyama, and T. Suganuma, J. Non-C.yst. Solids, 55, 455 (1983).

32. S. Satoh, K. Susa, I. Matsuyama, and T. Suganurna, J. Am. Ceram. Soc., 68, 399 (1985).

33. O.-H. Kwon and G. L. Messing, J. Am. Ceram. Soc., 72, 1011 (1989).

34. Y.-K. Paek, K.-Y. Eun, and S.-J. L. Kang, J. Am. Ceram. Soc., 71 C-380 (1988).

35. R. H. Doremus, J. of Phys. Chèm., 80, 1773 (1976).

36. R. H. Doremus, Glass Science, Wiley, New York, 1973.

37. P. Balk, The Si-SiO 2 system, Elsevier, New York 1988.

38. O. V. Mazurin, M. V. Streltsina, and T. P. Shvaiko-Shvaikovskaya, Handbook of Glass Data, Elsevier, New York, 1983.

39. J. E. Shelby, Treatise on Mat. Sci. and Tech., 17, 1 (1979).

40. T. Bell, G. Hetherington, and K. H. Jack, Phys. and Chem. of Glass, 3, 141 (1962). 
41. C. G. Granqvist and O. Hunderi, Physical Review B, 16, 3513 (1977).

42. Y. Hayafuji and K. Kajiwara, J of Electrochem. Soc., 129, 2102 (1982).

43. F. H. P. M. Habraken, A. E. T. Kuiper, Y. Tamminga, and J. B. Theeten, J. Appl. Phys., 53, 6996 (1982).

44. H. Hwang, W. Ting, B. Maiti, D-L Kwong, and J. Lee, Appl. Phys. Lett., 57, 1010 (1990).

45. C. G. Pantano, R.K Brow, and L.A. Carman, Oxynitride Thin Filims from Sol-Gel Process, Sol-Gel Technology, Edited by I.C. Klein, Noyes Publication, NJ, 1988.

46. G. Eriksson, Chemica Scripta, 8, 100 (1975).

47. T. Ito, T. Nozaki, and H. Ishikawa, J. Electrochem. Soc., 127, 2053 (1980).

48. R. K. Brow and C. G. Pantano, J. Am. Ceram. Soc., 70, 9 (1987).

49. D. L. Parker and K. R. Hall, US Patent, patent \# 4801380.

50. D. E. Aspnes and J. B. Theeten, Physical Review B, 20, 3292 (1979).

51. G. A. Niklasson, C. G. Granqvist, and O. Hunderi, Applied Optics, 20, 26 (1981).

52. T. Hori and H. Iwasaki, IEDM, 26.2, 570 (1987).

53. K. Ando, A. Ishitani, and K. Hamano, Appl. Phys. Lett., 59, 1081 (1991).

54. E. G. Lee, H. B. Im, and J. S. Roh, J. Am. Ceram. Soc., 74, 1563 (1991).

55. H. Wong and X. C. Cheng, J. Appl. Phys., 67, 7132 (1990).

56. J. A. Nemetz and R. E. Tressler, Solid State Tech., February, 79 (1983).

57. Q. A. Shams and W. D. Brown, J. Electrochem. Soc., 137, 1244 (1990).

58. R. P. Vasquez, M. H. Hecht, F. J. Grunthaner, and M.L. Naiman, Appl. Phys. Lett., 44, 969 (1984).

59. P. M. Glaser and C.G. Pantano, J. of Non-Cryst. Solids, 63, 209 (1984).

60. T. Ito, H. Arakawa, T. Nozaki, and H. Ishikawa, Electrochem. Soc., 127, 2248 (1980).

61. S. I. Raider, R. A. Gdula, and J. R. Petrak, Appl. Phys. Lett., 27, 150 (1975). 
62. R. E. Loehman, Treatise on Mat. Sci and Tech., 26, 119 (1985).

63. S. K. Ray, S. Das, C. K Maiti, S. K. Lahiri, and N. B. Chakrabati, Appl. Phys. Lett., 58, 2476 (1991).

64. S. S. Wong and W. G. Oldham, IEEE EDL, EDL-5, 175 (1984).

65. R. C. Anderson, R. S. Muller, and C. W. Tobias, Sensors and Actuators, A21.23, 835 (1990).

66. M. J. Kelley, T. R. Guilinger, D. W. Peterson, M. R. Tuck, a dn J. N. Sweet, J. of Metals, 43-6, 4 (1991).

67. T. Drury and J.P. Roberts, Physics and Chemistry of Glasses, 4-3, 79 (1963).

68. F. J. Norton, Nature (London), 171, 701 (1961). 
Chapter 5 Suppression of Oxidation-Induced Stacking Faults by Using Porous Siticon as a Gettering Center in Silicon Wafers

\subsection{Intraduction}

Oxidation-induced stacking faults (OISF) in silicon wafers have deleterious effects on device performance ${ }^{1-6}$. They increase the leakage current of a $p-n$ junction diode 7 , degrade the storage time of a MOS (Metal Oxide Semiconductor) devices, and enhance the possibility of localized microplasma breakdown' 9 . There have been many efforts ${ }^{10-30}$ to understand the formation mechanism of OISF defects to eliminate them because the thermal oxidation of silicon is common in the silicon integrated circuit (IC) processing. The OISF lies along $\{111\}$ planes and is bounded by Frank partial dislocations with a Burgers vector of $1 / 3<111>13,14$. The nature of the OISF is extrinsic, i.e., formed by the precipitation of supersaturated silicon interstitials. These silicon interstitials are generated during silicon oxidation. Two mechanisms have been proposed to explain the generation of supersaturated silicon interstitials during silicon oxidation: (1) The oxidation of silicon at the $\mathrm{SiSiO}_{2}$ interface is incomplete. These unoxidized silicon atoms enter the silicon substrate and occupy the interstitial positions ${ }^{26}$. (2) There is a volume stress associated with silicon oxidation since the volume increases $125 \%$ when silicon transforms into silicon dioxide. The injection of silicon interstitials into the silicon substrate can relieve this volume stress 30,31 . Both models predict the ratio of oxidized silicon atoms to the supersaturated silicon inierstitials is from 1,000 to 10,000,26,32 The formation of OISF is a heterogeneous nucleation process ${ }^{26}$. The possible nucleation centers are impurity precipitates,26,33,34(e.g., transition metals, oxygen, and carbon), mechanical damage at the surface ${ }^{15}$, Swirl defects 35 , and HF acid attacked areas 24 . Therefore, two logical ways to suppress the formation of OISF are: eliminating 
heterogeneous nucleation sites and reducing the supersaturated silicon interstitial concentration. The former one, especially eliminating metal impurity precipitates, has been studied ${ }^{91,99}$. Gettering ${ }^{37-121}$ is a technique to remove the metallic impurities from the device active area of a silicon wafer to a predetermined region. Removing the metal impurities from the device active area is very important for device performance and yield. Beside acting as nucleation.sites for the OISF, metallic impurities can also act as a generation/recombination center to decrease the minority carrier lifetime. They also can decorate defects (e.8., stacking fault, dislocation) to increase the leakage current of a diode ${ }^{36}$. Basically, the gettering technique has two steps: (1) forming a gettering center outside the device active area in a silicon wafer and (2) annealing the silicon wafer at an elevated temperature (gettering temperature, $850-1100^{\circ} \mathrm{C}$ ) to let the impurities diffuse into (and then be trapped in) the gettering center. According to the origin of the gettering center, there are two kinds of gettering techniques: intrinsic and extrinsic. Intrinsic gettering 37.52 employs the defects (e.g., stacking fault and dislocation) created by the oxygen precipitates (intrinsic impurities) in the bulk region to getter the metallic impurities in the device active area. It consists of three temperature steps: (1) High temperature $\left(\sim 1150^{\circ} \mathrm{C}\right)$ step for the out-diffusion of oxygen in the device active area, (2) Low temperature $\left(-650^{\circ} \mathrm{C}\right)$ step for the nucleation of oxygen precipitate in the bulk region, and (3) High iemperature $\left(>1000^{\circ} \mathrm{C}\right)$ step for the growth of the oxygen precipitate $\left(\mathrm{SiO}_{\mathrm{x}}\right)$. The gettering of metallic impurities takes place during the cooling period of the last step. 53,54 Because of the complex precipitation kinetics of oxygen in a silicon wafer and the variation of the oxygen concentration in an as-received silicon wafer, there are still difficulties in introducing intrinsic gettering technique successfully in an IC production line. Also, it is necessary to determine experimentally the gettering efficiency to optimize the gettering process for a specific production line. 55 Moreover, there is always some residual oxygen 43,47 , which precipitates later, in the device active area after the out- 
diffusion of oxygen. These residual oxygen precipitates have adverse effect on the device performance 47 and make the intrinsic gettering technique unacceptable. A current trend is toward a low oxygen silicon wafer to minimize the risk of oxygen defect related failures. 56 Then, the extrinsic gettering technique becomes the only choice to remove the unwanted impurities from device active area when a low oxygen silicon wafer is used. In extrinsic gettering, the impurities are captured by a gettering center introduced externally, e.g., at the backside of the wafer. There are many ways to form extrinsic gettering centers:

(1) Damage: mechanical scratching 57-64, laser irradiation $62,64-68$, ion implatation $69-86$.

(2) Thin film deposition: polysilicon62,87-89, nitride89-93, germanium, 94 metal95-98.

(3) Phosphorus diffusion $62,63,69,99-106$.

(4) Ge-doped Si epitaxy.107-109

(5) Low-current corona discharge. 110

(6) Chlorine oxidation. $111-116$

(7) Sacrificial oxidation 63,117-121

There is a different optimum gettering temperature, which gives the highest gettering efficiency, for each technique. These gettering techniques are additive, ${ }^{62,123}$ e.g., when two or more gettering techniques are applied together, the gettering result obtained is better than that of each one applied alone. 62,89 Generally, the polysilicon thin film technique and phosphors diffusion technique are more efficient than others.62,122 There are four models to explain the extrinsic gettering mechanism:

(1) Extended defect model 122,135: This model is one of the most wildly accepted and applicable. The defects, such as dislocations, stacking faults, surfaces, and grain boundaries, can act as sinks for impurities. This defect-impurity interaction can relieve the strain energy, so it is energetically favorable. 
(2) Enhanced metal-solid solubility model: This model works quite well in the phosphorus diffusion gettering case. The metal solubility is enhanced through a Fermi level effect, ${ }^{101}$ ion pairing reaction, ${ }^{101}$ and compound formation. ${ }^{142}$ The solubility of impurities (e.g., $\mathrm{Au}, \mathrm{Cu})$ in silicon is changed by the presence of charged phosphorus, which has an effect on the Fermi level. As the Fermi level is altered, the concentration of the charged impurity is changed. The concentration of the neutral impurity is independent on the Fermi level. So the total concentration of the impurity depends on the Fermi level, Le., the concentration of phosphorus. Also, the Au-P and Cu-P ion-pairing reactions to relieve the strain and the formation of $\mathrm{Au}_{2} \mathrm{P}_{3}$ and $\mathrm{Cu}_{2} \mathrm{P}_{3}$ compounds, increase the impurity solubility in the high phosphorus concentration area. This solubility enhancement is used to explain how the impurities are gettered in a high $\mathrm{P}$ concentration area.

(3) Interstitial silicon model 143 : This model only works in the phosphorus diffusion case too. Phosphorus diffusion causes an emission of silicon interstitials. These silicon interstitials kick out impurities (e.g., Au, $\mathrm{Pt}$ ) from low-mobility substitutional positions into high-mobility interstitial positions. Then the impurities can easily diffuse to the surface and are trapped there.

(4) Segregation model122: This model is quite general. It states that the driving force for gettering is due to the segregation coefficient being greater than one between the gettering area and the device active area. So the impurities prefer to segregate in the gettering area. The whole gettering process consists of release, diffusion, and capture of impurities as shown in Figure 5.1. Although this model can not provide any practical information about gettering, it outlines a conceptual picture about what gettering is.

This study proposes a novel extrinsic gettering technique to reduce the impurity concentration and then suppress the formation of the OISF by forming a patch of porous silicon on the backside of a silicon wafer. 


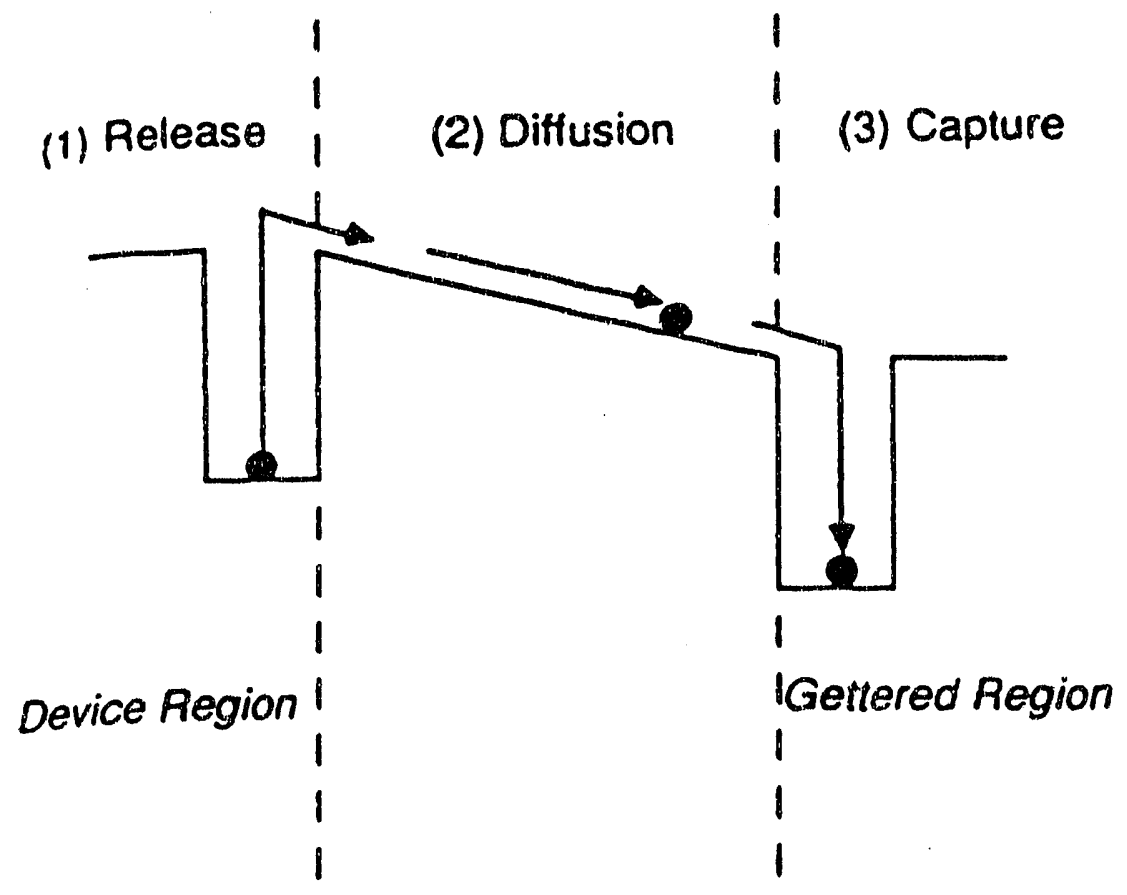

Figure 5.1 Conceptual gettering process of segregation model. ${ }^{122}$ 


\subsection{Experimental Procedures}

Four sets of experiments were used to show the ability and the possible mechanism of the suppression of OISF by using PS as an extrinsic gettering center.

I. Experiment I was employed to show the suppression of OISF by using PS. The flow chart of experiment I is shown in Figure 5.2:

1. Formation of PS on the backside of silicon wafer: A boron-doped, (100) oriented, 0.02-0.005 ohm-cm, and Czochralski method grown silicon wafer was anodized in an $\mathrm{HF}$ solution $\left(25 \% \mathrm{HF}, 50 \% \mathrm{C}_{2} \mathrm{H}_{5} \mathrm{OH}, 25 \% \mathrm{H}_{2} \mathrm{O}\right)$ at a current density of $60 \mathrm{~mA} / \mathrm{cm}^{2}$. An approxmately $3-\mu \mathrm{m}$ thick PS was formed on the backside of the $525-\mu \mathrm{m}$ thick silicon wafer.

2. Preoxidation gettering: Extrinsic gettering procedure was applied by annealing the sample in a nitrogen environment at $1000^{\circ} \mathrm{C}$ for 1 hour.

3. Wet oxidation to form OISF: The annealed sample was oxidized in wet oxygen (oxygen bubbled through $95^{\circ} \mathrm{C}$ deionized water) at $1000^{\circ} \mathrm{C}$ for 2 hours to grow OISF.

4. Removal of oxide and Secco etching ${ }^{141}$ to reveal the OISF: The oxidized sample was dipped into a $10 \%$ HF solution for 10 minutes to remove the thermally grown silicon dio. iste, then etched in the Secco etchant $\left(49 \mathrm{wt} \% \mathrm{HF}: 0.1 \mathrm{M} \mathrm{K}_{2} \mathrm{Cr}_{2} \mathrm{O}_{7}=2: 1\right.$, by volurne) for 1 minute. The characterization tool was scanning electron microscope (SEM). The result is shown in Figure 5.3

II. Experiment II was used to examine the OPS/Si and PS/Si interfaces to understand why the PS getters impurities. The flow chart of experiment II is shown in Figure 5.4:

1. Formation of PS on the front side of silicon wafer: The other conditions were the same as those used in the experiment $L$ 


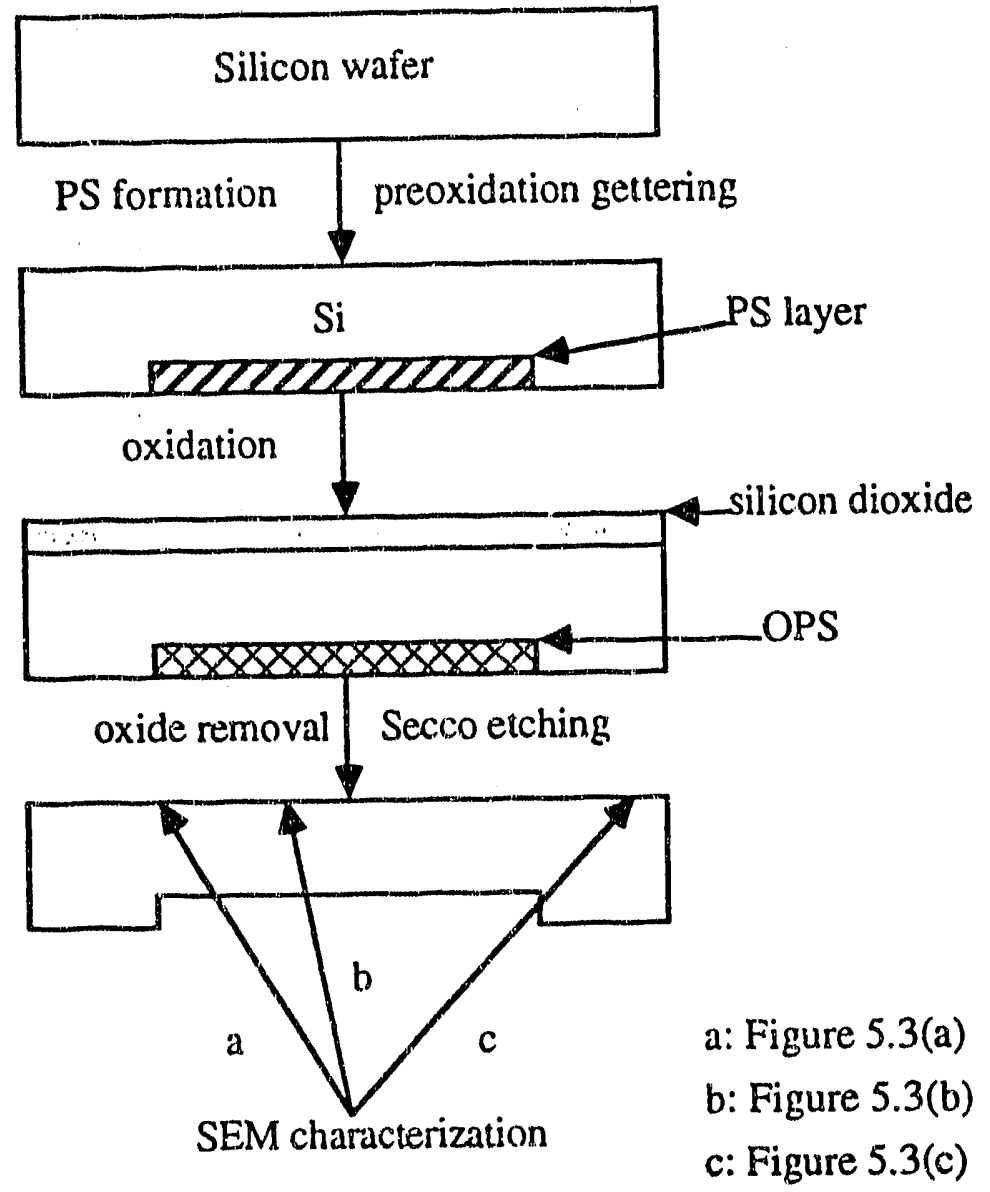

Figure 5.2 Experimental procedures of the suppression of OISF by using PS. 


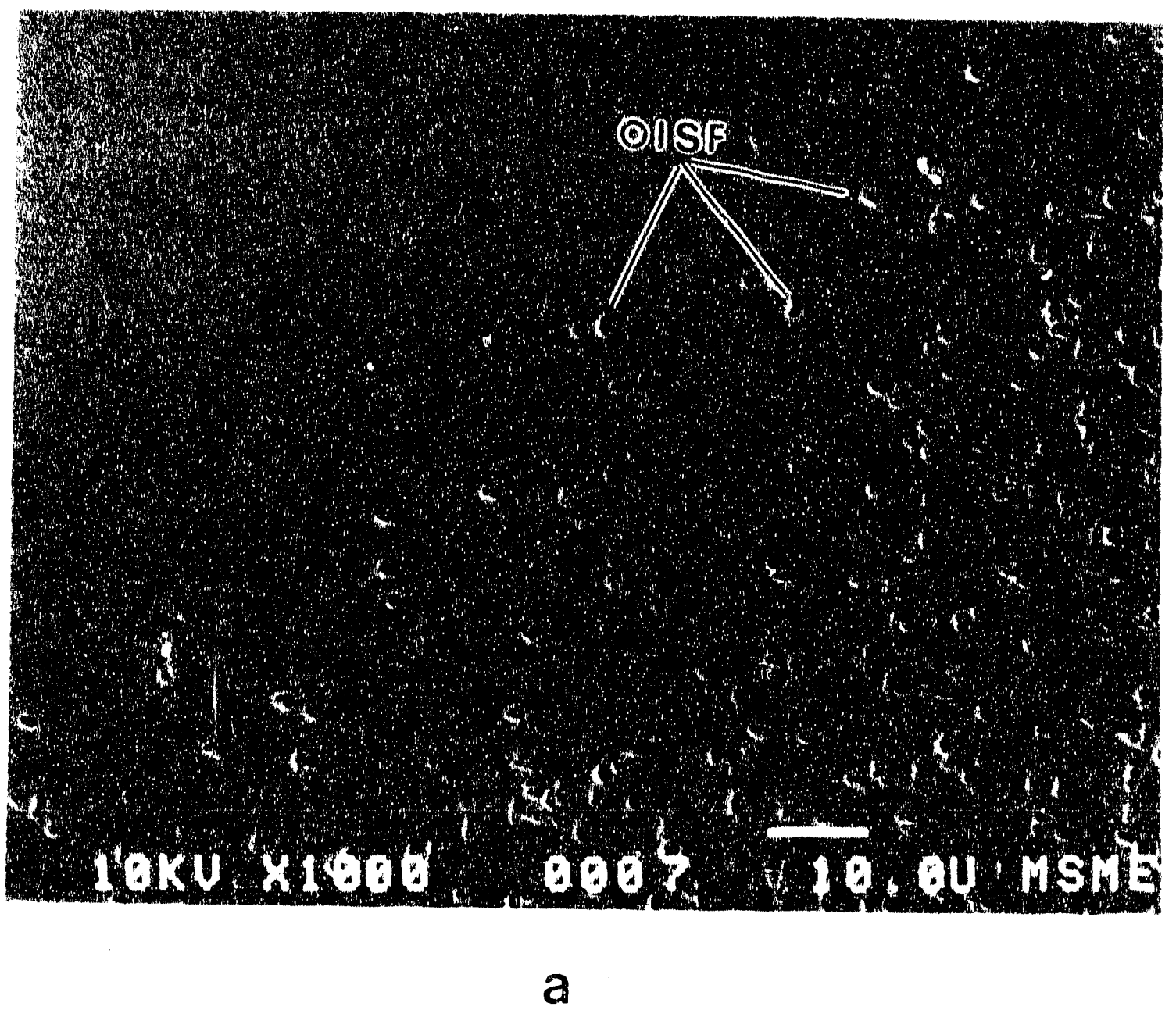

Fig. 5.3 


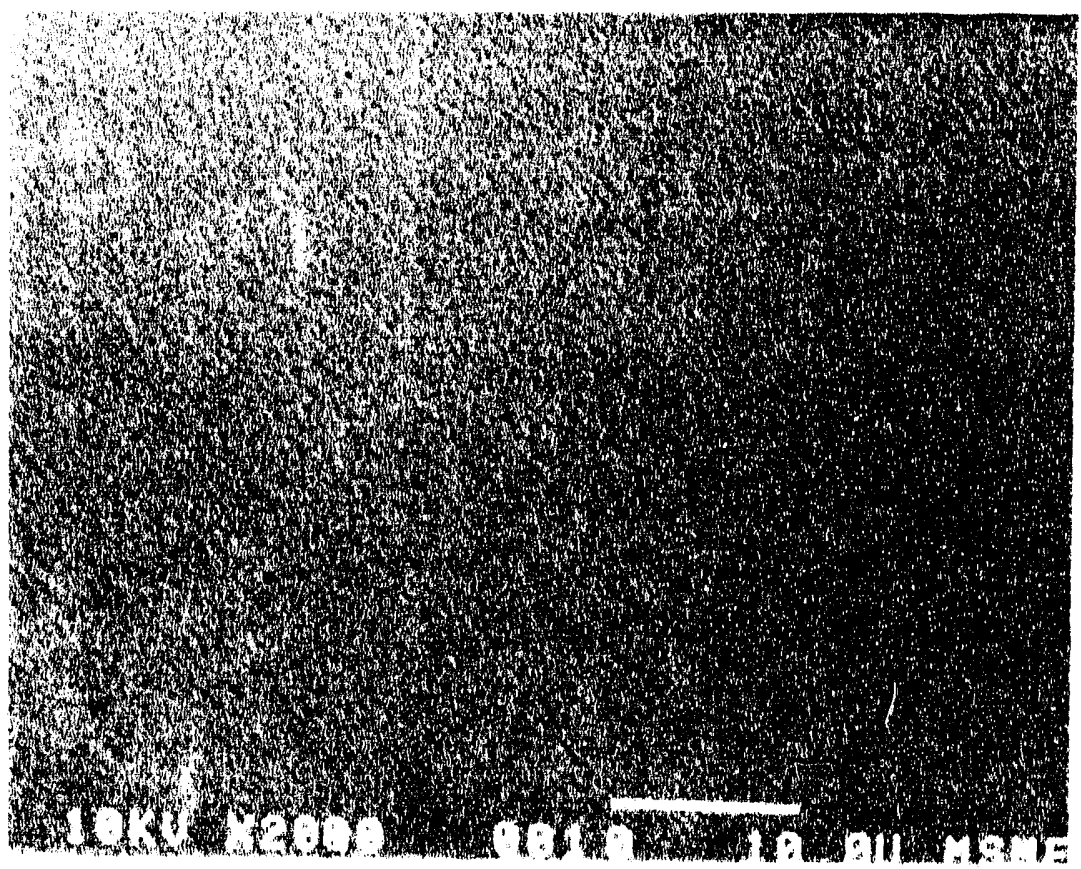

b

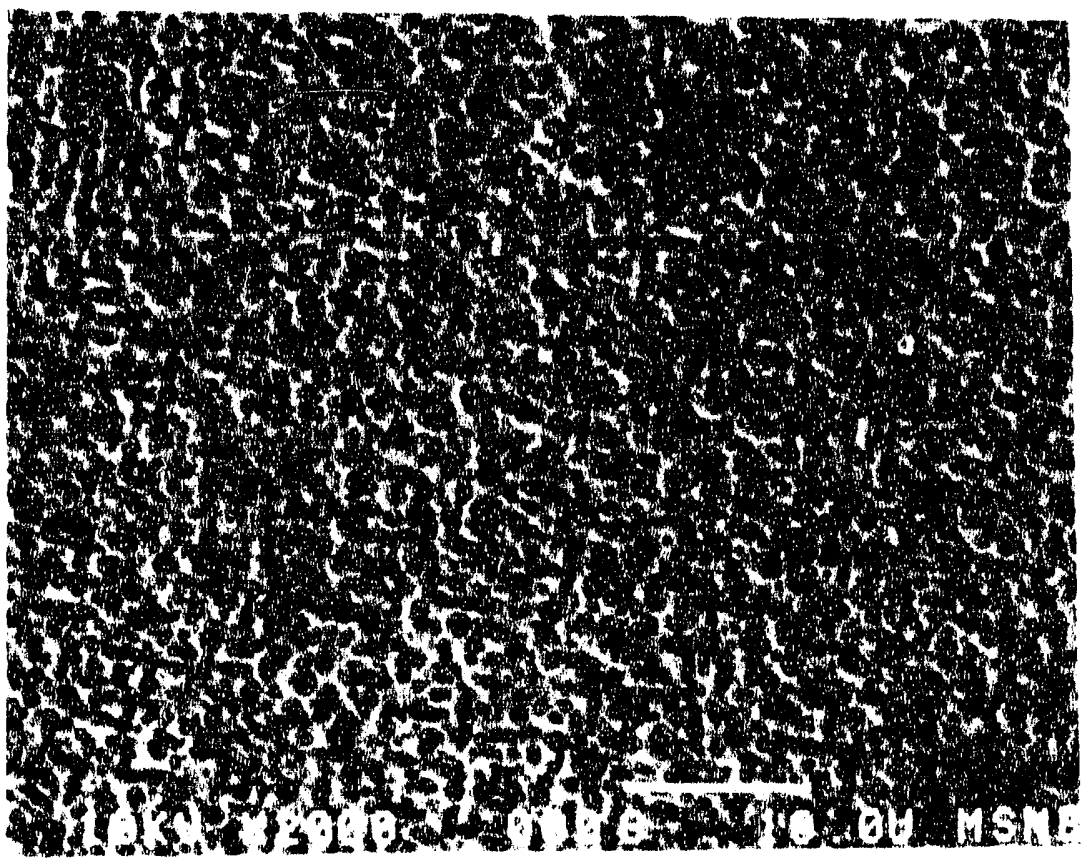

C

Fig. 5.3 cont.

XBB 924-2366 


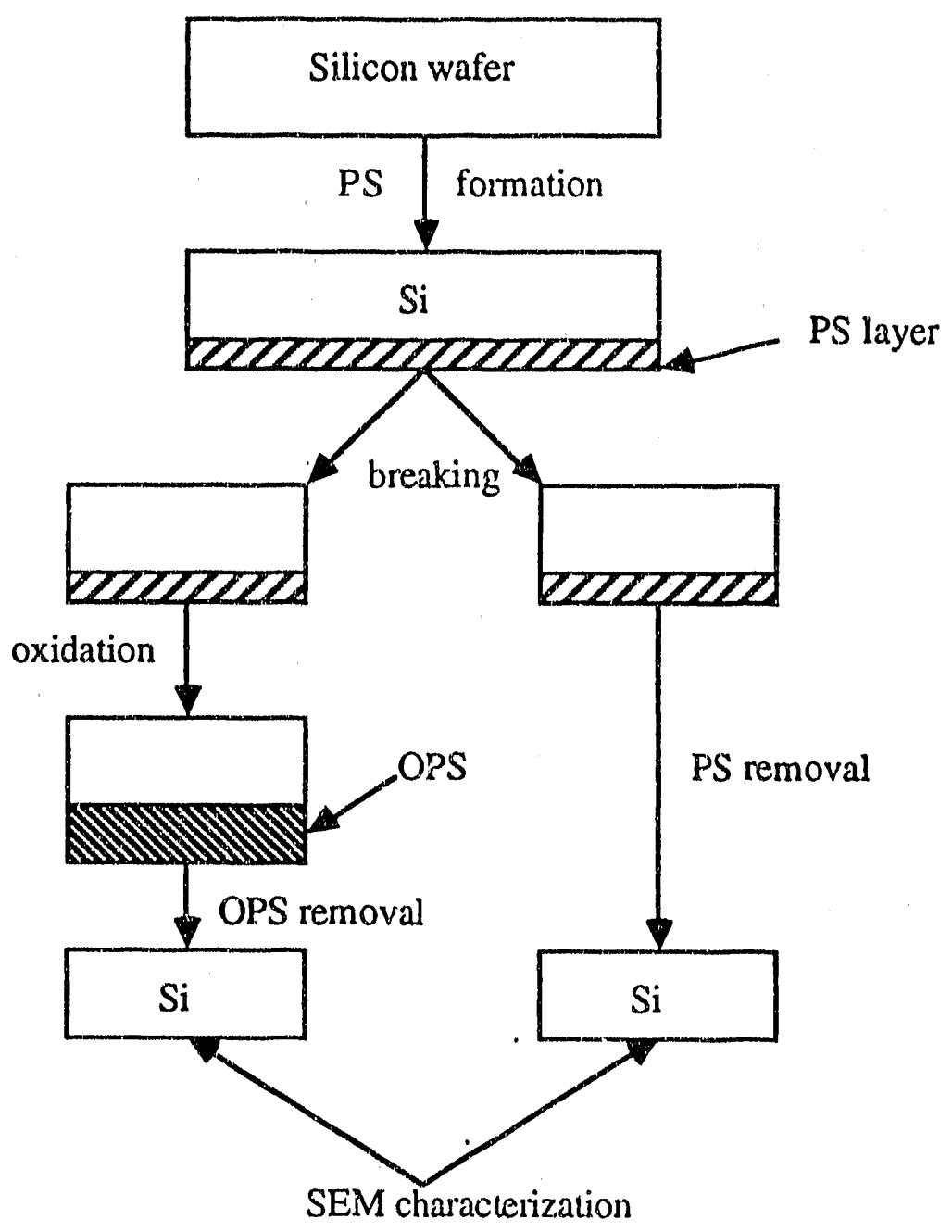

Figure 5.4 Experimental procedures to examine the PS/Si and OPS/Si interfaces 
2. Wet oxidation: One half of the sample was oxidized in dry oxygen at $300^{\circ} \mathrm{C}$ for 1 hour and then in wet oxygen (oxygen bubbled through $87^{\circ} \mathrm{C}$ deionized water) at $800^{\circ} \mathrm{C}$ for 1 hour. The other one was left unoxidized.

3. Removal of OPS and PS to examine the OPS/Si and PS/Si interfaces: The oxidized one was dipped into a $10 \% \mathrm{HF}$ solution for 1 hour to remove the OPS layer. The unoxidized one was dipped into a $0.1 \% \mathrm{KOH}$ solution for 1 hour to remove the PS layer.

4. Secco etching: The samples were etched in the Secco etchant for 2 minutes. SEM was used to examine the interfaces of Si/OPS and Si/PS. The results are shown in Figure 5.5 .

III. Experiment III was designed to understand that the role of PS was to getter metal impurities or silicon interstitials when the formation of OISF was suppressed. The flow chart of experiment III is shown in Figure 5.6:

1. Introducing impurity-Au into a silicon wafer: A $0.5 \mu \mathrm{m}$ thick gold film was sputtered onto the both sides of a boron-doped, (100) oriented, 0.02-0.005 ohm-cm, and Czochralski method grown silicon wafer. Then, the gold was driven into the silicon wafer at $1000^{\circ} \mathrm{C}$ in a nitrogen environment for 2 hours. The residual gold films were removed by dopping into an etchant solution $\left(\mathrm{HNO}_{3}: \mathrm{HCl}=1: 3\right)$ for 1 minute. The wafer was annealed at $900^{\circ} \mathrm{C}$ in a nitrogen environment for 2 hours to homogenize the gold distribution.

2. Formation of PS on the backside of silicon wafer: The Au-doped silicon wafer was anodized in an $\mathrm{HF}$ solution $\left(25 \% \mathrm{HF}, 50 \% \mathrm{C}_{2} \mathrm{H}_{5} \mathrm{OH}, 25 \% \mathrm{H}_{2} \mathrm{O}\right)$ at a current density of $60 \mathrm{~mA} / \mathrm{cm}^{2}$. An approxmately $6 \mu \mathrm{m}$ thick PS was formed on the backside of silicon wafer. 

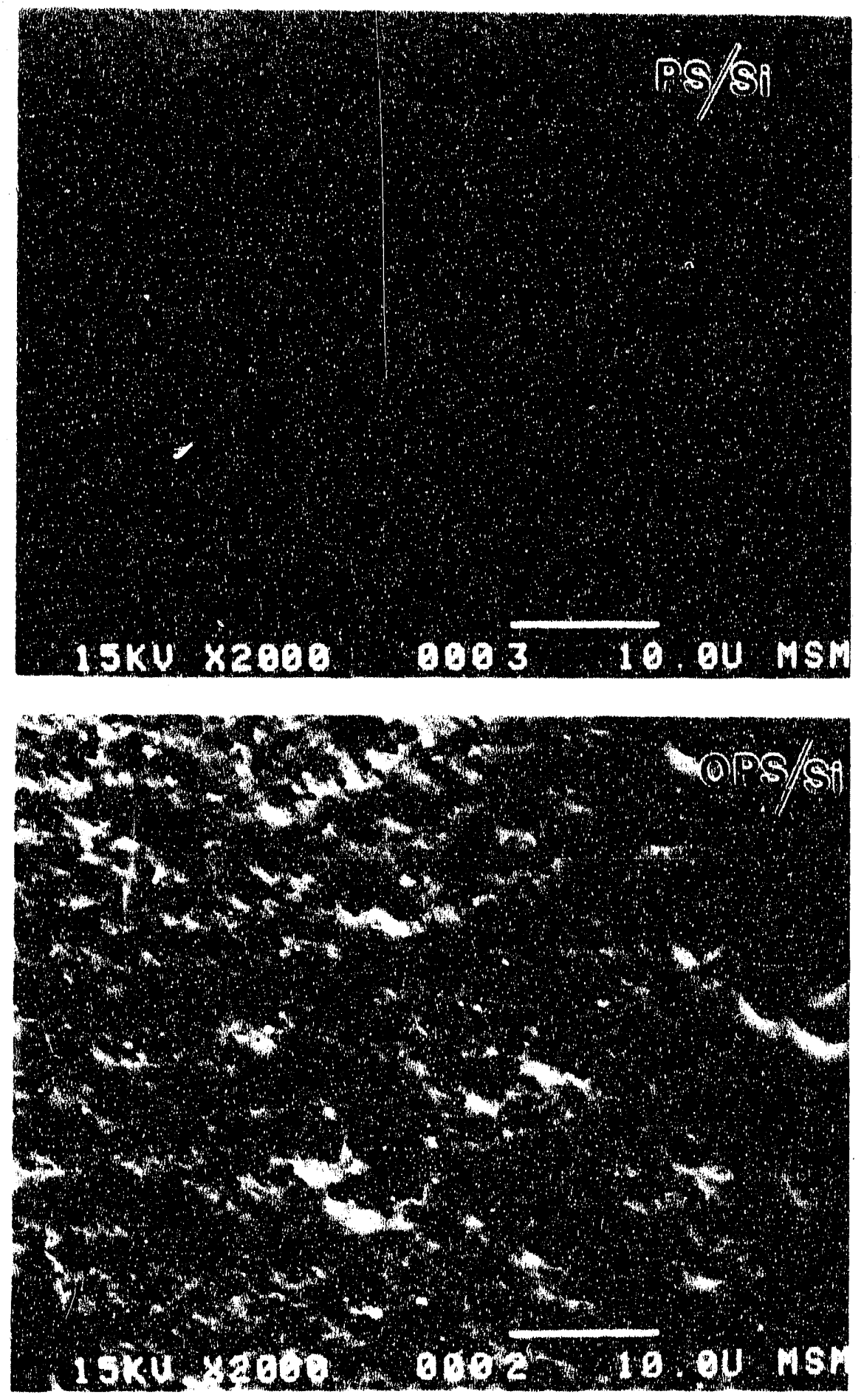

Fig. 5.5

XBB 924-2367 


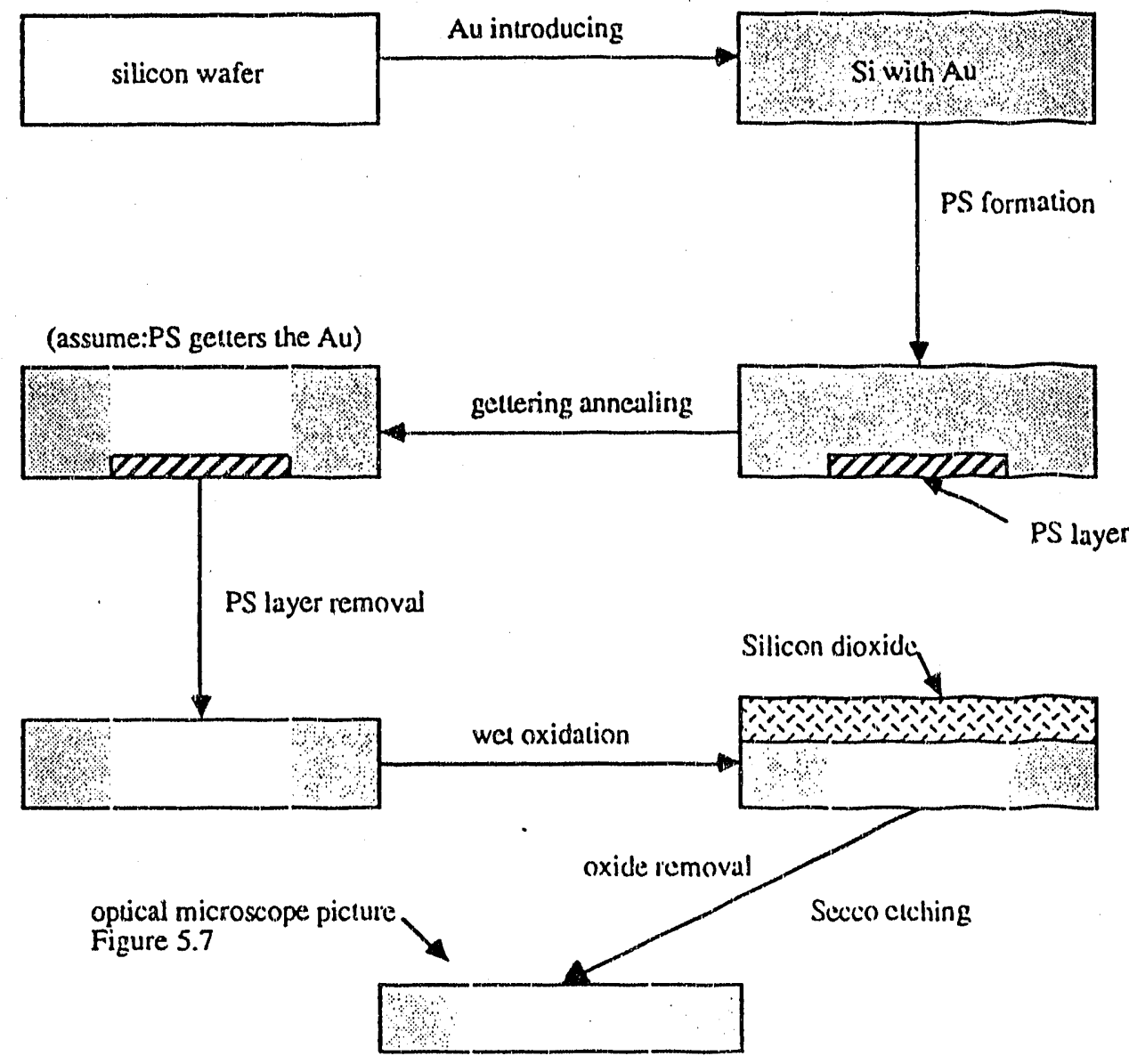

Figure 5.6 Experimental procedures to examine the role of PS 
3. Preoxidation gettering: Extrinsic gettering procedure was applied by annealing the sample in a nitrogen environment at $1000^{\circ} \mathrm{C}$ for 1 hour.

4. Removal of PS patch: The PS patch was removed by mechanical grinding and approximately $100 \mu \mathrm{m}$ thick silicon (with PS patch) was removed.

5. Wet oxidation to form OISF: The sample was oxidized in wet oxygen (oxygen bubbled through $95^{\circ} \mathrm{C}$ deionized water) at $1000^{\circ} \mathrm{C}$ for 100 minutes.

6. Removal of oxide and Secco etching to reveal the OISF: The oxidized sample was dipped into a $10 \% \mathrm{HF}$ solution for 10 minutes to remove the thermally grown silicon dioxide and then was etched in the Secco etchant for 1 minute. The characterization tool was an optical microscope. The result is shown in Figure 5.7.

IV. Experiment IV was a deep level transient spectroscopy (DLTS) study, which provided a direct evidence for PS's gettering ability. The flow chart of experiment IV is shown in Figure 5.8:

1. Introducing impurity-Au into silicon wafer: An approximately $0.1 \mu \mathrm{m}$ gold thin film was sputtered onto the both sides of a boron-doped, (100) oriented, $5-8 \mathrm{ohm}-\mathrm{cm}$, and Czochralski method grown silicon wafer. Then, the gold was driven into the silicon wafer at $900 \mathrm{C}$ in a nitrogen environment for 2.5 hour. The residual gold films were removed by dipping into an etchant solution $\left(\mathrm{HNO}_{3}: \mathrm{HCl}=1: 3\right)$ for 1 minute. Then, a silicon carbide paper (grid 1200, Excel Tech. Inc.) was used to rub (damage) the front side of silicon wafer to facilitate porous silicon formation.

2. Formation of PS on the backside of silicon wafer: The Au-dopped silicon wafer was anodized in an $\mathrm{HF}$ solution $\left(25 \% \mathrm{HF}, 50 \% \mathrm{C}_{2} \mathrm{H}_{5} \mathrm{OH}, 25 \% \mathrm{H}_{2} \mathrm{O}\right)$ at a current density of $10 \mathrm{~mA} / \mathrm{cm}^{2}$. The anodization time was 10 minutes.

3. Preoxidation gettering: Extrinsic gettering procedure was applied by annealing the sample in an argon environment at $900^{\circ} \mathrm{C}$ for 1.5 hours. Then, the PS layer was 
porous silicon on the backside

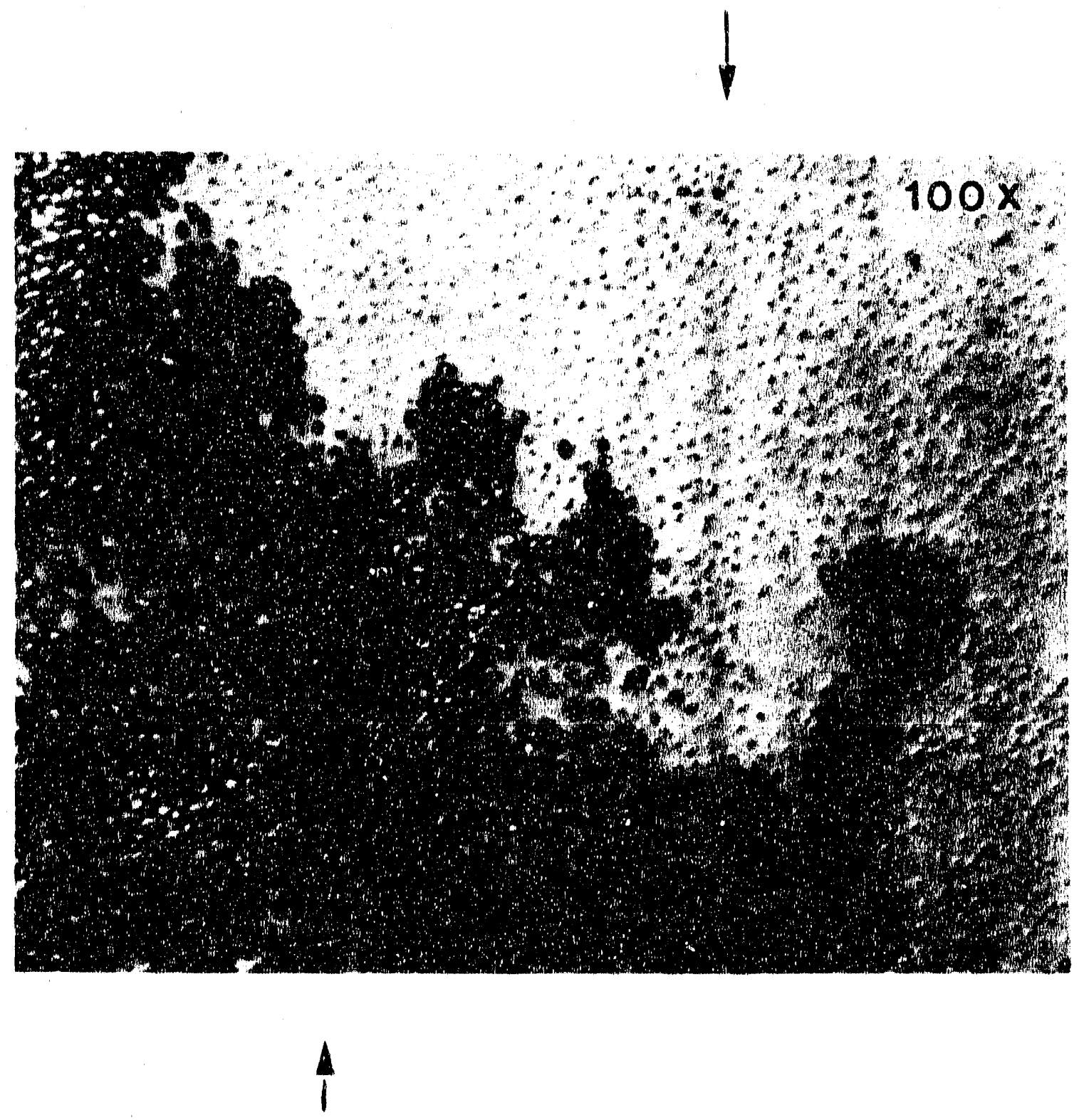

no porous silicon on the backside

Fig. 5.7

XBB $\quad 924=2987$ 


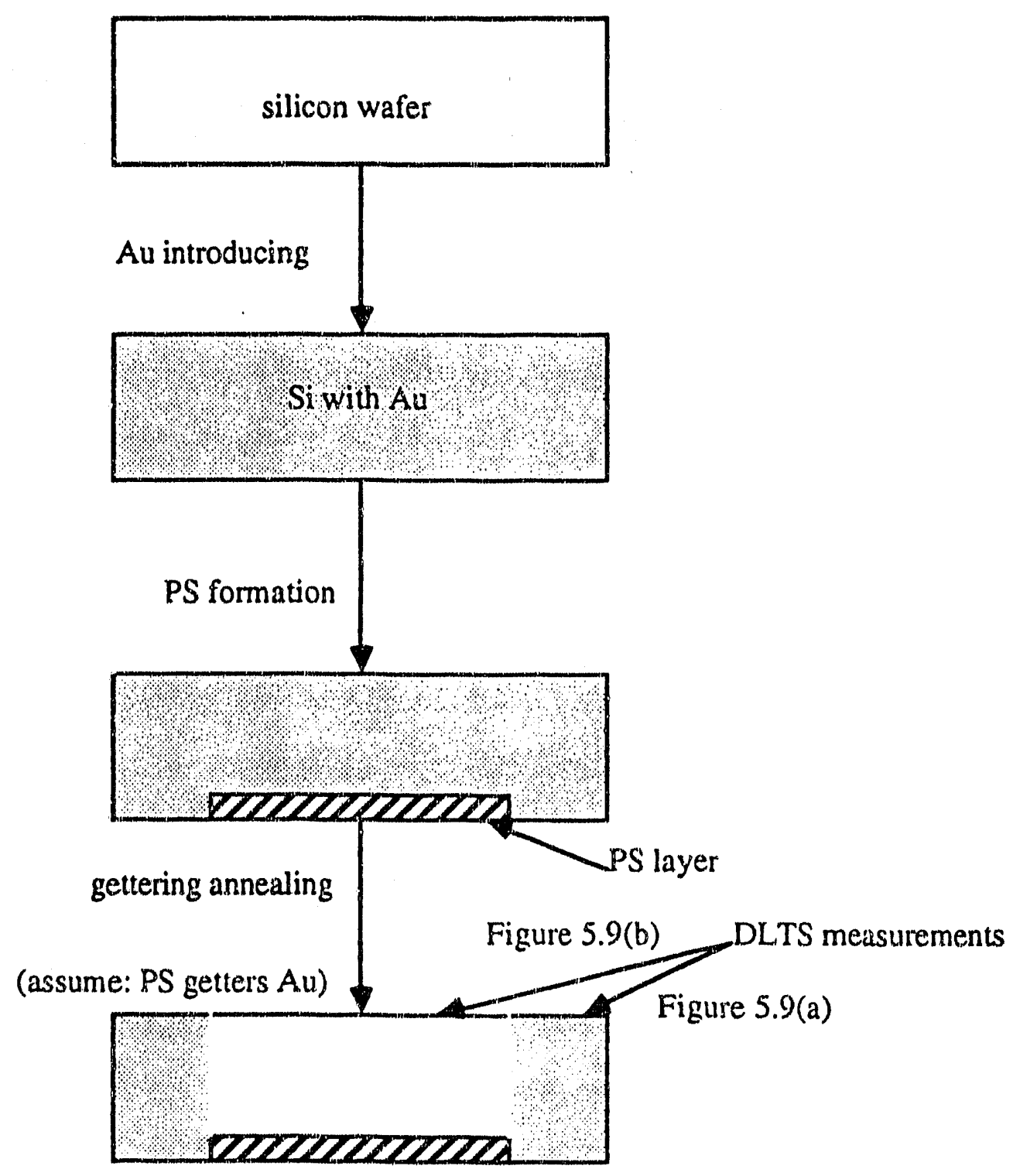

Figure 5.8 Experimental procedures for DLTS study 
removed by mechanical grinding.

4. Chemical polishing the front surface of silicon wafer: The front surface of the silicon wafer was chemically polished by being dipped in a silicon etching solution (HF : $\mathrm{HNO}_{3}: \mathrm{CH}_{3} \mathrm{COOH}=3: 5: 3$ ) for 10 seconds.

5. Schotky barrier diodes formation:" To perform the DLTS study, Schottky barrier diodes were made by sputtering aluminum dots (about $1 \mathrm{~mm}$ in diameter) on the front side of the silicon wafer. A copper foil with punched holes (about $1 \mathrm{~mm}$ in diameter) was placed directly on the top of sample wafer as a mechanical mask. The diodes were tested to ensure they were Schottky barriers. If not, the diodes were removed and reproduced.

6. DLTS measurements: ${ }^{*}$ The DLTS spectra of both samples without and with PS patch on the backside are shown in Figure 5.9.

\subsection{Results and Discussion}

From Figure 5.3, it is seen that the density of stacking faults is much lower in the area where there is PS on the backside. So the PS can act as a gettering center to suppress the formation of OISF. Two possible mechanisms can be used to explain this result:

(1) The PS acts as a gettering center for impurities: Maybe due to its very high specific surface area ${ }^{124}$ (up to $600 \mathrm{~m}^{2} / \mathrm{cm}^{3}$ ) or/and its larger lattice with respect to the bulk silicon substrate ${ }^{125}$, PS performs as an extrinsic gettering center for metal impurities. Once the concentration of the nucleation sites (metal precipitatcs) is reduced, the formation of the OISF is suppressed. It bas been experimentally proven that the impurities prefer to segregate and precipitate at/near the silicon surface.126-132 The reason why the surface getters impurities is still unknown. 126 It may be related to the defect

\footnotetext{
- The author gratefully acknowledge the assistance of Mr. Jeff Bailey in the DLTS measurements.
} 


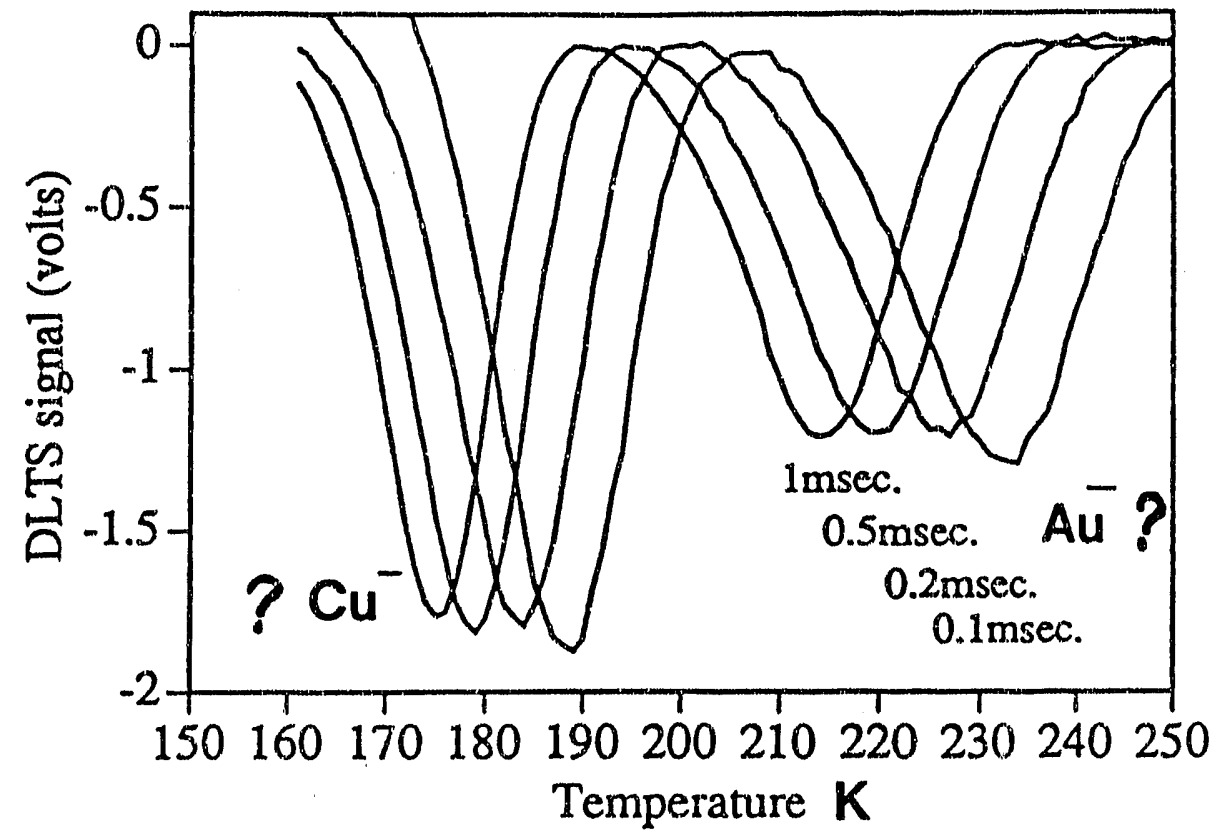

a

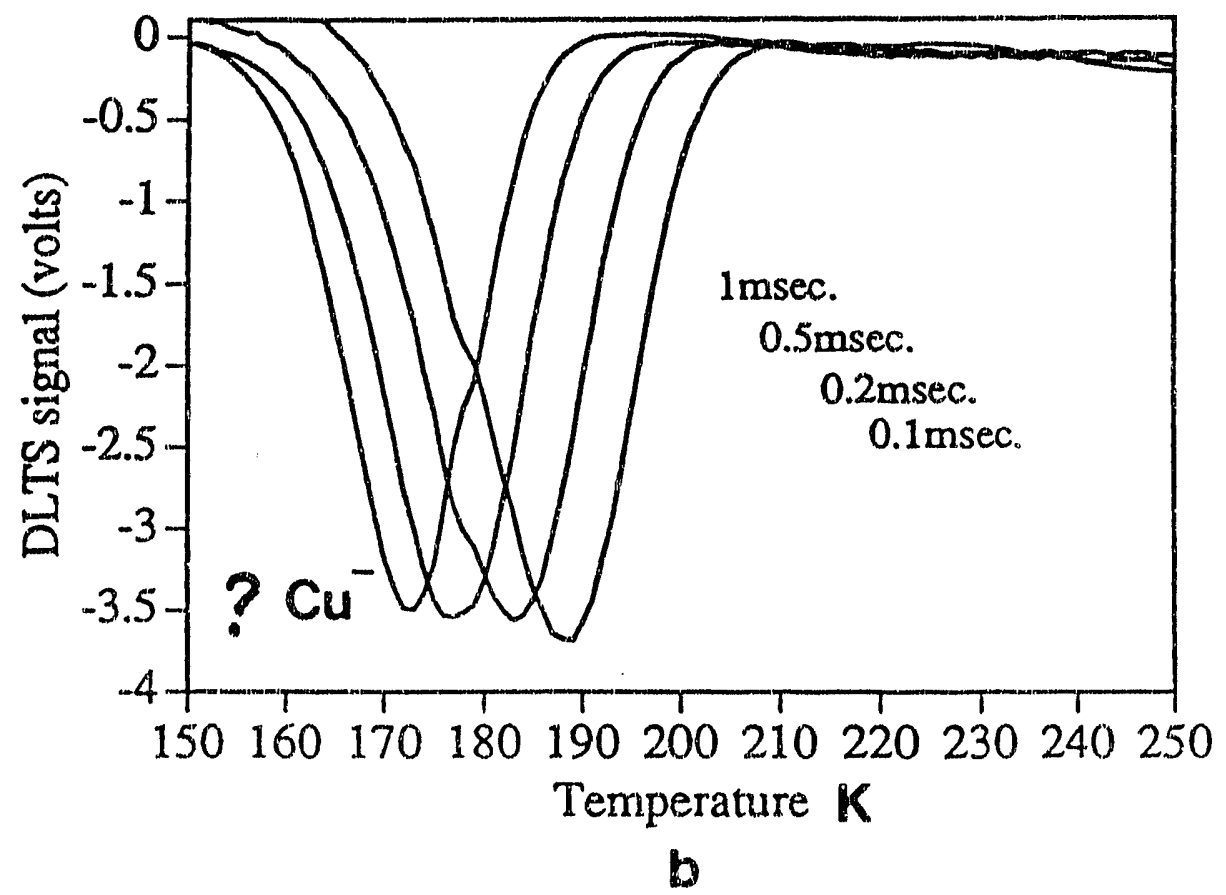

Figure 5.9 The DLTS measurements, (a) without PS gettering and (b) with PS gettering. 
nature of the surface. The PS patch provides enormous surface area to getter impurities. The larger lattice of the PS with respect to the bulk silicon also gives two possible reasons why PS patch getters impurities: (a) the metal impurities prefer to stay in an area with larger lattice to reduce the strain energy, and (b) the metal impurities are gettered by the extended defects formed by the lattice mismatch between the PS and the bulk silicon, i.e., the PS gettering is just a kind of a thin film deposition gettering. Since the mismatch is very small (only $0.5 \% 125$ ), the latter explanation is unlikely. Figure 5.5(a) shows that there is almost no defect formed at the interface of PS/Si. But the OPS patch might getter impurities through its extended defects formed at the interface of OPS/Si as shown in Figure 5.5(b). These defects are OISF and dislocations, which formed during the oxidation of PS.

(2) The PS performs as a sink for silicon interstitials: The enormous surface area of PS provides an ideal sink for silicon interstitials, generated during silicon oxidation. The high diffusivity of silicon interstitial makes this gettering mechanism possible. For example, the diffusivity of the silicon interstitial is $2 \times 10^{-7} \mathrm{~cm}^{2} / \mathrm{sec}$ at $1000^{\circ} \mathrm{C} .133$ Then, the characteristic diffusion length for 1 hour diffusion time is about $270 \mu \mathrm{m}$, which is the same order of magnitude of the thickness of the silicon wafer. This mechanism is similar to the $\mathrm{Cl}^{+}$implantation to create vacancy to annihilate silicon interstitials resulting in the reduction of OISF. 134

The results of the experiment III might be helpful to figure out which one is the operative mechanism. Figure 5.7 also shows the defect density is much smaller in the area where there was PS on the backside. Since the PS patch was removed before the oxidation, the low defect density is due to the preoxidation gettering of the once existed PS patch. Unfortunately, whether the defects are OISF can not be identified from Figure 5.7. If those defects are OISF, then the role of PS is to getter metal impurities rather than silicon interstitials. Beacuse there was no PS patch to getter silicon interstitials during 
oxidation. If the operative mechanism is to getter silicon interstitials, a high and uniform defect density should be observed across the whole area with or without PS patch on the backside of silicon wafer.

The results of DLTS measurements can provide direct evidence for the gettering ability of PS. Figure 5.9(a) is the DLTS spectrum of a silicon sample without PS gettering. There are two groups of peaks: the right one is similar to the gold acceptor level $0.52 \mathrm{eV}$ above the silicon valence band, the left one is unknown $(0.47 \mathrm{eV}$ above valence band, which is very close to the copper acceptor level145). This gold acceptor disappears in the silicon sample with PS gettering as shown in Figure 5.9(b), ie., the Au is gettered. But the unknown set of peaks is still present. There are two possibilities: (1) The unknown impurity was introduced after the PS gettering step. The Schottky barrier diode formation step might be responsible for this contanmination, because this step had been repeated more than ten times before a usable Schottky diode was formed. For example, copper contamination might be introduced through direct contact with the mechanical mask, a copper foil with punched holes. This also explain why the unknown energy level is very similar to the copper acceptor level. (2) The PS patch can only getter gold. This is very unlikely and hard to find a theory to support it.

Although it still far away to reach the conclusion of the gettering mechanism of PS, the above experimental results provide some evidence that the PS can act as a gettering center for metal impurities to reduce the density of OISF.

Some of the extrinsic gettering techniques are not stable ${ }^{1}$, especially at high temperature. The damage and extended defects are annealed out and then can no longer trap the impurities. Polysilicon recrystallizes and results in the reduction of gettering efficiency. ${ }^{136}$ Although the heat treatment effect ${ }^{137}$ (pores coarsen at an elevated temperature) can reduce the specific surface area, the microstructure of PS can be stabilized through a low temperature $\left(300^{\circ} \mathrm{C}\right)$ dry oxidation process as discussed in 
Chapter 2. The PS patch performs as a reasonably stable extrinsic gettering center. From the cost point of view, PS gettering is also superior to others. The cost of the anodization process to form a PS patch is likely to be much less expensive than those of CVD (chemical vapor deposition) processes for thin film gettering techniques, that of ion implantation process, and that of laser processing. The drawbacks of the PS gettering technique might be: (1) PS has the potential to absorb impurities in the solution during any wet chemistry step, (2) Wafer warpage ${ }^{144}$ might take place when PS is formed and becomes worse when PS is oxidized, (3) The PS patch must be formed before any IC processing step is performed. The other gettering techniques ( $e . g$. , thin film deposition, phosphorus diffusion, ion implantation) can be introduced at any time provided the gettering temperature is not high enough to damage the existed pattern, and (4) There might be some unknown damage on the front surface of silicon wafer (i.e., the device active area) when PS patch is formed on the backside of the wafer.

\subsection{Summary}

Porous silicon can act as an extrinsic gettering center to suppress the formation of oxidation-induced stacking faults. This new technique may be more stable and less expensive than most of other existing extrinsic gettering ones. The possible mechanisms to suppress the formation of OISF are to getter the metal impurities to reduce the nucleation sites of OISF and to getter the silicon interstitials produced during oxidation. Some experimental results show that the former one might be the operative one but how the metal impurities are gettered by PS is still unclear. 
References

1. S. Wolf and R. N. Tauber, "Silicon Processing", Vol. 1, Lattice Press, Sunset Beach, CA, 1986.

2. Y. Hayafuji, K Kajiwara, and S. Usui, J. Appl. Phys., 53, 8639 (1982).

3. K. V. Ravi, C. J. Varker, and C.E. Volk, J. Electrochem. Soc., 120, 533 (1973).

4. S. Kawado, Y. Hayafuji, and T. Adachi, Jpn. J. Appl. Phys. 14, 407 (1975).

5. K. Tanikawa, Y. Ito, and H. Sei, Appl. Phy. Lett., 28, 285 (1976).

6. P. S. D. Lin, R. B. Marcus, and T. T. Sheng, J. Electrochem. Soc., 130, 1878 (1983).

7. C. J. Varker and K. Ravi, J. Appl. Phys., 45, 272 (1974).

8. G. H. Schwuttke, K. Brock, and E. W. Hearn, Microelectronics Reliability, 10, 467 (1971).

9. H. J. Quiesser and A Goetzberger, Phil. Mag., 8, 1063 (1963).

10. D. J. D. Thomas, Phys. Status Solidi, 3, 2261 (1963).

11. H. J. Queisser and P. G. G. van Loon, J. Appl. Physs, 35, 3066 (1964).

12. G. R. Brooker and R. Stickler, Phil. Mag., 11, 1303 (1965).

13. G. R. Brooker and W. J. Tunstall, Phil. Mag., 13, 71 (1966).

14. R. J. Jaccodine and C. M. Drum, Appl. Phys. Lett., 8, 29 (1966).

15. W. A. Fisher and J. A Amick, J. Electrochem. Soc., 113, 1054 (1966).

16. M. L. Joshi, Acta Metall., 14, 1157 (1966).

17. I. R. Sanders and P.S. Dobson, Phü. Mag., 20, 881 (1969).

18. J. E. Laurence, J. Appl. Phys., 40, 360 (1969).

19. A. Mayer, RCA Rev., 31, 414 (1970).

20. S. Dash and M. L. Joshi, IBM. J. Res. Devel pp., 14, 453 (1970).

21. Y. Sugita, T. Kato, and M. Tamura, J. Appl. Phys., 42, 5847 (1971).

22. T. Kato, Y. Sugita, and A. Yoshinaka, Jpn. J. Appl. Phys., 11, 1066 (19972). 
23. S. Prussin, J. Appl. Phys., 43, 733 (1972).

24. C. M. Drum and W. van Gelder, J. Appl. Phys., 43, 4465 (1972).

25. C. M. Hsieh and D. M. Maher, J. Appl. Phys., 44, 1302 (1973).

26. S. M. Hu, J. Appl. Phys., 45, 1567 (1974).

27. M. Conti, G. Corda, and R. Matteucci, J. Mat. Sci, 10, 705 (1975).

28. H. Shiraki, Jpn. J. Appl. Phys., 15, 1 (1976).

29. Y. Hayafuji, K. Kajiwara, and S. Usui, J. Appl. Phys., 53, 8639 (1982).

30. W. Boyd Rogers and H.Z. Massoud, J. Electrochem. Soc., 138, 3483 (1991).

31. G. Charitat and A. Martinez, J. Appl. Phys., 55, 909 (1984).

32. S. T. Dunham and J. D. Plummer, J. Appl. Phys, 59, 2551 (1986).

33. C. M. Drum and W. van Gelder, J. Appl. Phys., 43, 4465 (1972).

34. H. Shiraki, in "Semiconductor Silicon 1977", Vol. 77-2, H.R. Huff and E. Sirtl, Eiditors, p. 546, The Electrochemical Society Proceedings Series, Princeton, NJ (1977).

35. A. J. R. de Kock, Philips Research Report, Suppl. 1, 1973.

37. K. Nagasawa, Y. Matsushita, and S. Kishino, Appl. Phys. Lett., 37, 622 (1980).

38. L. Jastrzebski, R. Soydan, B. Goldsmith, and J.T. McGinn, J. Electrochem. Soc., 131, 2944 (1984).

39. O. Ueda, K. Nauka, J. Lagowski, and H.C. Gatos, J. Appl. Phys., 60, 622 (1986).

40. K. Nauka, J. Lagowski, H.C. Gatos, and O. Ueda, J. Appl. Phys., 60, 615 (1986).

41. L. Jastrzebski, R. soydan, J. McGinn, R. Kleppinger, M. Blumenfeld, G. Gillespie, N. Armour, B. Goldsmith, W. Henry, and S. Vecrumba, J. Electrochem. Soc., 134, $1018(1987)$.

42. M. S. Goorsky, J. Langowski, and H. C. Gatos, J. Appl. Phys., 64, 6716 (1988).

43. W. Wijaranakula, J.H. Matlock, and H. Mollenkopf, J. Electrochem. Soc., 135, 3113 (1988). 
44. W. Wijaranakula and J. H. Matlock, J. Appl. Phys., 65, 2078 (1989).

45. D. Gilles, E.K. Weber, and S. Hahn, Phys. Rev. Lett., 64, 196 (1990).

46. W. Wijaranakula and J. H. Matlock, J. Electrochem. Soc., 138, 2153 (1991).

47. W. Wijaranakula and J. H. Matlock, J. Appl. Phys., 69, 6982 (1991).

48. S. Kishino, K. Nagasawa, and T. Iizuka, Jpn. J. Appl. Phys., 19, L466 (1980).

49. K. Graff, H. A. Hefner, änd W. Hennerici, J. Electrochem. Soc., 135, 952 (1988).

50. J. Li, J. Appl. Phys., 70, 511 (1991).

51. T. Y. Tan, E. E. Gardner, and W. K. Tice, Appl. Phys. Lett., 30, 175 (1977).

52. K. Wada, N. Inone, and K. Kohra, J. Cryst. Growth, 49, 749 (1980).

53. K. Graff, H. A. Hefner and W. Hennerici, J. Electrochem. Soc., 135, 952 (1988),

54. D. Grilles, E. R. Weber, S. Hahn, O.R. Monteiro, and K. Cho, private communication.

55. K. Graff, H. A. Hefner, and W. Hennerici, J. Electrochem. Soc., 135, 952 (1988).

56. R. Falster and W. Bergholz, J. Electrochem. Soc., 137, 1548 (1990)。

57. T. J. Magee, C. Leung, H. Kawagoski, B. K. Furman, and C. A. Evans, Appl. Phys. Lett., 38, 891 (1981).

58. J. C. Mikkelsen, Appr. Phys. Lett, 42, 695 (1983).

59. E. J. Mets, J. Electrochem. Soc., 112, 420 (1965).

60. D. Pomerantz, J. Appl. Phys., 38, 5020 (1967).

61. M. Nakamura, T. Kato, and N. Oi, Jpn. J. Appl. Phys., 7, 512 (1968).

62. D. E. Hill in Defects in Silicon, edited by W.M. Bullis and L.C. Kimerling, p433, The Electrochernical Society, Pennington, NJ, 1983.

63. K. Leo, R. Schindler, J. Knobloch, and B. Voss, J. Appl. Phys., 62, 3472 (1987).

64. D. R. Sparks, R. G. Chapman, and N. S. Alvi, Appl. Phys. Lett., 49, 525 (1986).

65. C. W. Pearce and V. J. Zaleckas, J. Electrochem. Soc., 126, 1436 (1979).

66. C. W. Pearce and V. J. Zaleckas, J. Electrochem. Soc., 126, 1436 (1979). 
67. K. H. Yang and G. H. Schwuttke, Phys. Status Solidi A, 58, 127 (1980).

68. Y. Hayafuji, T. Yanada, and Y. Aodi, J. Electrockem. Soc., 128, 1975 (1981).

69. D. Lecrosnier, J. Paugam, G. Pelous, F. Richou, and M. Salvi, J. Appl. Phys., 52, 5090 (1981).

70. H. Wong, N. W. Cheung, and P. K. Chu, Appl. Phys. Lett., 52, 889 (1988).

71. T. E. Seidel, R. L Meck, and A. G. Gullis, J. Appl. Phys., 7, 512 (1975).

72. T. M. Buck, K. A. Pickar, J. M. Poate, and C-M Hsieh, Appl. Phys. Lett., 21, 485 (1972).

73. T. W. Sigmon, L. Csepregi, and J. W. Mayer, J. Electrochem. Soc., 123, 1116 (1976).

74. A. G. Nassibian and B. Golja, J. Appl. Phys., 53, 6168 (1982).

75. A. G. Cullis, T.E. Seidel, and R. L. Meek, J. Appl. Phys., 49, 5188 (1978).

76. A. G. Nassibian, V. A. Browne, and K. D. Perkins, J. Appl. Phys., 47, 992 (1976)。

77. K. D. Beyer and T. H. Yeh, J. Electrochem. Soc., 129, 2527 (1982).

78. J. A. Topich, J. Electrochem. Soc., 128, 866 (1981).

79. M. J. T. Lo, J. G. Skalnik, and P. F. Ordung, J. Electrochem. Soc., 128, 1569 (1981).

80. M. R. Poponiak, T. Nagasaki, and T. H. Yeh, J. Electrochem. Soc., 124, 1802 (1977).

81. B. H. Yun, Appl. Phys. Lett., 39, 330 (1981).

82. P. M. Engel and J. P. deSouza, J. Appl. Phys., 54, 4211 (1983).

83. S. S. Gong and D. K. Schroder, Solid State Electron., 30, 209 (1987).

84. C-M Hsieh, J. R. Mathews, H. D. Seidel, K. A. Pickar, and C. M. Drum, Appl. Phys. Lett., 22, 238 (1973). 
85. M. Delfino, M. Jaczynski, A. E. Morgan, C. Vorst, M. E. Lunnon, and P. Maillot, J. Electrochem. Soc., 134, 2027 (1987).

86. 'T. I. Kamins and S-Y Chiang, J. Appl. Phys., 58, 2559 (1985).

87. M. C. Chen and V. J. Silvestri, J. Electrochem. Soc., 129, 1294 (1982).

88. W. T. Stacy, M. C. Arst, K. N. Ritz, J. G. de Groot, and M. H. Norcott in Defects in Silicon, edited by W.M. Bullis and L.C. Kimerling, p423, The Electrochemical Society, Pennington, NJ, 1983.

89. J. W. Medernach, V. A. Wells, and L. Witherspoon in Defects in Silicon, edited by W. M. Bullis and L. C. Kimerling, p915, The Electrochemical Society, Pennington, NJ, 1983.

90. P. M. Petroff, G. A.Rozgonyi and T. T. Sheng, J. Electrochem. Soc., 123, 565 (1976).

91. G. A. Rozgonyi and R. A. Kushner, J. Electrockem. Soc., 123, 570 (1976).

92. K. Tanno, F. Shimura and T. Kawamura, J. Electrochem. Soc., 128, 395 (1981).

93. M. C. Chen and V. J. Silvestri, J. Electrochem. Soc., 128, 389 (1981).

94. T. A. Baginski and J. R. Monkowski, J. Electrochem. Soc., 133, 142 (1986).

95. R. A. Logan and M. Schwartz, J. Appl. Phys., 26, 1287 (1955).

96. S. J. Silvermaa and J. B. Singleton, J. Electrochem. Soc., 105, 591 (1958).

97. G. Bemski and D. Struthers, J. Electrochem. Soc., 105, 588 (1958).

98. R. D. Thompson and K. N. Tu, Appl. Phy. Lett., 41, 440 (1982).

99. G. A. Rozgonyi, P. M. Petroff and M. H. Read, J. Electrochem. Soc., 122, 1725 (1975).

100. W. F. Tseng, T. Koji, J. W. Mayer, and T. E. Seidel, Appl. Phys. Lett., 33, 442 (1978).

101. R. L. Meek and T. E. Seidel, J. Phys. Chem. Solids, 36, 731 (1975). 
102. L. Baldi, G. F. Cerofolíni, G. Ferle, and G. Frigerio, Phys. Status Solidi A, 48, 523 (1978).

103. B. Hartiti, J. C. Muller, and P. Siffert, Appl. Phys. Lett., 59, 425 (1991).

104. B. Hartiti, A. Slaoui, M. Loghmarti, J. C. Muller, and P. Siffert, Appl. Phys. Lett., 59, 3446 (1991).

105. R. Falster, Appl. Phys. Lett., 46, 737 (1985).

106. A. G. Shaikh, W. Schroter, and W. Bergholz, J. Appl. Phys, 58, 2519 (1985).

107. A. S. M. Salih, H. J. Kim, R. F. Davis, and G. A. Rozgonyi, Appl. Phys. Lett., 46, 419 (1985).

108. A. S. M. Salih, J. S. Ryu, and G. A. Rozgonyi, J. Electrochem. Soc., 133, 475 (1986).

109. A. S. M. Salih, Z. Radzimski, J. Honeycutt, and G. A. Rozgonyi, Appl. Phys. Lett., 50, 1678 (1987).

110. R. J. Falster, D.N. Modlin, W. A. Tiller, and J. F. Gibbons, J. Appl. Phys., 57, 554 (1985).

111. P. HL Robinson and F. P. Heiman, J. Electrochem. Soc., 118, 141 (1971).

112. D. R. Young and C. M. Osburn, J. Electrochem. Soc., 120, 1578 (1973).

113. H. Shiraki, Jpn. J. Appl. Phys., 14, 747 (1975).

114. T. Hattori, Appl. Phys. Lett., 30, 312 (1977).

115. P. D. Esquenda and M. B. Das, Solid State Electron., 23, 741 (1980).

116. T. A. Baginski and J.R. Monkowski, J. Electrochem. Soc., 132, 2032 (1985).

117. P. Bai, G-R Yang, and T-M Lu, J. Apph. Phys., 68, 3313 (1990).

118. H. Wendt, H. Cerva, V. Lehmann, and W. Pamler, J. Appl. Phys., 65, 2402 (1989).

119. K. Wittmaack, Appl. Phys. Lett., 48, 1400 (1986).

120. K. Wittmaack and N. Menzel, Appl. Phys. Lett., 50, 815 (1987). 
121. M. Itsumi and F. Kiyosumi, Appl. Phys. Lett., 40, 496 (1982).

122. J. S. Kang and D. K. Schroder, J. Appl. Phys., 65, 2974 (1989).

123. J. S. Kang and D. K. Schroder, J. Appl. Phys., 65, 2974 (1989).

124. R. Herino, G. Bomchil, K. Barla, and C. Bertrand, J. Electrochem. Soc., 134, 1994 (1987).

125. K. Barla, R. Herino, G. Bomchil, and J.C. Pfister, J. of Crystal Growth, 68, 727 (1984).

126. W. Bergholz, J. Phys. Di Appi. Phys., 14, 1099 (1981).

127. C. B. Collins and R.O. Carlson, Phys. Rev., 105, 1409 (1957).

128. F. A. Huntley and A.F.W. Willoughby, Solid-State Electronics, 13, 1231 (1970).

129. G. J. Sprokel and J.M. Fairfield, J. Electrochem. Soc, 112, 200 (1965).

130. N. A. Stolwijk, B. Schuster, and J. Holzl, Appl. Phys. A, 33, 133 (1984).

131. B. Hartiti, Vu-Thuong-Quat, W. Eichhammer, J.C. Muller, and P. Siffert, Appl. Phys. Lett., 55, 873 (1991).

132. G. B. Bronner and J. D. Plummer, J. Appl. Phys., 61, 5286 (1987).

133. T. Y. Tan and U. Gosele, Appl. Phys. A, 37, 1 (1985).

134. J. Y. Xu, P. M. Bronsveld, G. Boom, and J. Th. M. DeHosson, J. Appl. Phys., 55, 3485 (1984).

135. R. Bullough and R. C. Newman, Progress in Semiconductors, 8, 100 (1964).

136. M. S. Choi and E. W. Hearn, J. Electrochem. Soc., 131, 2443 (1984).

137. T. Unagami and M. Seki, J. Electrochem. Soc., 125, 1339 (1978).

138. D. I. Pomerantz, J. Electrochem. Soc., 119, 255 (1972).

139. G. A. Rozgonyi, R.P. Deysher, and C.W. Pearce, J. Electrochem. Soc., 123, 1910 (1976).

140. D. Huber and E. Sirtl, Japn. J. Appl. Phys., 19-1, 615 (1980).

141. F. Secco d'Aragona, J. Electrochem. Soc , 119, 948 (1972). 
142. E. D. Wolley and R. StickJer, J. Electrochem. Soc , 114, 1287 (1969).

143. A Ourmazd and W. Schroter, Appl. Phys. Lett., 45, 781 (1984).

144. L. A. Nesbit, IEDM Tech. Dig. Papers, 800 (1984).

145. B. G. Streetman, Solid State Electronic Devices, 2th edition, Prentice-Hall Co.. 
Chapter 6 Summary

In this thesis the processing of porous silicon (PS) and its potential applications have been studied. The stability of a cylindrical void under the influence of surface energy is very important for PS processing. Once the zig-zag cylindrical pores of PS or oxidized PS (OPS) are unstable and breakup into rows of isolated spherical pores, the oxidation of PS and densification/nitridation of OPS become difficult. This is attributed to the difficulty of the transport of reactant gas (oxygen and ammonia for the oxidation of PS and nitridation of OPS, respectively) or trapped gas (for the densification of OPS). For viscous flow and evaporation/condensation as the transport mechanisms for the disintegration processes, a first order analysis (an infinitesimal sinusoidal perturbation introduced on the surface of the void) of the stability of cylindrical voids (and cylinders) has been given and summarized in Table 2.1. The analysis shows that whenever the perturbation wavelength is larger than $2 \pi r_{0}$ ( $r_{0}$ is the initial radius of cylindrical void or cylinder), disintegration occurs. In the case of viscous flow, the longer the perturbation wavelength is, the more unstable the cylindrical void is. This theoretical predication has been examined experimentally by heat treatment of artificial pores inside glass wafers. The experimental results show that the pores disintegrate at a quite broad distribution of wavelengths $\left(7-70 \mathrm{r}_{0}\right)$ but most of the pores break up at a wavelength of about $10-15$ ro. The possible reasons why there appears to be a range of preferential breakup wavelengths (10 - 15 ro) are: the theoretical consideration is only a first order approximation and the artificial pores are not infinitely long. No preferential breakup occurs at the bending point (the bending angle is 150 ) for zig-zag artificial pores. According to these theoretical and experimental stability studies, the pores of OPS after breakup are expected to be very large (tenths of micrometer), compared to the initial pore 
size (tens of angstroms), which has been confirmed experimentally. This pore size enlargement increases the adverse effect of the trapped gas for the OPS densification.

Rapid thermal processing provides an alternative to the processing of PS. Due to the enhancement of oxidation rate by the photoeffect of rapid thermal oxidation (RTO), reactive nature of $P S$, and only a very thin silicon pore wall (hundreds of angstroms) to be oxidized, the oxidation time is so short that the PS is fully oxidized before the heat treatment effect becomes serious. This has been confirmed by the characterization results of transmission electron microscopy (TEM), energy dispersive spectroscopy (EDS), and electron spectroscopy for chemical analysis (ESCA). Also, The rapid thermal nitridation of OPS in ammonia really enhances the resistance to hydrofluoric acid (HF). But the etching rate in a buffered HF solution is still higher than that of a fully densified OPS because the nitridized OPS is still porous.

The densification rate of OPS is greatly enhanced in a wet ambient. Although the trapped gas effect in the OPS densification is not as significant as that in the alumina densification, wet $\mathrm{He}$ (He bubbled through water) is still recommended as the densification ambient.

PS can act as an extrinsic gettering center to suppress the formation of oxidationinduced stacking faults (OISF). This new technique may be more stable and less expensive than most of other existing extrinsic gettering methods. The possible mechanisms to suppress the formation of OISF are to getter the metal impurities to reduce the nucleation sites of OISF, and to getter the silicon interstitials produced during oxidation. Some experimental results suggest that the former one might be the operative one but how the metal impurities are gettered by PS is still unclear.

The following future extensions to this study are suggested:

(1) Stability study: Computer simulation is recommended to study the stability of cylinders or cylindrical voids to relax the limitation of the first-order analysis. 
Experimentally, find the bending angle of the artificial pore, which has a preferential breakup at the bending point, then compare it with the common bending angle of pores of the real OPS. This information will be helpful to predict the pore breakup of OPS.

(2) RTO of PS: Create a silicon on oxidized porous silicon (SOPS) structure and examine the lateral size limitation on the epi-silicon island by using the RTO process.

(3) Densification of OPS: The detailed evolution of porosity during densification is very informative and can be obtained by using a light scattering technique ${ }^{1}$ or ellipsometer. The former method employs a He-Ne laser to beam into the sample and the light scattering perpendicular to the laser beam is detected. This scattered light provides the information of pore size and density. The latter employs an ellipsometer to measure the refractive index of the sample and then applies the effective medium theory 2,3 to calculate the porosity of the sample. Besides the pore size from TEM study, the quality of the OPS can be characterized by measuring its breakdown voltage and dielectric constant.

(4) Gettering: The deep level transient spectroscopy work should be repeated. The surface photovoltage technique (SPV) can be used to measure the average diffusion length of carriers, which is related to the metal impurity concentration. This information will be very helpful to figure out the role of PS in the suppression of OISF. A test device on a silicon wafer with PS patch on the backside should be produced and tested to ensure that the PS gettering process does not induce any adverse effect on the device performance.

\section{Reference:}

1. S. Satoh, K. Susa, I. Matsuyama, and T. Suganuma, J. Non-Cryst. Solids, 55, 455 (1983).

2. C. G. Granqvist and O. Hunderi, Physical Review B, 16, 3513 (1977).

3. D. E. Aspens and J. B. Theeten, Physical Review B, 20, 3292 (1979). 
Appendix: Derivation of Densification Rate with a Stable Cylindrical Pore

The following assumptions are made:

(1) quasi-steady statc;

(2) gravitational and inertial effects may be neglected;

(3) the cylindrical pore shape is stable;

(4) physical properties are constant.

Then, the suitable equations to describe the viscous flow of the densification process are

$$
\begin{aligned}
& \frac{\partial}{\partial r}\left[\frac{1}{r} \frac{\partial(r u)}{\partial r}\right]=0 \\
& \frac{\partial^{2} w}{\partial z^{2}}=0
\end{aligned}
$$

where the circumferential components disappear because of cylindrical symmetry, $u$ and $\mathrm{w}$ are the velocities in $\mathrm{r}$ and $z$ directions, respectively.

With continuity equation

$$
\frac{1}{r} \frac{\partial}{\partial r}(r u)+\frac{\partial w}{\partial z}=0
$$

and boundary conditions

$$
u=0 \text { for } r=r_{2} \quad \text { and } w=0 \text { for } z=0
$$


The equations (1) and (2) can be solved:

$$
\mathrm{u}=\mathrm{cr}-\frac{\mathrm{cr}_{2}^{2}}{\mathrm{r}} \text { and } \mathrm{w}=-2 \mathrm{cz}
$$

where $\mathrm{c}$ is a constant.

The average rate of dissipation energy for unit volume of silica is

$$
E_{v}=2 \mu\left[\left(\frac{\partial u}{\partial r}\right)_{a v e}^{2}+\left(\frac{u}{r}\right)_{a v e}^{2}+\left(\frac{\partial w}{\partial z}\right)_{a v e}^{2}\right]
$$

where $\mu$ is the viscosity and

$$
\begin{aligned}
& \left(\frac{\partial u}{\partial r}\right)_{a v e}^{2}=\frac{1}{V} \int_{r}^{r 2}\left(\frac{\partial u}{\partial r}\right)^{2} 2 \pi r d r \\
& \left(\frac{u}{r}\right)_{a v e}^{2}=\frac{1}{V} \int_{r 2}^{r z}\left(\frac{u}{r}\right)^{2} 2 \pi r d r \\
& \left(\frac{\partial w}{\partial z}\right)_{a v e}^{2}=4 c^{2} \\
& V=J\left(r_{2}^{2}-r_{1}^{2}\right)
\end{aligned}
$$

Equations (3)-(5) lead to

$$
E_{v}=4 \mu c^{2}\left(3+\left(\frac{r_{2}}{r_{1}}\right)^{2}\right)
$$

$u_{1}\left(u\right.$ for $\left.r=r_{1}\right)$ is equal to: 


$$
\mathrm{cr}_{1}-\frac{\mathrm{ct}_{2}^{2}}{\mathrm{r}_{1}}
$$

then the $\mathrm{E}_{\mathrm{v}}$ can be expressed as

$$
E_{v}=4 \mu u_{1}^{2} \frac{\left(r_{2}^{2}+3 r_{1}^{2}\right)}{\left(r_{1}^{2}-r_{2}^{2}\right)}
$$

Since the aspect ratio is very large, the surface energy changes on the top and bottom of silica tube can be neglected. The rate of total surface energy reduction per unit volume of silica is

$$
E_{s}=\frac{\gamma}{V h} \frac{\partial}{\partial t}\left(2 \pi r_{1} h\right)=2 \gamma u_{1} \frac{\left(r_{2}^{2}+r_{1}^{2}\right)}{\left(r_{2}^{2}-r_{1}^{2}\right)}
$$

The $E_{v}$ is assumed to be equal to $-E_{s}$, then the $u_{1}$ can be obtained:

$$
\begin{aligned}
& u_{1}=\frac{\partial r_{1}}{\partial t}=-\gamma(2 \mu) \frac{\left(r_{2}^{2}+r_{1}^{2}\right)}{\left(r_{2}^{2}+3 r_{1}^{2}\right)} \\
& \rightarrow \frac{\gamma t}{\mu}=4 r_{2}\left[\tan ^{-1}\left(\frac{r_{1}}{r_{2}}\right)-\tan ^{-1}\left(\frac{r_{10}}{r_{2}}\right)\right]+6\left(r_{10}-r_{1}\right)
\end{aligned}
$$

where $r_{10}$ is the initial pore radius and $t$ is the densification time. 

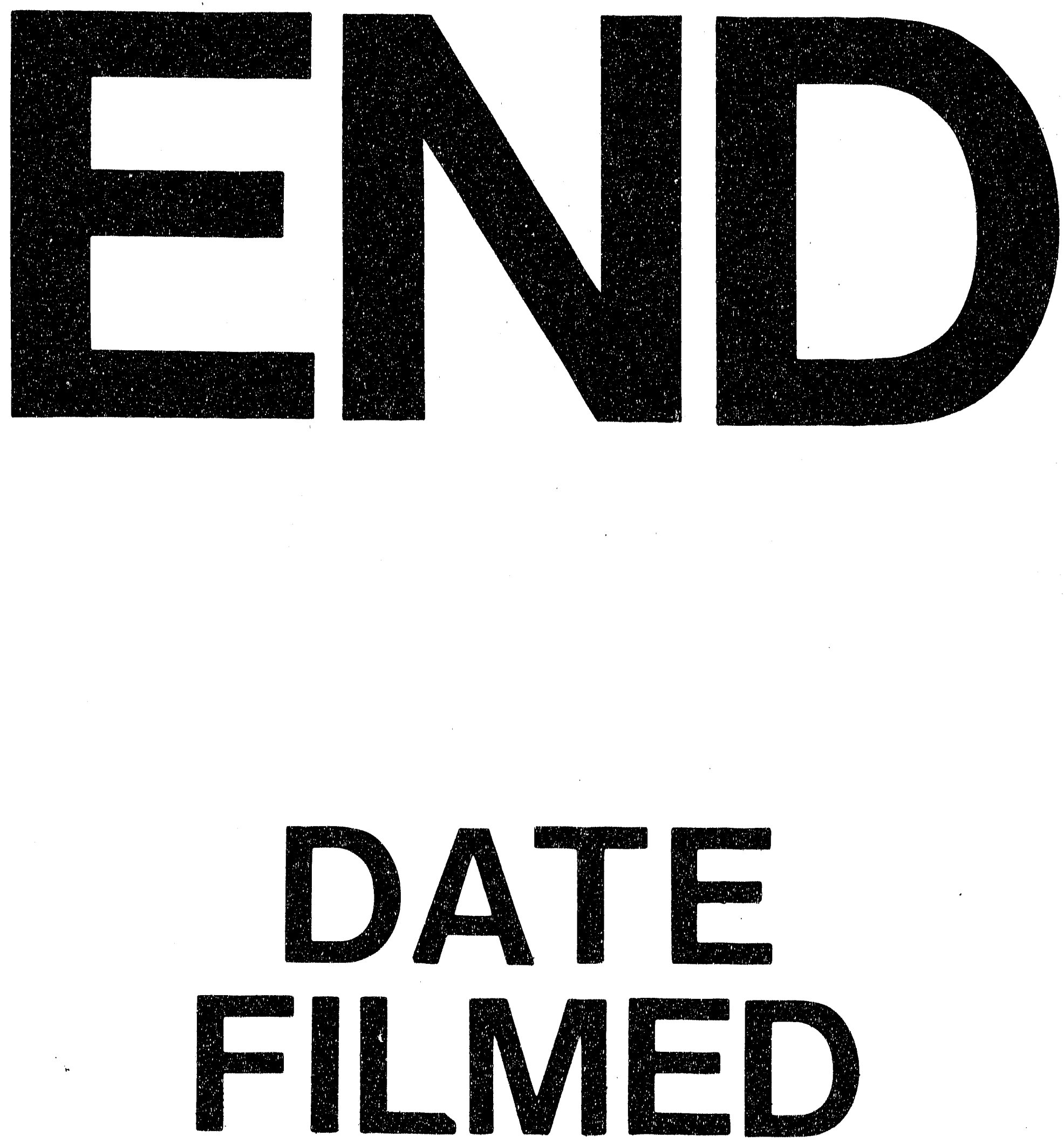

承

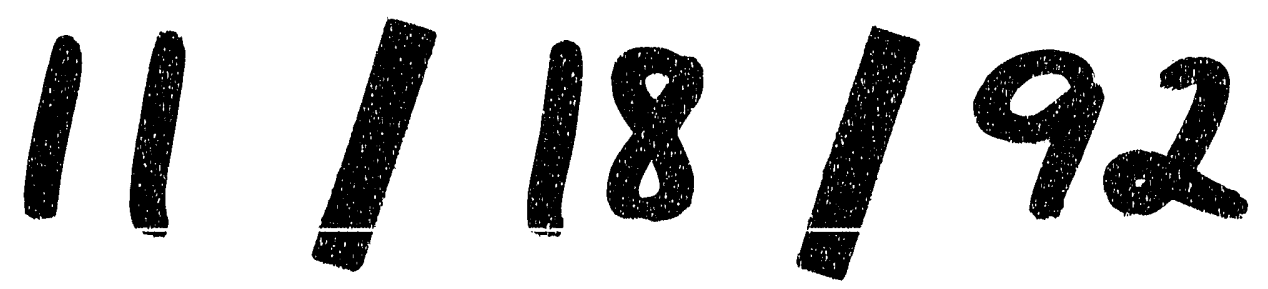


